University of Wollongong

Research Online

Australian Institute for Innovative Materials -

Papers

Australian Institute for Innovative Materials

$1-1-2018$

Recent progress on sodium ion batteries: Potential high-performance anodes

Li Li

Donghua University, University of Wollongong, lilyli@uow.edu.au

Yang Zheng

University of Wollongong, yz966@uowmail.edu.au

Shilin Zhang

University of Wollongong, sz384@uowmail.edu.au

Jianping Yang

Donghua University, jpy546@uowmail.edu.au

Zongping Shao

Nanjing Tech University

See next page for additional authors

Follow this and additional works at: https://ro.uow.edu.au/aiimpapers

Part of the Engineering Commons, and the Physical Sciences and Mathematics Commons

Research Online is the open access institutional repository for the University of Wollongong. For further information contact the UOW Library: research-pubs@uow.edu.au 


\title{
Recent progress on sodium ion batteries: Potential high-performance anodes
}

\author{
Abstract \\ Due to massively growing demand arising from energy storage systems, sodium ion batteries (SIBs) have \\ been recognized as the most attractive alternative to the current commercialized lithium ion batteries \\ (LIBs) owing to the wide availability and accessibility of sodium. Unfortunately, the low energy density, \\ inferior power density and poor cycle life are still the main issues for SIBs in the current drive to push the \\ entire technology forward to meet the benchmark requirements for commercialization. Over the past few \\ years, tremendous efforts have been devoted to improving the performance of SIBs, in terms of higher \\ energy density and longer cycling lifespans, by optimizing the electrode structure or the electrolyte \\ composition. In particular, among the established anode systems, those materials, such as metals/alloys, \\ phosphorus/phosphides, and metal oxides/sulfides/selenides, that typically deliver high theoretical \\ sodium-storage capacities have received growing interest and achieved significant progress. Although \\ some review articles on electrodes for SIBs have been published already, many new reports on these \\ anode materials are constantly emerging, with more promising electrochemical performance achieved via \\ novel structural design, surface modification, electrochemical performance testing techniques, etc. So, \\ we herein summarize the most recent developments on these high-performance anode materials for SIBS \\ in this review. Furthermore, the different reaction mechanisms, the challenges associated with these \\ materials, and effective approaches to enhance performance are discussed. The prospects for future \\ high-energy anodes in SIBs are also discussed. \\ Disciplines \\ Engineering | Physical Sciences and Mathematics \\ Publication Details \\ Li, L., Zheng, Y., Zhang, S., Yang, J., Shao, Z. \& Guo, Z. (2018). Recent progress on sodium ion batteries: \\ Potential high-performance anodes. Energy and Environmental Science, 11 (9), 2310-2340.

\section{Authors} \\ Li Li, Yang Zheng, Shilin Zhang, Jianping Yang, Zongping Shao, and Zaiping Guo
}




\title{
Recent progress on sodium ion batteries: Potential high- performance anodes
}

Received 00th January 20xx, Accepted 00th January 20xx

DOI: $10.1039 / x 0 x \times 00000 x$

www.rsc.org/

\author{
$\mathrm{Li} \mathrm{Li},{ }^{a b} \ddagger$ Yang Zheng, ${ }^{b} \neq$ Shilin Zhang, ${ }^{b}$ Jianping Yang, ${ }^{* a}$ Zongping Shao, ${ }^{* c}$ and Zaiping Guo*b
}

Due to massively growing demand arising from energy storage systems, sodium ion batteries (SIBs) have been recognized as the most attractive alternative to the current commercialized lithium ion batteries (LIBs) owing to the wide availability and accessibility of sodium. Unfortunately, the low energy density, inferior power density and poor cycle life are still the main issues for SIBs in the current drive to push the entire technology forward to meet the benchmark requirements for commercialization. Over the past few years, tremendous efforts have been devoted to improving the performance of SIBs, in terms of higher energy density and longer cycling lifespans, by optimizing the electrode structure or the electrolyte composition. In particular, among the established anode systems, those materials, such as metals/alloys, phosphorus/phosphides, and metal oxides/sulfides/selenides, that typically deliver high theoretical sodium-storage capacities have received growing interest and achieved significant progress. Although some review articles on electrodes for SIBs have been published already, many new reports on these anode materials are constantly emerging, with more promising electrochemical performance achieved via novel structural design, surface modification, electrochemical performance testing techniques, etc. So, we herein summarize the most recent developments on these high-performance anode materials for SIBs in this review. Furthermore, the different reaction mechanisms, the challenges associated with these materials, and effective approaches to enhance performance are discussed. The prospects for future high-energy anodes in SIBs are also discussed.

\section{Introduction}

Lithium-ion batteries (LIBs) have overwhelmingly dominated the power source markets of advanced consumer electronics and even electric vehicles, due to their high energy density, long lifespan, and low maintenance..$^{1,2}$ The low abundance and uneven distribution of lithium, however, make it difficult to meet the massively growing demand for energy in the near future. Inspired by the similar chemical nature of sodium to lithium, sodium-ion batteries (SIBs) have been extensively investigated and regarded as the most promising alternative power technology to the commercialized LIBs, especially for largescale energy storage from intermittent and renewable energy sources and smart grid applications, owing to the low cost and natural abundance of sodium resources. ${ }^{3-6}$ Considerable efforts have been made to apply the successful experience on LIB systems to the SIBs, especially in the terms of the electrode materials. The larger ionic radius $\left(1.02 \AA\right.$ for $\mathrm{Na}^{+}$vs. $0.76 \AA$ for $\mathrm{Li}^{+}$), resulting in sluggish reaction kinetics, usually causes lower capacity, inferior rate capability, poor cycling stability, or even complete electrochemical inactivity, as in the case of graphitic carbon, the most commonly used anode material in LIBs. Thus, developing desirable electrode materials for high performance SIBs is still an urgent need for their practical application.

Similar to the LIB system, there are mainly three mechanisms involved in sodium storage for anode materials: the intercalation/de-intercalation reaction, the conversion reaction, and the alloying/de-alloying reaction. Hard carbon could be the most widely investigated intercalation-type anode material for SIBs due to its large layer spacing of $0.352 \mathrm{~nm}$, which has benefits for the storage of $\mathrm{Na}^{+} .{ }^{7}$ In comparison, the layer spacing of the conventional graphite is only $0.335 \mathrm{~nm}$. In addition to carbonaceous materials, a few

\footnotetext{
a. State Key Laboratory for Modification of Chemical Fibers and Polymer Materials, College of Materials Science and Engineering, Donghua University, Shanghai 201620, P. R. China. Email: jianpingyang@dhu.edu.cn

b. Institute for Superconducting and Electronic Materials, Australian Institute for Innovative Materials, University of Wollongong, Innovation Campus, North Wollongong, NSW 2500, Australia; School of Mechanical, Materials and Mechatronics Engineering, University of Wollongong, North Wollongong, NSW 2500, Australia.Email: zguo@uow.edu.au

State Key Laboratory of Materials-Oriented Chemical Engineering, Faculty of Chemical Engineering, Nanjing Tech University, No. 5 Xin Mofan Road, Nanjing 210009, P. R. China.Email: shaozp@njtech.edu.cn

$\ddagger$ These authors contributed equally to this work
}

titanium oxide-based materials, such as $\mathrm{Na}_{2} \mathrm{Ti}_{3} \mathrm{O}_{7}$ and $\mathrm{Li}_{4} \mathrm{Ti}_{5} \mathrm{O}_{12},{ }^{8-10}$ are also capable of reversible sodium intercalation, and they have been exploited extensively as well during the past several years. Such intercalation-type materials have generally exhibited relatively low sodium storage capability ( $300 \mathrm{~mA} \mathrm{h/g}$ ), which may be insufficient to meet the requirements of highenergy SIBs.

Unlike intercalation-type anode materials, some anode materials can store $\mathrm{Na}^{+}$through the conversion reaction or alloying reaction, with theoretical capacities two or three times higher than that for intercalation-type anodes (Fig. 1), ${ }^{11-61}$ making them highly promising for application in high-energy SIBs. Unfortunately, one important challenge associated with the conversion and alloying-type anode materials for SIBs is the large volume variation occurring during the sodiation/desodiation processes. Such large volume change could easily cause the pulverization of electrode materials, thus inducing the exfoliation of electrodes from the current collector along with the formation of the so-called "inactive electrode part".

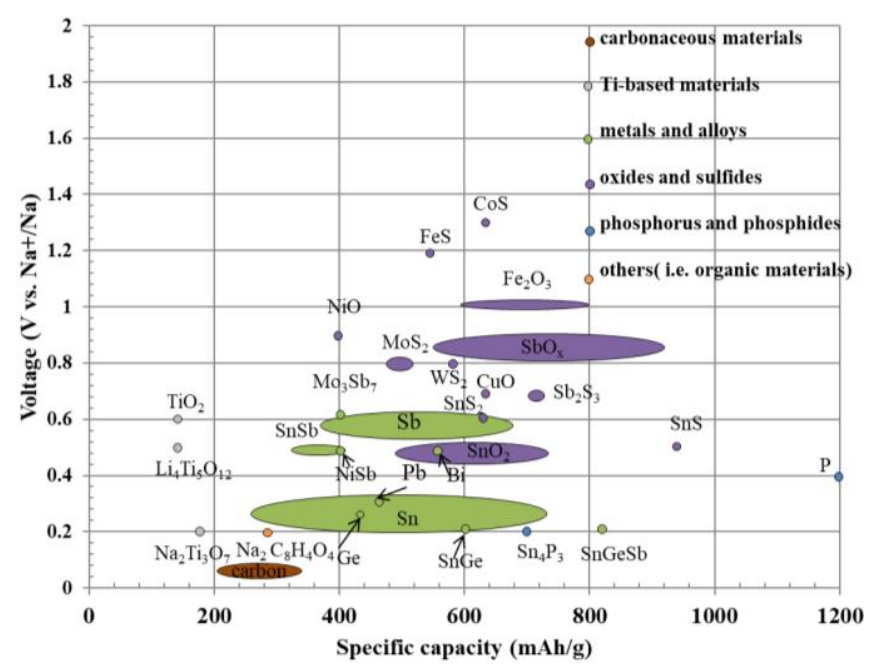

Fig. 1 Average plateau voltage versus discharge capacity for five kinds of anode materials in SIBs. Ref. 11-61 
As a result, quick capacity decay during cycling will occur for such conversion or alloying-type electrodes in SIBs. In addition, the sluggish reaction kinetics due to the larger radius of $\mathrm{Na}^{+}$usually resulted in inferior rate-capacity and power density, thus hindering their practical application. Moreover, low coulombic efficiency may be another drawback for this type of electrode, which also seriously obstructs their large-scale application in SIBs. Under working potentials lower than $1.0 \mathrm{~V}$, reactions would take place between the electrode materials and the organic electrolyte, leading to the formation of a solid-electrolyte interphase (SEI) film, which is the main cause of low coulombic efficiency. Normally, the SEI film will prevent further contact between the active electrode material and the liquid electrolyte, and an improved coulombic efficiency may then appear during the following galvanostatic charge-discharge processes. Nevertheless, the large volume variation in the conversion or alloying-type electrode materials during cycling could dynamically cause damage to the SEI film, leading to the exposure of new fresh electrode surface to the electrolyte. This would induce the electrode-electrolyte interface reactions to take place all over again, thus lowering the coulombic efficiency during the subsequent cycling process. Hence, numerous studies have recently been conducted to solve these issues, including the design of innovative electrode materials and architectures, the development of new electrode configuration, the control of operating voltage, and the utilization of novel electrolyte system, thus improving the energy density, powder density and the cycle lifespan of SIBs. Moreover, the in-depth understanding of the reaction mechanism and kinetics of electrode materials by advanced characterization techniques, especially those in-situ measurements is critical for optimizing current NIB systems.

Currently, a few good review articles on cathode and anodes for SIBs have been published already, but an overwhelming volume of research has been reported in the last two years and much significant progress has been made on high-performance anodes. For instance: in the area of structural design, the vaporization-condensation method (V-C) has been widely applied recently to prepare phosphorus based electrode instead of the previous ballmilling technique, since it is easy to construct nanosized phosphorus anchored on a given matrix by the $\mathrm{V}-\mathrm{C}$ method rather than a simple mixture of large sized phosphorous with carbonaceous materials. ${ }^{57,62,63}$ For surface modification, single-heteroatom doping (i.e., nitrogen, boron, phosphorus, and sulfur) and even dual-heteroatom doping have been demonstrated as an effective way to tune the electrical performance of electrodes, thus improving the energy storage performance. ${ }^{61,64,65}$ For electrochemical testing, controlling the reaction step by altering the working voltage window may be an efficient strategy to obtain long-term cycling life. ${ }^{66,67}$ So, an updated and timely review on recent progress on anode materials may be needed.

In this review, we summarized the recent advances in the development of high-capacity anode materials (metals and alloys, phosphorus and phosphides, oxides and sulfides/selenides) for high-energy SIBs, in terms of materials fabrication, electrochemical performance, and the corresponding reaction mechanisms. The effective strategies to improve the electrochemical performance via structural design, surface modification, dimension reduction, electrolyte optimization, and cut-off window control are introduced as well. In addition, the most likely future outlook on advanced conversion/alloying type anodes for next-generation energy storage systems will also be proposed.

\section{Metals and alloys}

Alloy-based materials have recently received increasing attention as anode materials for SIBs, because they can alloy with sodium to form various $\mathrm{Na}$ metal-alloy phases, thus generating higher capacities compared to those of carbon-based and Ti-based materials. For example, Chevrier and Cede reported that $\mathrm{Si}, \mathrm{Ge}, \mathrm{Sn}, \mathrm{Pb}$, and $\mathrm{Sb}$ could alloy with sodium to form binary compounds with the compositions of $\mathrm{NaSi}, \mathrm{NaGe}, \mathrm{Na}_{15} \mathrm{Sn}_{4}, \mathrm{Na}_{15} \mathrm{~Pb}_{4}$, and
$\mathrm{Na}_{3} \mathrm{Sb}$, which show theoretical capacities of 954, 369, 847, 485, and $660 \mathrm{~mA}$ $\mathrm{h} / \mathrm{g}$, respectively. ${ }^{68}$

As is well known, group IVA elements ( $\mathrm{Si}, \mathrm{Ge}, \mathrm{Sn}$, and $\mathrm{Pb}$ ) and a group VA element ( $\mathrm{Sb}$ ) have been intensively investigated as anode materials for $\mathrm{LIBS}^{69}$ 73 and Si element has been found to be the most promising anode material for commercialization due to its ultrahigh theoretical capacity and abundant resources, although it possesses relatively low sodiation capacity in comparison with lithiation in LIBs, so that it is nearly inactive with sodium. C. Y. Chou and G. Gwang ${ }^{74}$ found that Na-induced lattice disturbance is significant in $\mathrm{Si}$ due to its relatively smaller interstitial space and higher stiffness, which negatively affects the incorporation of $\mathrm{Na}$; therefore, $\mathrm{Si}$ anode exhibits sluggish sodiation performance in SIBs. Interestingly, the diffusion coefficient $\left(D_{\mathrm{Na}}\right)$ is predicted to approach the experimentally measured selfdiffusivity (around $10^{-8} \mathrm{~cm}^{2} / \mathrm{s}$ at room temperature), approximately 1 order of magnitude larger than for $D_{L i}$ in amorphous $a$-LiSi after the host has been moderately sodiated, so this suggests that presodiated $\mathrm{Si}$ could be used to overcome the poor sodiation at the cost of a slightly compromised initial capacity. This would offer a new approach for the future application of Sibased anode in SIBs.

In addition, relatively larger activation energy $\left(E_{a}\right)$ barriers to the migration of interstitial $\mathrm{Na}$ still need to be overcome compared with Li diffusion, indicating the difficulty for sodiation of alloy based materials in comparison to lithiation. Chevier and $\mathrm{Ceder}^{68}$ also stated that huge volume expansion would be involved during the sodiation of Si (143\%), Sn (423\%), and Sb (293\%), which could significantly restrict long-term cycling in electrodes for SIBs.

Several effective strategies have been developed to solve these issues with respect to the sluggish $\mathrm{Na}$ diffusion and large volume expansion, including the fabrication of nanoarchitectured materials and optimization of electrolytes and binders. The detailed electrochemical performances of various nanostructured metals and alloys are summarized in Table 1.

\subsection{Tin-based anode materials}

The electrochemical sodiation of crystalline $\mathrm{Sn}$ is a two-step reaction at room temperature, as reported by Wang. ${ }^{75}$ As shown in Fig. 2 , in the first step, an amorphous $\mathrm{Na}_{x} \mathrm{Sn}\left(a-\mathrm{Na}_{x} \mathrm{Sn}, x^{\sim} 0.5\right)$ phase is growing and consuming the pristine $\mathrm{Sn}$, with a moving phase boundary in between, and the formation of such a Na-poor phase causes a modest volumetric expansion of around $60 \%$. In the second step, continuous $\mathrm{Na}$ insertion leads to the formation of Na-rich amorphous phases and finally the crystalline $c-\mathrm{Na}_{15} \mathrm{Sn}_{4}$ phase. The total volumetric change after full sodiation approaches approximately $420 \%$. This large volume variation would result in the substantial pulverization of the active materials and loss of electrical contact with the current collector, leading to poor cycling capability. 
Table 1 Electrochemical performances of various metals and alloys as anode for SIBs in very recent reports in the literature.

\begin{tabular}{|c|c|c|c|c|c|c|c|}
\hline Metal & Nanostructure & $\begin{array}{l}\text { Redox } \\
\text { potential (V) } \\
\text { vs. } \mathrm{Na} / \mathrm{Na}^{+}\end{array}$ & $\begin{array}{l}\text { Current } \\
\text { density } \\
(\mathrm{mA} / \mathrm{g})\end{array}$ & $\begin{array}{l}\text { Reversible capacity(mA } \\
\mathrm{h} / \mathrm{g})\end{array}$ & $1^{\text {st }} \mathrm{CE}$ & Electrolyte & Ref. \\
\hline \multirow{5}{*}{ Sn } & $\begin{array}{l}\text { Pipe-wire } \mathrm{TiO}_{2}-\mathrm{Sn} @ \mathrm{CNFs} \\
\text { paper }\end{array}$ & $0.1-1.0$ & 100 & $413 / 400$ cycles & $58.3 \%$ & $\begin{array}{l}1 \mathrm{M} \mathrm{NaClO}_{4} \text { in } \\
\mathrm{EC} / \mathrm{DMC}\end{array}$ & 76 \\
\hline & Sn/graphite/PANa & $0.00-0.56$ & 50 & $618 / 100$ cycles & - & $\begin{array}{l}1 \mathrm{M} \mathrm{NaPF}_{6} \text { in } \\
\mathrm{PC}+2 \% \mathrm{FEC}\end{array}$ & 77 \\
\hline & Sn@N-doped CNF & $0.00-0.70$ & $\begin{array}{l}84.7 \\
847\end{array}$ & $\begin{array}{l}600 / 200 \text { cycles } \\
390 / 1000 \text { cycles }\end{array}$ & - & $\begin{array}{l}1 \mathrm{M} \mathrm{NaClO}{ }_{4} \text { in } \\
E C / P C+5 \% \mathrm{FEC}\end{array}$ & 78 \\
\hline & Forest-like Sn nanorods & $0.00-0.82$ & 50 & $405 / 150$ cycles & - & $\begin{array}{l}1 \mathrm{M} \mathrm{NaClO}_{4} \text { in } \\
\mathrm{EC} / \mathrm{DEC}\end{array}$ & 79 \\
\hline & $\begin{array}{l}8 \mathrm{~nm} \text {-Sn nanoparticles } \\
\text { /carbon }\end{array}$ & $0.05-0.80$ & $\begin{array}{l}500 \\
1000\end{array}$ & $\begin{array}{l}445 / 200 \text { cycles } \\
415 / 500 \text { cycles }\end{array}$ & & $\begin{array}{l}1 \mathrm{M} \mathrm{NaClO}_{4} \text { in } \\
\mathrm{EC} / \mathrm{DEC}\end{array}$ & 17 \\
\hline \multirow{7}{*}{$\mathrm{Sb}$} & $\begin{array}{l}\text { Hollow Sb@C yolk-shell } \\
\text { spheres }\end{array}$ & $0.27-0.85$ & $\begin{array}{l}50 \\
1000\end{array}$ & $\begin{array}{l}400 / 100 \text { cycles } \\
280 / 200 \text { cycles }\end{array}$ & $60.3 \%$ & $\begin{array}{l}1 \mathrm{M} \mathrm{NaClO}{ }_{4} \text { in } \\
\mathrm{PC}+5 \% \mathrm{FEC}\end{array}$ & 80 \\
\hline & $\begin{array}{l}\text { Sb/porous biomass } \\
\text { carbon nanocomposite }\end{array}$ & $0.32-0.88$ & 100 & $567 / 250$ cycles & $62.8 \%$ & $\begin{array}{l}1 \mathrm{M} \mathrm{NaClO}_{4} \text { in } \\
\mathrm{EC} / \mathrm{PC}+5 \% \mathrm{FEC}\end{array}$ & 81 \\
\hline & Sb@C-5 coaxial nanotube & $0.25-0.91$ & $\begin{array}{l}100 \\
1000\end{array}$ & $\begin{array}{l}407 / 240 \text { cycles } \\
240 / 2000 \text { cycles }\end{array}$ & & $\begin{array}{l}1 \mathrm{M} \mathrm{NaClO} \text { in } \\
\mathrm{PC}+5 \% \mathrm{FEC}\end{array}$ & 82 \\
\hline & $\begin{array}{l}\text { Double-walled Sb@ } \mathrm{TiO}_{2-x} \\
\text { nanotubes }\end{array}$ & $0.35-0.88$ & 2640 & $320 / 1000$ cycles & & $\begin{array}{l}1 \mathrm{M} \mathrm{NaClO}{ }_{4} \text { in } \\
\mathrm{PC}+\mathrm{FEC}\end{array}$ & 83 \\
\hline & $\begin{array}{l}\text { Ordered Sb nanorod } \\
\text { arrays }\end{array}$ & $0.13-0.98$ & 500 & $612.6 / 200$ cycles & $79.5 \%$ & $\begin{array}{l}1 \mathrm{M} \mathrm{NaClO} \\
4 \text { in } \\
\mathrm{EC} / \mathrm{PC}+5 \% \mathrm{FEC}\end{array}$ & 84 \\
\hline & $\begin{array}{l}\text { Sb porous hollow } \\
\text { microspheres }\end{array}$ & $0.32-1.20$ & $\begin{array}{l}100 \\
660\end{array}$ & $\begin{array}{l}617 / 100 \text { cycles } \\
502.3 / 100 \text { cycles }\end{array}$ & $64.6 \%$ & $\begin{array}{l}1 \mathrm{M} \mathrm{NaClO} \text { in } \\
\mathrm{PC}+5 \% \mathrm{FEC}\end{array}$ & 85 \\
\hline & Nanoporous Sb particles & $0.32-1.10$ & 100 & $573.8 / 200$ cycles & & $\begin{array}{l}1 \mathrm{M} \mathrm{NaClO} \text { in } \\
\mathrm{PC}+5 \% \mathrm{FEC}\end{array}$ & 86 \\
\hline \multirow{3}{*}{$\mathrm{Ge}$} & $\begin{array}{l}\text { Core-shell } \\
\text { Ge@graphene@ } \mathrm{TiO}_{2} \\
\text { nanofibers }\end{array}$ & $\begin{array}{l}\text { No apparent } \\
\text { redox peaks }\end{array}$ & 100 & $182 / 250$ cycles & & $\begin{array}{l}1 \mathrm{M} \mathrm{NaClO}_{4} \text { in } \\
\mathrm{EC} / \mathrm{DEC}(6: 4)\end{array}$ & 87 \\
\hline & $\begin{array}{l}\text { 3D Si/Ge Nanorods Array } \\
\text { anode buffered } \\
\text { by TiN/Ti interlayer }\end{array}$ & $0.01-0.90$ & $10 \mu \mathrm{A} / \mathrm{cm}^{2}$ & $20 \mu \mathrm{Ah} / \mathrm{cm} / 200$ cycles & & $\begin{array}{l}1 \mathrm{M} \mathrm{NaPF}_{6} \text { in } \\
\mathrm{EC} / \mathrm{DEC}\end{array}$ & 88 \\
\hline & $\begin{array}{l}\text { Nanocolumnar } \\
\text { germanium thin film }\end{array}$ & $0.13-0.60$ & 72 & $378 / 100$ cycles & & $\begin{array}{l}1 \mathrm{M} \mathrm{NaPF}_{6} \text { in } \\
\mathrm{FEC} / \mathrm{DEC}\end{array}$ & 22 \\
\hline $\mathrm{Pb}$ & $\mathrm{Pb}$ particles & $0.10-0.51$ & 13 & $464 / 50$ cycles & & $1 \mathrm{M} \mathrm{NaPF}_{6}$ in DG & 21 \\
\hline \multirow{3}{*}{$\mathrm{Bi}$} & Bulk Bi & $0.46-0.77$ & 400 & $389 / 2000$ cycles & $94.8 \%$ & $\begin{array}{l}1 \mathrm{M} \mathrm{NaPF}_{6} \text { in } \\
\text { Diglyme }\end{array}$ & 89 \\
\hline & Bi@graphene & $0.42-0.77$ & 40 & 200/50 cycles & & $\begin{array}{l}1 \mathrm{M} \mathrm{NaClO} \text { in } \\
\mathrm{EC} / \mathrm{PC}\end{array}$ & 23 \\
\hline & $\begin{array}{l}\text { Bi nanoparticles in carbon } \\
\text { spheres }\end{array}$ & $0.40-0.78$ & 100 & $123.5 / 100$ cycles & & $\begin{array}{l}1 \mathrm{M} \mathrm{NaClO} \text { in } \\
\mathrm{EC} / \mathrm{PC}\end{array}$ & 90 \\
\hline
\end{tabular}

Hence, in order to alleviate this issue, it has been reported that the electrochemical performance of Sn electrode can be effectively enhanced by

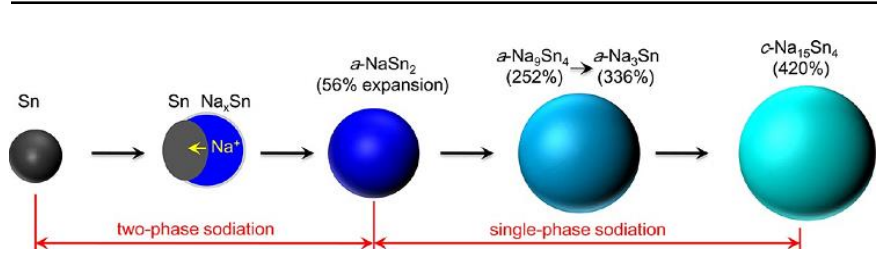

Fig. 2 Schematic illustration of the reaction of Sn during sodiation. Reprinted from Ref. 75 with permission from American Chemical Society. structural design, surface modification, cut-off voltage window control, etc., as summarized in Table 1.12,13,15,17,76-79,91,92

For instance, Komaba's group ${ }^{77}$ reported that slightly altering the cut-off voltage would significantly affect the reversibility of electrochemical sodiation for Sn electrode by limiting the formation of the SEl at the given potential. In the voltage range of $0-0.70 \mathrm{~V}$, the sodiation/desodiation process was not stable, and the capacity decayed from $800 \mathrm{~mA} \mathrm{~h} / \mathrm{g}$ to $600 \mathrm{~mA} \mathrm{~h} / \mathrm{g}$ after 100 cycles due to the dissolution and reformation of SEl at 0.68 and 0.4 $\mathrm{V}$. In contrast, the cycling stability was improved when the upper cut-off voltage was decreased to $0.65 \mathrm{~V}$ by excluding the voltage plateau at $0.68 \mathrm{~V}$, so that the capacity retention was $85 \%$ after 100 cycles. This case may demonstrate that fully understanding the reason causing the capacity decay is vital to finding the most effective solution to improve the cycling performance of $\mathrm{Sn}$-based electrodes. 
In addition, in order to suppress the severe volume changes in Sn anode, Mao et al. ${ }^{76}$ fabricated flexible pipe-wire $\mathrm{TiO}_{2}$-Sn@carbon nanofibers $\left(\mathrm{TiO}_{2}\right.$ Sn@CNFs) as anode for LIBs and SIBs via electrospinning and atomic layer deposition, in which the carbon nanofibers and $\mathrm{TiO}_{2}$ pipe act as a dual protective shell on the outside of the $\mathrm{Sn}$ nanoparticles to prevent pulverization of the electrode (Fig. 3). Hence, an improved capacity of $413 \mathrm{~mA}$ $\mathrm{h} / \mathrm{g}$ at $100 \mathrm{~mA} / \mathrm{g}$ for $\mathrm{TiO}_{2}$-Sn@CNFs binder-free anode was achieved after 400 cycles for SIBs.

Interestingly, reducing the particle size of Sn to the nanoscale (especially less than $10 \mathrm{~nm}$ ) could enable the electrode to endure higher strain and effectively mitigate the pulverization of the active materials. Considering that nanosized particles tend to aggregate during cycling, Chen's group ${ }^{17}$ designed such a nanostructure, in which Sn nanoparticles approximately $8 \mathrm{~nm}$ in size were homogeneously embedded in a spherical carbon network via an aerosol spray pyrolysis method (Fig. 4a and b). This mesoporous $\mathrm{Sn} / \mathrm{C}$ possessed a large specific surface area $\left(150.43 \mathrm{~m}^{2} / \mathrm{g}\right)$, indicating highly dispersed small $\mathrm{Sn}$ nanoparticles in the carbon matrix, and it delivered a stable capacity of 415 $\mathrm{mA} \mathrm{h} / \mathrm{g}$ after 500 cycles at $1 \mathrm{~A} / \mathrm{g}$, and a high-rate capacity of $349 \mathrm{~mA} \mathrm{h/g}$ when the current density was increased to 4 A/g (Fig. 4c, d). In contrast, Sn@C electrodes with a Sn particle size of approximately $50 \mathrm{~nm}$ experienced relatively low rate capacity and poor cycling performance (Fig. 4c). This further demonstrates that electrode materials with fine nanoparticles are likely to yield good electrochemical performance due to the greater abundance of active sites and the higher tolerance for strain of nanosize particles compared with large-size particles.

\subsection{Sb-based anode materials}

In addition to $\mathrm{Sn}$, Sb electrode was also investigated as an alloying-type anode for SIBs. The reaction mechanism of Sb with $\mathrm{Na}$ does not fully involve the same alloying mechanism as that with $\mathrm{Li}$. It was proposed that $\mathrm{Sb}$ first reacts with $\mathrm{Na}$ to form amorphous intermediates ( $\mathrm{Na}_{x} \mathrm{Sb}$ with $\left.x^{\sim 1.5}\right)$ upon discharge. When all of the $\mathrm{Sb}$ is transformed into the amorphous phase, it converts to cubic-hexagonal $\mathrm{Na}_{3} \mathrm{Sb}$ before being stabilized as hexagonal $\mathrm{Na}_{3} \mathrm{Sb}$ (Fig. $5 \mathrm{a}$, b). ${ }^{14}$

To further investigate the alloying mechanism of Sb anode for SIBs, Alan ${ }^{93}$ applied both operando pair distribution function analysis and ex-situ ${ }^{23} \mathrm{Na}$ magic-angle spinning solid-state nuclear magnetic resonance (NMR). Two previously uncharacterized intermediate phases were identified: one is $\alpha-\mathrm{Na}_{3}$. ${ }_{x} \mathrm{Sb}(x \approx 0.4-0.5)$, the structure of which is similar to that of crystalline $\mathrm{Na}_{3} \mathrm{Sb}$ but with sodium vacancies and a limited correlation length; and the other one is $\alpha-\mathrm{Na}_{1.7} \mathrm{Sb}$, a highly amorphous structure (Fig. $5 \mathrm{c}$ ). It was observed that $c$ $\mathrm{Na}_{3} \mathrm{Sb}$ possessed high sodium mobility, possibly leading to the high-rate capability of Sb anode in SIBs.

Recently, a variety of nanostructures, including nanofibers/nanotubes, ${ }^{20,82,83}$ leaf-like structures, $^{94}$ nanospheres, ${ }^{85,95}$ nanorods, ${ }^{84}$ three-dimensional (3D) nanoporous ${ }^{86}$ and yolk-shell structures, ${ }^{80}$ were fabricated to maximize the advantages of $\mathrm{Sb}$ anode, such as high capacity and appropriate voltage plateaus, while minimizing the volume expansion. Liu et al. ${ }^{86}$ employed the chemical dealloying method to control the morphology and size of Sb particles in the presence of AlSb $b_{x}$ (Fig. 6a), where $\mathrm{Sb}$ acts as the porous structure-forming element, while Al acts as sacrificial element. Based on the atomic ratio of $\mathrm{Al}$ to $\mathrm{Sn}$, the morphologies of nanoporous $\mathrm{Sb}$ varied from a coral-like structure $\left(\mathrm{Al}_{30} \mathrm{Sb}_{70}, \mathrm{NP}-\mathrm{Sb} 70\right)$ to a honeycomb-like structure $\left(\mathrm{Al}_{20} \mathrm{Sb}_{80}\right)$, in accordance with the porosity ( $\left.V_{\text {pore }}\right)$ of $69.2 \%$ and $50.4 \%$, respectively (Fig. $6 \mathrm{~b}$ ). As the anode for SIBs, the NP-Sb70 electrode exhibited better cycling stability than the other electrodes in Fig. $6 \mathrm{c}$, maintaining a reversible capacity of $573.8 \mathrm{~mA} \mathrm{~h} / \mathrm{g}$ after 200 cycles at 100 $\mathrm{mA} / \mathrm{g}$ in the voltage range of 0.1 to $1.5 \mathrm{~V}$ and delivering a capacity of $420 \mathrm{~mA}$ $\mathrm{h} / \mathrm{g}$ at the high current density of $3300 \mathrm{~mA} / \mathrm{g}$. The reason for the improved electrochemical performance can be attributed to the 3D porous framework and interconnected nanopores, which could enrich this electrode with active (a)
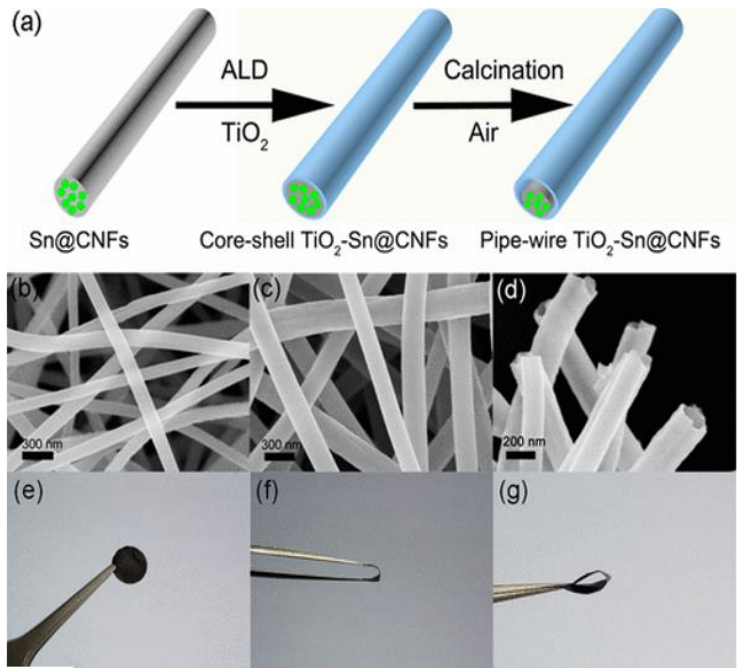

(h)

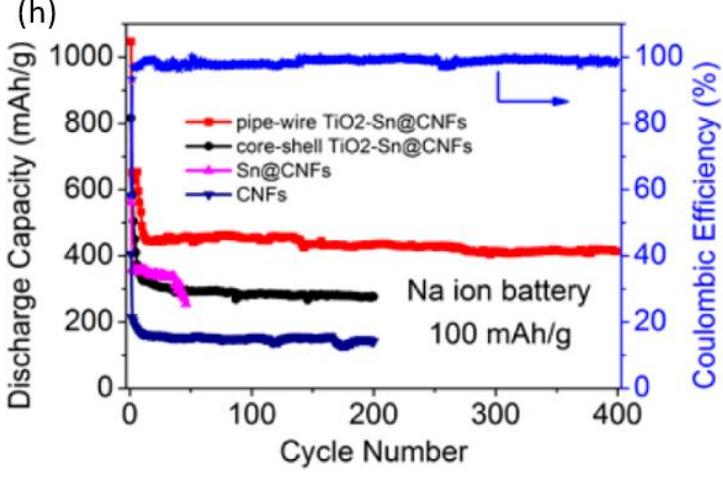

Fig. 3 (a) Schematic illustration of the preparation process for pipe-wire $\mathrm{TiO}_{2}$ Sn@CNFs. (b-d) Scanning electron microscope (SEM) images of Sn@CNFs, core-shell $\mathrm{TiO}_{2}-\mathrm{Sn} @ \mathrm{CNFs}$, and pipe-wire $\mathrm{TiO}_{2}-\mathrm{Sn} @ \mathrm{CNFs}$, respectively. (e-g) Digital photographs of pipe-wire $\mathrm{TiO}_{2}$-Sn@CNFs paper. (h) Cycling life of pipewire $\mathrm{TiO}_{2}$-Sn@CNFs, core-shell TiO $\mathrm{T}_{2}$-Sn@CNFs, Sn@CNFs, and CNFs in SIBs at a current density of $100 \mathrm{~mA} / \mathrm{g}$ in the voltage range of $0.01-2 \mathrm{~V}$. Reprinted from Ref. 76 with permission from American Chemical Society.

sites and accommodate the volume changes associated with $\mathrm{Na}$ insertion. Nevertheless, the good electrochemical performance of these nanoporous $\mathrm{Sb}$ particles was achieved at the cost of the sacrifice of Al metal, which may increase the cost of material preparation. Similar work has been conducted by Ji's group. ${ }^{16}$ Porous hollow microspheres of Sb (Sb PHMS) were prepared via a replacement reaction employing $\mathrm{Zn}$ microsphere templates, and they exhibited high capacity retention of $97.2 \%$ after 100 cycles at $100 \mathrm{~mA} \mathrm{~h} / \mathrm{g}$ due to their hollow and porous properties.

Moderately tailoring the size of $\mathrm{Sb}$ particles is probably another effective strategy to enhance the electrochemical properties of $\mathrm{Sb}$ anode. Sb nanocrystals with mean sizes in the range of 10-20 nm were synthesized by the colloidal method. ${ }^{95}$ It was demonstrated that, with the reduction of $\mathrm{Sb}$ size to $20 \mathrm{~nm}$, fast kinetics and stable operation can be achieved, while further downsizing to $10 \mathrm{~nm}$ or less may be detrimental to electrode performance. In comparison, bulk Sb, and $10 \mathrm{~nm}$ and $20 \mathrm{~nm}$ Sb nanocrystals possessed capacities of 580,520, and $620 \mathrm{~mA} \mathrm{~h} / \mathrm{g}$ at $0.5 \mathrm{C}$, respectively, at which the 20 $\mathrm{nm}$ Sb particles exhibited the highest capacity among these three different particle sizes. The plausible reason for the lower capacity of $10 \mathrm{~nm} \mathrm{Sb}$ nanocrystals in the battery could be the relatively greater density of active sites in relation to the small size of the active metal electrode, which can readily form a large volume fraction of amorphous oxide on the 

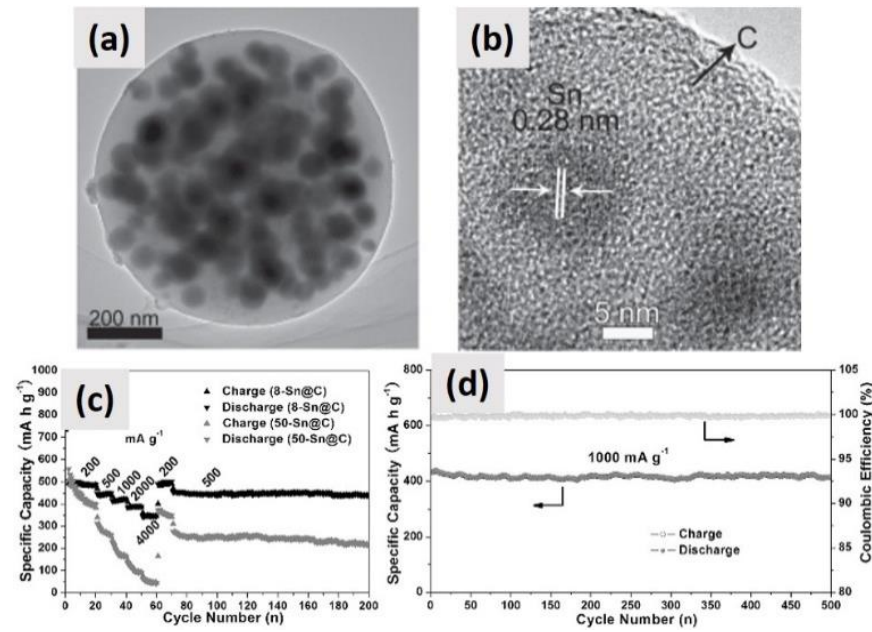

Fig. 4 (a) Transmission electron microscope (TEM) image and (b) high resolution TEM (HRTEM) image of 8-Sn@C; (c) Rate capability of the 8-Sn@C and 50-Sn@C electrodes in the voltage range of 0.01 to $2.0 \mathrm{~V}$, and (d) longterm cycling stability of the 8-Sn@C electrode in the same voltage range at a current density of $1 \mathrm{~A} / \mathrm{g}$. Reprinted from Ref. 17 with permission from John Wiley and Sons.

electrode surface, leading to irreversible capacity loss resulting from the formation of $\mathrm{Na}_{2} \mathrm{O}$ in the first-cycle discharge. Therefore, tailoring the size of the nanostructure to a moderate scale has a significant effect in terms of the surface area, side reactions, and the electrochemical performance of electrodes.

In addition, combining electrodes with carbonaceous materials is a traditional but still favorable technique to enhance the charge transfer, promote $\mathrm{Na}^{+}$diffusion, and maintain the structural integrity. ${ }^{19,81,96-99} \mathrm{~A}$ Sb@carbon coaxial nanotube electrode fabricated via carbon coating coupled with a thermal-reduction strategy as anode material for SIBs exhibited good cycling stability and rate capability, with the specific capacity of $407 \mathrm{~mA} \mathrm{~h} / \mathrm{g}$ retained at $100 \mathrm{~mA} / \mathrm{g}$ after 240 cycles, and $240 \mathrm{~mA} \mathrm{~h} / \mathrm{g}$ at $1 \mathrm{~A} / \mathrm{g}$ after 2000 cycles. The enhanced sodium storage performance of Sb@C can be attributed to the coaxial structure, in which the hollow space and the amount of $\mathrm{Sb}$ inside the tube can be easily tuned to accommodate the volume expansion of $\mathrm{Sb}$, as well as the carbon shell, which could enhance the conductivity and prevent the aggregation of $\mathrm{Sb}$, as well as protecting $\mathrm{Sb}$ from direct contact with the electrolyte, so as to prevent the repeated formation of SEI film on the surface of the active electrode. ${ }^{82}$ Similar work has also been reported by other research groups. ${ }^{19,98}$

\subsection{Germanium-based anode materials}

During the past decade, germanium has been extensively studied as an anode material for LIBs, since it has a high lithium storage capacity and high lithium diffusivity. ${ }^{71,72,100}$ Recently, it was also investigated as a potential anode for SIBs. Unfortunately, it was observed that sodium diffusion in crystalline germanium was several orders of magnitude slower than for lithium in germanium, and the larger radius of sodium results in much higher activation energy for hopping between interstitial sites in the lattice $(0.51 \mathrm{eV}$ for Li vs. $1.5 \mathrm{eV}$ for sodium). ${ }^{99}$ Consequently, bulk-phase Ge usually presented poor $\mathrm{Na}^{+}$ storage performance.

In order to overcome the low diffusion coefficient of sodium in germanium, nanocolumnar germanium thin films were synthesized by evaporative deposition as anode for SIBs, ${ }^{22}$ which presented a reversible capacity of 430 $\mathrm{mA} \mathrm{h} / \mathrm{g}$, and retained $88 \%$ of the initial capacity after 100
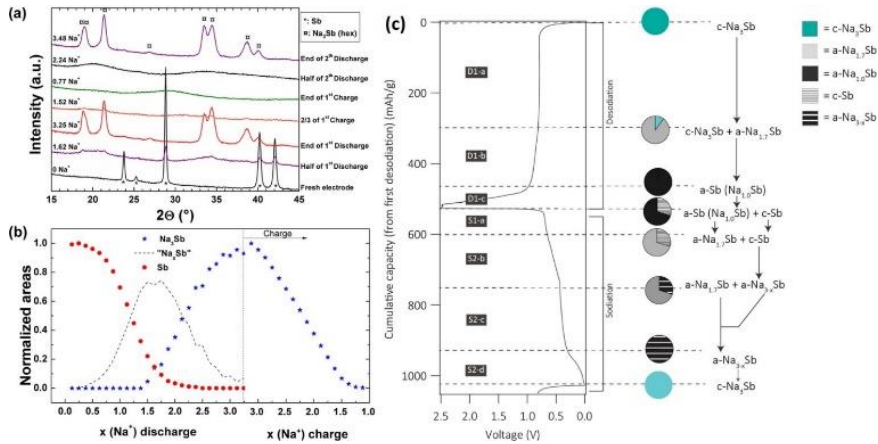

Fig. 5 (a) Selected operando X-ray diffraction (XRD) patterns at various stages of discharge and charge of a $\mathrm{Sb} / \mathrm{Na}$ cell and $\not x$ are used to indicate the Bragg peaks corresponding to $\mathrm{Sb}$ and $\mathrm{Na}_{3} \mathrm{Sb}$, respectively. (b) Normalized areas under the most intense diffraction peaks for $\mathrm{Sb}\left(28.8^{\circ}\right)$ (in red) and $\mathrm{Na}_{3} \mathrm{Sb}$ $\left(21.2^{\circ}\right)$ (in blue) during the first cycle, plotted as a function of Na number $(x)$. The dashed line represents the calculated intensity of amorphous $\mathrm{Na}_{x} \mathrm{Sb}$ phase. Reprinted from Ref. 14 with permission from American Chemical Society. (c) PDF- and NMR-derived mechanism of (de)sodiation of antimony from the first desodiation during galvanostatic cycling at a rate of $\mathrm{C} / 20$. Reprinted from Ref. 93 with permission from American Chemical Society.

cycles at C/5. Furthermore, the capacity of $164 \mathrm{~mA} \mathrm{~h} / \mathrm{g}$ was achieved at the high rate of $27 \mathrm{C}(10 \mathrm{~A} / \mathrm{g})$. In comparison, a dense germanium film exhibited serious capacity fading after 15 cycles due to the severe pulverization experienced by bulk films; therefore, nanoscale dimensions are critical for stable, reversible, and high-rate sodiation of $\mathrm{Ge}$ electrode, and the evaporative deposition method is also a quite facile technique to fabricate thin film materials for energy storage application. Wang et al. ${ }^{87}$ fabricated germanium@graphene@ $\mathrm{TiO}_{2}$ core-shell nanofibers by atomic layer

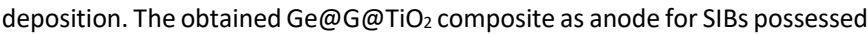
an initial capacity of $368 \mathrm{~mA} \mathrm{~h} / \mathrm{g}$ and maintained $182 \mathrm{~mA} \mathrm{~h} / \mathrm{g}$ (at the $250^{\text {th }}$ cycle) at a current density of $100 \mathrm{~mA} / \mathrm{g}$.

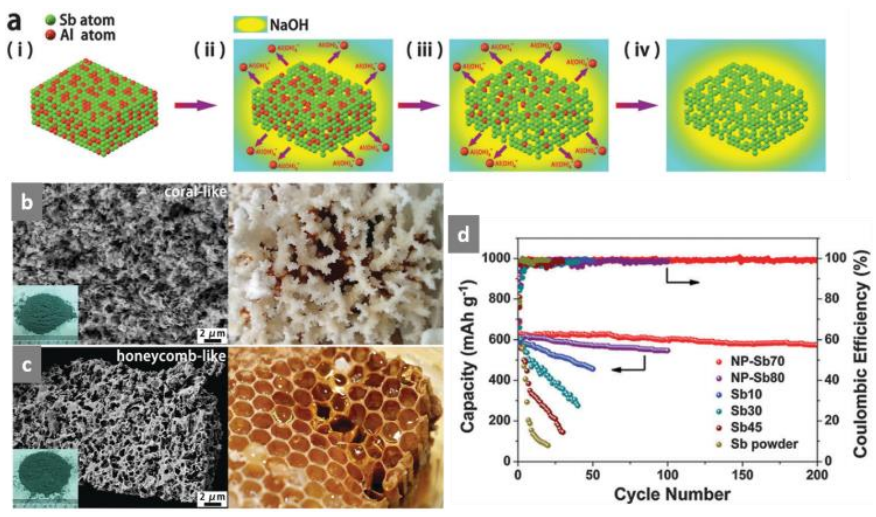

Fig. 6 (a) Schematic illustration of the evolution of the NP-Sb structure via chemical dealloying. (b) SEM image of the coral-like NP-Sb70 with a photograph of coral on the right; inset is a photograph of the powdery NPSb70. (c) SEM image of the honeycomb-like NP-Sb80 with a photograph of a honeycomb on the right; inset is a photograph of the powdery NP-Sb80. (d) Cycling performance of the NP-Sb70, NP-Sb80, Sb10, Sb30, Sb45, and commercial Sb powder electrodes at a current density of $100 \mathrm{~mA} / \mathrm{g}$ from 0.1 $\mathrm{V}$ to $1.5 \mathrm{~V}$ versus $\mathrm{Na}^{+} / \mathrm{Na}$. Reprinted from Ref. 86 with permission from The Royal Society of Chemistry. 
The reason for the higher reversible capacity reported in the above literature might be explained by Lu et al.'s report. ${ }^{101}$ They proposed that the final sodiated phase of $\mathrm{Ge}$ is close to $\mathrm{Na}_{1.6} \mathrm{Ge}$, rather than $\mathrm{NaGe}$, since the volume expansion of amorphous $\mathrm{Ge}$ is over $300 \%$. The results illustrated that the potential of $a$-Ge for SIBs may have been previously underestimated. Nevertheless, the scarcity and high cost of the Ge may still hinder further large-scale application of Ge anode for SIBs.

\subsection{Other metal based anodes}

Unlike $\mathrm{Sn}, \mathrm{Sb}$, and $\mathrm{Ge}$, other metals such as $\mathrm{Pb}$ and $\mathrm{Bi}$ have rarely been investigated as anode materials for SIBs. ${ }^{21,23,90,102}$ Recently, Monconduit's group $^{21}$ fabricated a highly loaded $\mathrm{Pb}$ electrode that showed capacity retention of $464 \mathrm{~mA} \mathrm{h/g}$ after 50 cycles, representing a high volumetric capacity of $5289 \mathrm{~mA} \mathrm{~h} / \mathrm{cm}^{3}$ due to the high density of $\mathrm{Pb}$, which demonstrated the potential of $\mathrm{Pb}$ anode for $\mathrm{SIBs}$ in terms of electrochemical performance. Nevertheless, becasue $\mathrm{Pb}$ is toxic and environmentally unfriendly, $\mathrm{Pb}$ may not be promising as an anode material for the practical commercialization of SIBs in the long run.

Su and his colleagues ${ }^{23}$ investigated a Bi@graphene composite as anode for SIBs, and it had a capacity of $561 \mathrm{~mA} \mathrm{~h} / \mathrm{g}$ in the voltage range of $0.01-2 \mathrm{~V}$ at $40 \mathrm{~mA} / \mathrm{g}$. They also found that Bi took part in an intercalation process, rather than alloying with $\mathrm{Na}$. Similar work with $\mathrm{Bi}$ /carbon spheres for SIBs was also reported by Yang et al..$^{90}$ Interestingly, Wang et al. ${ }^{102}$ observed that the bulk $\mathrm{Bi}$ also could exhibit very stable cycling capability with the capacity retention of $94.4 \%$ after 2000 cycles ( $389 \mathrm{~mA} \mathrm{h/g}$ ) in glyme-based electrolyte. The good cycling stability can be ascribed to the following reason: the bulk Bi electrode can gradually become porous in glyme-based electrolyte during initial cycling, ensuring facile $\mathrm{Na}^{+}$transport and structural stability. In contrast, this phenomenon could not be observed in carbonate-based electrolytes. This demonstrates that selecting the optimal electrolytes is quite important for enhancing the electrochemical performance of electrodes. Furthermore, it was stated that $\mathrm{Bi}$ electrode in the $\mathrm{NaPF}_{6}-\mathrm{G} 2$ electrolyte exhibited two typical two-phase reactions of $\mathrm{Bi} \leftrightarrow \mathrm{NaBi}$ and $\mathrm{NaBi} \leftrightarrow \mathrm{Na}_{3} \mathrm{Bi}$ with flat discharge/charge plateaus at $0.67 / 0.77 \mathrm{~V}$ and $0.46 / 0.64 \mathrm{~V}$, respectively, via a highly reversible alloying/dealloying mechanism. The proposed reaction mechanism is different from the results reported by Su et al., ${ }^{23}$ as mentioned above. Nevertheless, these results will encourage more researchers to investigate the relationship between electrolyte and electrode for performance enhancement in all electrochemical systems.

\subsection{Intermetallic alloy based anode}

A comparison of a series of intermetallic anode materials for SIBs in terms of their compositions, potential windows, and capacities is summarized in Table 2 .

Based on the composition, intermetallic anodes can be classified into two types:

1) Alloys of $\mathrm{M}-(\mathrm{Sn}, \mathrm{Sb}$, and $\mathrm{Ge})$, in which $\mathrm{M}$ is an electrochemically active component, such as $\mathrm{SnSb},{ }^{26,27,103} \mathrm{Sn}-\mathrm{Ge},{ }^{25} \mathrm{Zn}_{4} \mathrm{Sb}_{3},{ }^{104} \mathrm{Sn}-\mathrm{Ge}-\mathrm{Sb},{ }^{24}$ and $\mathrm{Sn}$ $\mathrm{Bi}-\mathrm{Sb},{ }^{105}$ which have attracted increasing attention because the two different metal phases can work as mutual buffers for each other to alleviate the volume fluctuations. Specifically, for these alloys, the single metal has certain electrochemical performance but not that promising, for instance, Sn metal as anode for batteries has very high theoretical capacity, but poor cycling performance, while Sb metal as anode for batteries has lower theoretical capacity, but better cycling performance, so the formed SnSb alloy have better electrochemical performance than that of single one.

Our group developed SnSb-core/carbon-shell nanocables anchored on graphene sheets via the hydrothermal technique and chemical vapor deposition, which demonstrated stable cycling capability as anode for SIBs, with a capacity of $360 \mathrm{~mA} \mathrm{h/g}$ retained up to 100 cycles. The electrolyte was also optimized, and the results revealed that the electrode in the electrolyte of $1 \mathrm{M} \mathrm{NaClO}_{4}$ in propylene carbonate $(\mathrm{PC})+5 \%$ fluoroethylene carbonate (FEC) demonstrated better electrochemical performance compared to that in $1 \mathrm{M} \mathrm{NaClO}_{4}$ in $\mathrm{PC}, 1 \mathrm{M} \mathrm{NaClO}_{4}$ in PC/FEC (1:1 v/v), and $1 \mathrm{M} \mathrm{NaPF}_{6}+\mathrm{PC}^{26}$ Additionally, ternary $\mathrm{Sn}-\mathrm{Ge}-\mathrm{Sb}$ thin film alloys were also employed as anode materials for SIBs, as shown in Table $2 .{ }^{24}$ When the proportion of Sn increased to $80 \%$, the battery nearly failed after 50 cycles due to the large volume variation of $\mathrm{Sn}$ metal during repeated $\mathrm{Na}^{+}$storage, whilst the $\mathrm{Sn}_{50} \mathrm{Ge}_{25} \mathrm{Sb}_{25}$ alloy exhibited the most promising electrochemical behavior. Nie et al. ${ }^{104}$ reported on the electrochemical sodiation-desodiation process in $\mathrm{Zn}_{4} \mathrm{Sb}_{3}$ nanowires as anode via employing in-situ TEM, and it was demonstrated that the reaction mechanism of $\mathrm{Zn}_{4} \mathrm{Sb}_{3}$ with sodium can be summarized by the following process:

During the first cycle:

$1^{\text {st }}$ sodiation: $\mathrm{Zn}_{4} \mathrm{Sb}_{3}+\mathrm{Na}^{+}+e^{-} \rightarrow \mathrm{Na}_{3} \mathrm{Sb}+\mathrm{NaZn}_{13}$

$1^{\text {st }}$ desodiation: $\mathrm{Na}_{3} \mathrm{Sb}+\mathrm{NaZn}_{13} \rightarrow \mathrm{NaZnSb}+\mathrm{Zn}+\mathrm{Na}^{+}+e^{-}$(2)

After the first cycle: $\mathrm{NaZnSb}+\mathrm{Zn}+\mathrm{Na}^{+}+e^{-} \leftrightarrow \mathrm{Na}_{3} \mathrm{Sb}+\mathrm{NaZn}_{13}$ (3)

Accordingly, it was found that the $\mathrm{Zn}_{4} \mathrm{Sb}_{3}$ nanowire displayed about $161 \%$ volume expansion after the first sodiation and then was cycled with an $83 \%$ reversible volume expansion. Despite the massive expansion, the nanowires could be cycled without any cracking or fracturing during the ultrafast sodiation/desodiation process. The coulombic efficiency of $\mathrm{Zn}_{4} \mathrm{Sb}_{3}$ nanowires reached $99 \%$ after 50 cycles from $45 \%$ for the $1^{\text {st }}$ cycle, and then remained steady at this value for subsequent cycles, indicating good cycling performance.

2) Another class of intermetallics, $M-(S n, S b$, and $\mathrm{Ge})$, where $M$ is an electrochemically inactive component, such as $\mathrm{SnSe},{ }^{106} \mathrm{Cu}_{2} \mathrm{Sb}_{1}{ }^{107} \mathrm{Mo}_{3} \mathrm{Sb}_{7},{ }^{29,108}$ $\mathrm{FeSb}_{2},{ }^{109} \mathrm{NiSb}^{28}$ and $\mathrm{SiGe},{ }^{88}$ in principle, provides excellent candidates as substitutes for the pure elemental electrodes, since the lower volume changes and the presence of the inactive element can provide a more stable structure and more efficient electronic conduction within the expanding/shrinking framework.

For instance, a carbon-coated $\mathrm{Mo}_{3} \mathrm{Sb}_{7}$ composite demonstrated a capacity of $400 \mathrm{~mA} \mathrm{~h} / \mathrm{g}$ at $0.2 \mathrm{C} \mathrm{(1} \mathrm{C=} 494 \mathrm{~mA} / \mathrm{g})$, and sustained $180 \mathrm{~mA} \mathrm{~h} / \mathrm{g}$ at $20 \mathrm{C}$, as well as maintaining $338 \mathrm{~mA} \mathrm{~h} / \mathrm{g}$ at $0.5 \mathrm{C}$ after 800 cycles with capacity retention of $91.8 \%$, indicating excellent cycling stability. The good performance of $\mathrm{Mo}_{3} \mathrm{Sb}_{7} @ \mathrm{C}$ is ascribed to the buffering effect of the Mo component for the $\mathrm{Sb}$, as well as the carbon coating and refined particle sizes of $\mathrm{Mo}_{3} \mathrm{Sb}_{7}$ during the cycling. ${ }^{29}$ Yue et al. ${ }^{88}$ reported 3D hexagonal match-like $\mathrm{Si} / \mathrm{TiN} / \mathrm{Ti} / \mathrm{Ge}$ nanorod arrays (NR), which were fabricated by nanosphere lithography and inductively coupled plasma (ICP) dry etching, followed by a sputtering technique. The 3D Si/TiN/Ti/Ge composite electrode exhibited the best electrochemical performance among all the fabricated samples, and it maintained a reversible areal capacity of about $20 \mu \mathrm{A} \mathrm{h} / \mathrm{cm}^{2}$ after 200 cycles due to the 3D nanostructure and the effective conductive layers, while the 3D $\mathrm{Si} / \mathrm{Ge}$ nanorod (NR), 3D Si NR, and planar Si/TiN/Ti/Ge composite electrodes showed dramatically reduced capacities and terminated their operations after 15 cycles. These wafer-scale Si-based Na-ion micro-/nano-battery anodes may be integrated into microelectronic devices such as on-chip power systems in the future.

As mentioned above, the main issue for the alloying type of electrode material arises from the volume expansion of the electrode, resulting in the destruction of the nanostructure and loss of electrical connectivity. The aim of current research on such alloying type anodes is to design the nanoarchitecture of the metal electrode by tailoring the particle size or forming a composite to suppress the volume changes during sodiation, while further optimization by the formation of an intermetallic alloy and sensitive characterization of the structural evolution during the reaction with $\mathrm{Na}$ wil 
Table 2 Comparison of a range of intermetallic anode materials for SIBs in terms of their composition, potential window, and capacity.

\begin{tabular}{|c|c|c|c|c|c|c|c|c|}
\hline Type & Material & & $\begin{array}{l}\text { Redox } \\
\text { potential (V vs. } \\
\mathrm{Na} / \mathrm{Na}^{+} \text {) }\end{array}$ & $\begin{array}{l}\text { Current } \\
\text { density } \\
(\mathrm{mA} / \mathrm{g})\end{array}$ & $\begin{array}{l}\text { Discharge } \\
\text { capacity (mA h/g) }\end{array}$ & $\begin{array}{l}1 s t \\
C E\end{array}$ & Electrolyte & Ref. \\
\hline \multirow{15}{*}{$\begin{array}{l}\mathrm{M}-(\mathrm{Sn}, \mathrm{Sb} \text { and } \\
\mathrm{Ge}), \mathrm{M} \text { is an } \\
\text { electrochemically } \\
\text { active component }\end{array}$} & \multirow{3}{*}{\multicolumn{2}{|c|}{ SnSb@Carbon nanocable }} & & 100 & $360 / 100$ cycles & & $1 \mathrm{M} \mathrm{NaClO}_{4}$ in & \\
\hline & & & $0.087-0.920$ & 500 & 301 & $62 \%$ & PC+ & 26 \\
\hline & & & & 1000 & 268 & & $5 \% \mathrm{FEC}$ & \\
\hline & \multirow{2}{*}{\multicolumn{2}{|c|}{$\begin{array}{l}\text { SnSb-Porous Carbon } \\
\text { nanofibers }\end{array}$}} & $0.2-0.9$ & $\begin{array}{l}100 \\
5000\end{array}$ & $\begin{array}{l}345 / 200 \text { cycles } \\
198 / 140 \text { cycles }\end{array}$ & $53 \%$ & $\begin{array}{l}1 \mathrm{M} \mathrm{NaPF}_{6} \text { in } \\
\mathrm{EC} / \mathrm{DEC}\end{array}$ & 103 \\
\hline & & & & 10000 & 110 & & $+5 \%$ FEC & \\
\hline & \multirow{3}{*}{ Sn-Ge film } & $\mathrm{Sn}_{0.75} \mathrm{Ge}_{0.25}$ & $0.16-0.75$ & \multirow{3}{*}{$\mathrm{C} / 2$} & 190/100 cycles & \multirow{3}{*}{ - } & \multirow{3}{*}{$\begin{array}{l}1 \mathrm{M} \mathrm{NaPF}_{6} \text { in } \\
\mathrm{FEC} / \mathrm{DEC}\end{array}$} & \multirow{3}{*}{25} \\
\hline & & $\mathrm{Sn}_{0.5} \mathrm{Ge}_{0.5}$ & $0.17-0.58$ & & $500 / 100$ cycles & & & \\
\hline & & $\mathrm{Sn}_{0.25} \mathrm{Ge}_{0.75}$ & $0.21-0.60$ & & $380 / 100$ cycles & & & \\
\hline & \multirow{3}{*}{ Sn-Ge-Sb film } & $\mathrm{Sn}_{50} \mathrm{Ge}_{25} \mathrm{Sb}_{25}$ & \multirow{3}{*}{$0.03-1.20$} & \multirow{3}{*}{85} & $662 / 50$ cycles & $83 \%$ & \multirow{3}{*}{$\begin{array}{l}1 \mathrm{M} \mathrm{NaClO}_{4} \text { in } \\
\mathrm{EC} / \mathrm{DEC}\end{array}$} & \multirow{3}{*}{24} \\
\hline & & $\mathrm{Sn}_{60} \mathrm{Ge}_{20} \mathrm{Sb}_{20}$ & & & $625 / 50$ cycles & $78 \%$ & & \\
\hline & & $\mathrm{Sn}_{80} \mathrm{Ge}_{10} \mathrm{Sb}_{10}$ & & & $0 / 50$ cycles & $70 \%$ & & \\
\hline & \multicolumn{2}{|l|}{$\mathrm{Zn}_{4} \mathrm{Sb}_{3}$} & $0.01-1.00$ & 414 & 290/200 cycles & $45 \%$ & $\begin{array}{l}1 \mathrm{M} \mathrm{NaClO}_{4} \text { in } \\
\mathrm{PC}+5 \% \mathrm{FEC}\end{array}$ & 104 \\
\hline & \multirow{3}{*}{ Sn-Bi-Sb } & $\mathrm{Sn}_{10} \mathrm{Bi}_{10} \mathrm{Sb}_{80}$ & \multirow{3}{*}{$0.5-1.5$} & \multirow{3}{*}{200} & $621 / 100$ cycles & \multirow{3}{*}{-} & $1 \mathrm{M} \mathrm{NaClO}_{4}$ in & \multirow{3}{*}{105} \\
\hline & & $\mathrm{Sn}_{20} \mathrm{Bi}_{20} \mathrm{Sb}_{60}$ & & & $450 / 100$ cycles & & $\mathrm{EC} / \mathrm{DEC}+5 \%$ & \\
\hline & & $\mathrm{Sn}_{25} \mathrm{Bi}_{25} \mathrm{Sb}_{50}$ & & & $320 / 100$ cycles & & FEC & \\
\hline \multirow{13}{*}{$\begin{array}{l}\mathrm{M}-(\mathrm{Sn}, \mathrm{Sb} \text { and } \\
\mathrm{Ge}), \mathrm{M} \text { is an } \\
\text { electrochemically } \\
\text { inactive } \\
\text { component }\end{array}$} & \multirow{3}{*}{\multicolumn{2}{|c|}{$\mathrm{SnSe} / \mathrm{C}$}} & & & & & $1 \mathrm{M} \mathrm{NaClO}_{4}$ in & \\
\hline & & & $0.0-0.9$ & 143 & $707 / 50$ cycles & $75 \%$ & $\mathrm{EC} / \mathrm{DEC}+3 \%$ & 106 \\
\hline & & & & & & & FEC & \\
\hline & \multicolumn{2}{|l|}{$\mathrm{Cu}_{2} \mathrm{Sb} / \mathrm{Sb}$} & $0.40-0.75$ & $\begin{array}{l}0.1 \mathrm{C} \\
3 \mathrm{C}\end{array}$ & $\begin{array}{l}485 / 120 \text { cycles } \\
420\end{array}$ & $78 \%$ & $\begin{array}{l}1 \mathrm{M} \mathrm{NaClO} \text { in } \\
\mathrm{PC}+0.5 \% \mathrm{FEC}\end{array}$ & 107 \\
\hline & \multirow{3}{*}{\multicolumn{2}{|c|}{$\mathrm{Mo}_{3} \mathrm{Sb}_{7} @ \mathrm{C}$}} & & 247 & $338 / 800$ cycles & \multirow{3}{*}{$50 \%$} & $1 \mathrm{M} \mathrm{NaPF}_{6}$ in & \multirow{3}{*}{29} \\
\hline & & & $0.10-0.84$ & 4940 & 255 & & $\mathrm{EC} / \mathrm{DEC}+5 \%$ & \\
\hline & & & & 9880 & 180 & & FEC & \\
\hline & \multirow{2}{*}{\multicolumn{2}{|c|}{$\mathrm{FeSb}_{2}$}} & $0.14-0.87$ & 36 & $540 / 130$ cycles & \multirow{2}{*}{$85 \%$} & $1 \mathrm{M} \mathrm{NaClO}_{4}$ in & 109 \\
\hline & & & $0.14-0.87$ & 300 & $440 / 130$ cycles & & $\mathrm{PC}+5 \% \mathrm{FEC}$ & 年 \\
\hline & & & & 600 & $400 / 150$ cycles & & $1 \mathrm{M} \mathrm{NaClO}_{4}$ in & \\
\hline & Nisb hollow sp & eres & $0.01-0.92$ & 300 & $372 / 150$ cycles & $38 \%$ & PC & 28 \\
\hline & & & & 6000 & $230 / 150$ cycles & & $+5 \%$ FEC & \\
\hline & $\mathrm{Si} / \mathrm{Ge}$ & & $0.01-0.90$ & $10 \mu \mathrm{Ah} / \mathrm{cm}^{2}$ & $\begin{array}{l}20 \mu \mathrm{Ah} / \mathrm{cm}^{2} / 200 \\
\text { cycles }\end{array}$ & - & $\begin{array}{l}1 \mathrm{M} \mathrm{NaPF}_{6} \text { in } \\
\mathrm{EC} / \mathrm{DEC}\end{array}$ & 88 \\
\hline
\end{tabular}

offer another approach to enhance the electrochemical performance, especially in terms of the cycling life. Although an intermetallic alloy with an inactive element in the composite would significantly enhance the cycling stability of the electrode, it should be noted that it will sacrifice the initial coulombic efficiency, as the inactive element would not participate in the reaction with $\mathrm{Na}^{+}$from the first charging process, which may be detrimental to the whole electrochemical performance in a full cell.

\section{Phosphorus and phosphides}

Phosphorus is a nonmetallic element of the VA group in the periodic table with three kinds of allotropes, white, red, and black. Among these allotropes, white phosphorus is the least stable, the most reactive, the most volatile, the least dense, and the most toxic of the allotropes, so it is not suitable for application in LIBs and SIBs. White phosphorus can gradually change to red phosphorus under heat and light, so red phosphorus is more stable than white phosphorus. It is also commercially available and environmentally benign, but it has low electronic conductivity $\left(\sim 10^{-14} \mathrm{~S} / \mathrm{cm}\right){ }^{110}$ Black phosphorus is thermodynamically the most stable, insoluble in most solvents, practically non-flammable, and chemically the least reactive form. As anode for SIBs, phosphorus has the highest theoretical sodium ion storage capacity because it can react with $\mathrm{Na}$ to form $\mathrm{Na}_{3} \mathrm{P}$, rendering a capacity of $2596 \mathrm{~mA}$ $\mathrm{h} / \mathrm{g}$, and it has a relatively safe operating potential ( $0.45 \mathrm{~V}$ vs. $\left.\mathrm{Na} / \mathrm{Na}^{+}\right){ }^{46}$ $\mathrm{Na}_{3} \mathrm{P}$ as the reduction product, however, may release flammable and toxic phosphine $\left(\mathrm{PH}_{3}\right)$ upon hydrolysis, which will inevitably restrict its practical use.

Qian et al. ${ }^{46}$ reported amorphous red phosphorus/carbon nanocomposites for SIBs, which exhibited initial discharge/charge capacities of $2015 \mathrm{~mA} \mathrm{~h} / \mathrm{g}$ and $1764 \mathrm{~mA} \mathrm{~h} / \mathrm{g}$, respectively, in the voltage range of 0.01-2 V, corresponding to an initial coulombic efficiency of $87 \%$. Due to the inherent low electrical conductivity of commercial red phosphorus and its enormous volume expansion, however, both commercial red phosphorus and black phosphorus displayed poor electrochemical performance. In order to enhance the electrochemical performance, much significant improvement of the electrode chemical stability during sodiation/desodiation and mechanical robustness after hybridization was achieved by optimizing the synthesis methods, designing unique nanostructures, etc. The nanostructure, working voltage window, capacity at different current densities, and electrolytes for various recently reported phosphorus-based and phosphide anodes are summarized in Table 3. 
Table 3 Electrochemical performance of different phosphorous and phosphide based anodes for SIBs.

\begin{tabular}{|c|c|c|c|c|c|c|c|c|}
\hline Type & Nanostructure & $\begin{array}{l}\text { Synthesis } \\
\text { method }\end{array}$ & $\begin{array}{l}\text { Redox } \\
\text { potential (V) } \\
\text { vs. } \mathrm{Na} / \mathrm{Na}^{+}\end{array}$ & $\begin{array}{l}\text { Current } \\
\text { density } \\
(\mathrm{mA} / \mathrm{g})\end{array}$ & $\begin{array}{l}\text { Reversible capacity } \\
\text { (mA h/g) }\end{array}$ & $1^{\text {st }} \mathrm{CE}$ & Electrolyte & Ref \\
\hline \multirow{7}{*}{ Red $\mathrm{P}$} & $\begin{array}{l}\text { RP@Ni-P } \\
\text { core@shell }\end{array}$ & $\begin{array}{l}\text { Electroless } \\
\text { deposition }\end{array}$ & $0.05-1.79$ & $\begin{array}{l}260 \\
5000\end{array}$ & $\begin{array}{l}1256 / 200 \text { cycles } \\
409 / 2000 \text { cycles }\end{array}$ & $88.2 \%$ & $\begin{array}{l}1 \mathrm{M} \mathrm{NaClO}_{4} \text { in } \mathrm{PC}+ \\
5 \% \mathrm{FEC}\end{array}$ & 111 \\
\hline & $\begin{array}{l}\text { Hollow RP } \\
\text { nanospheres }\end{array}$ & $\begin{array}{l}\text { wet-chemical } \\
\text { synthesis }\end{array}$ & $0.2-1.4$ & $\begin{array}{l}0.5 \mathrm{C} \\
1 \mathrm{C}\end{array}$ & $\begin{array}{l}\text { 1501/80 cycles, } \\
969.8 / 600 \text { cycles }\end{array}$ & $77.3 \%$ & $\begin{array}{l}1 \mathrm{M} \mathrm{NaClO}_{4} \text { in } \\
\mathrm{EC} / \mathrm{DMC}+5 \% \mathrm{FEC}\end{array}$ & 112 \\
\hline & RP@N-MPC & $\begin{array}{l}\text { Vaporization } \\
\text { condensation }\end{array}$ & $0.31-1.37$ & $\begin{array}{l}150 \\
1000\end{array}$ & $\begin{array}{l}600 / 100 \text { cycles } \\
450 / 1000 \text { cycles }\end{array}$ & $54.1 \%$ & $\begin{array}{l}1 \mathrm{M} \mathrm{NaClO}_{4} \text { in } \\
\mathrm{EC}+\mathrm{DMC}^{-}\end{array}$ & 62 \\
\hline & RP@HPCNS & $\begin{array}{l}\text { vaporization- } \\
\text { condensation }\end{array}$ & $0.27-0.93$ & $\begin{array}{l}100 \\
1000\end{array}$ & $\begin{array}{l}1590 / 300 \text { cycles } \\
548 / 1000 \text { cycles }\end{array}$ & $42.5 \%$ & $\begin{array}{l}1 \mathrm{M} \mathrm{NaClO}_{4} \text { in } \\
\mathrm{EC} / \mathrm{DEC}+5 \% \mathrm{FEC}\end{array}$ & 63 \\
\hline & RP@RGO & $\begin{array}{l}\text { vapor } \\
\text { deposition }\end{array}$ & $0.0-0.7$ & $\begin{array}{l}1593.9 \\
318000\end{array}$ & $\begin{array}{l}914 / 300 \text { cycles } \\
510.6\end{array}$ & $75.2 \%$ & $\begin{array}{l}1 \mathrm{M} \mathrm{NaClO}_{4} \text { in } \\
\mathrm{DMC}+10 \% \\
\mathrm{FEC}\end{array}$ & 57 \\
\hline & P@CMK-3 & $\begin{array}{l}\text { vaporization-co } \\
\text { ndensation-con } \\
\text { version }\end{array}$ & $0.00-1.42$ & $\begin{array}{l}0.2 \mathrm{C} \\
5 \mathrm{C}\end{array}$ & $\begin{array}{l}2188(P) / 60 \text { cycles } \\
1020(P) / 210 \text { cycles }\end{array}$ & $59.4 \%$ & $\begin{array}{l}1 \mathrm{M} \mathrm{NaClO}_{4} \text { in } \\
\mathrm{EC} / \mathrm{DMC}\end{array}$ & 45 \\
\hline & $\begin{array}{l}\text { Amorphous } \\
\text { P@GN }\end{array}$ & $\begin{array}{l}\text { Phase } \\
\text { transformation }\end{array}$ & $0.00-0.53$ & 200 & $\sim 1000 / 350$ cycles & $87 \%$ & $\begin{array}{l}1 \mathrm{M} \mathrm{NaPF}_{6} \text { in } \\
\mathrm{EC} / \mathrm{DEC}\end{array}$ & 113 \\
\hline \multirow{3}{*}{$\begin{array}{c}\text { Black } \\
\text { P }\end{array}$} & $\begin{array}{l}\text { Phosphorene- } \\
\text { graphene }\end{array}$ & Exfoliation & $0.20-0.58$ & $\begin{array}{l}50 \\
8000 \\
26000\end{array}$ & $\begin{array}{l}2025(P) / 100 \text { cycles } \\
1218(P) / 100 \text { cycles } \\
496(P) / 100 \text { cycles }\end{array}$ & & $\begin{array}{l}1 \mathrm{M} \text { in } \mathrm{NaPF}_{6} \\
\mathrm{EC} / \mathrm{DEC}+10 \% \mathrm{FEC}\end{array}$ & 114 \\
\hline & E-BP/PEDOT & Exfoliation & $0.12-0.70$ & 100 & $1078 / 100$ cycles & $51.5 \%$ & $\begin{array}{l}1 \mathrm{M} \mathrm{NaClO}_{4} \text { in } 5 \% \\
\text { FEC }\end{array}$ & 115 \\
\hline & $\begin{array}{l}\text { BP/Ketjenblack-M } \\
\text { WCNT }\end{array}$ & Ball milling & $0.01-1.43$ & 1300 & $1700(P) / 100$ cycles & $>90 \%$ & $\begin{array}{l}1 \mathrm{M} \mathrm{NaPF}_{6} \text { in } \\
\mathrm{PC}+2 \% \mathrm{FEC}\end{array}$ & 116 \\
\hline \multirow{7}{*}{$\begin{array}{l}\text { Phos- } \\
\text { phide }\end{array}$} & Core/shell CoP@C & Phosphidation & $0.05-1.50$ & 100 & $473 / 100$ cycles & $47.3 \%$ & $\begin{array}{l}1 \mathrm{M} \mathrm{NaClO}_{4} \text { in } \\
\mathrm{PC}+5 \% \mathrm{FEC}\end{array}$ & 117 \\
\hline & $\begin{array}{l}\text { Core-shell } \\
\text { CoP/FeP }\end{array}$ & Phosphidation & $0.4-2.2$ & 100 & $456 / 200$ cycles & $56.9 \%$ & $\begin{array}{l}1 \mathrm{M} \mathrm{NaClO}_{4} \text { in } \\
\mathrm{PC}+5 \% \mathrm{FEC}\end{array}$ & 118 \\
\hline & $\mathrm{Se}_{4} \mathrm{P}_{4}$ & $\begin{array}{l}\text { mechanical } \\
\text { milling }\end{array}$ & $0.43-1.95$ & $\begin{array}{l}50 \\
3000\end{array}$ & $\begin{array}{l}804 / 60 \text { cycles } \\
332\end{array}$ & $70.6 \%$ & $\begin{array}{l}1 \mathrm{M} \mathrm{NaClO}_{4} \text { in } \\
\mathrm{PC} / \mathrm{EC}+5 \% \mathrm{FEC}\end{array}$ & 119 \\
\hline & $\mathrm{P}-\mathrm{TiP}_{2}-\mathrm{C}$ & $\begin{array}{l}\text { mechanical } \\
\text { milling }\end{array}$ & $0.1-0.8$ & 50 & $607 / 100$ cycles & $79.2 \%$ & $\begin{array}{l}1 \mathrm{M} \mathrm{NaClO}_{4} \text { in } \\
\mathrm{DEC} / \mathrm{EC}+5 \% \mathrm{FEC}\end{array}$ & 120 \\
\hline & $\mathrm{CuP}_{2} / \mathrm{C}$ & $\begin{array}{l}\text { mechanical } \\
\text { milling }\end{array}$ & $0.0-0.8$ & 50 & $430 / 100$ cycles & $65 \%$ & $\begin{array}{l}1 \mathrm{M} \mathrm{NaClO}_{4} \text { in } \\
\mathrm{DEC} / \mathrm{EC}+5 \% \mathrm{FEC}\end{array}$ & 121 \\
\hline & $\begin{array}{l}\text { Binder-Free } \mathrm{Cu}_{3} \mathrm{P} \\
\text { Nanowire }\end{array}$ & $\begin{array}{l}\text { in situ } \\
\text { phosphidation }\end{array}$ & $0.015-0.870$ & $\begin{array}{l}200 \\
500 \\
1000\end{array}$ & $\begin{array}{l}215 / 100 \text { cycles } \\
179 / 100 \text { cycles } \\
196 / 260 \text { cycles }\end{array}$ & $80.6 \%$ & $\begin{array}{l}1 \mathrm{M} \mathrm{NaClO}_{4} \text { in } \\
\mathrm{DMC} / \mathrm{EC}+5 \% \mathrm{FEC}\end{array}$ & 122 \\
\hline & $\begin{array}{l}\mathrm{Sn}_{4} \mathrm{P}_{3^{-}} \\
\mathrm{P} @ \text { graphene }\end{array}$ & $\begin{array}{l}\text { mechanical } \\
\text { milling }\end{array}$ & $0.02-0.78$ & $\begin{array}{l}400 \\
1000 \\
2000 \\
10000\end{array}$ & $\begin{array}{l}796 / 300 \text { cycles } \\
550 / 1000 \text { cycles } \\
371 / 1000 \text { cycles } \\
315\end{array}$ & $73.1 \%$ & $\begin{array}{l}1 \mathrm{M} \mathrm{NaClO}_{4} \text { in } \\
\mathrm{EC} / \mathrm{PC}+10 \% \text { FEC }\end{array}$ & 123 \\
\hline
\end{tabular}




\begin{tabular}{|c|c|c|c|c|c|c|}
\hline $\begin{array}{l}\mathrm{Sn}_{4} \mathrm{P}_{3} / \mathrm{RGO} \\
\text { nanohybrids }\end{array}$ & $\begin{array}{l}\text { in situ } \\
\text { phosphorization }\end{array}$ & $0.03-0.65$ & $\begin{array}{l}100 \\
1000\end{array}$ & $\begin{array}{l}656 / 100 \text { cycles } \\
362 / 1500 \text { cycles }\end{array}$ & $46.6 \%$ & $\begin{array}{l}1 \mathrm{M} \mathrm{NaClO}_{4} \text { in } \\
\mathrm{PC}+5 \% \mathrm{FEC}\end{array}$ \\
\hline $\mathrm{SnP}_{3} / \mathrm{C}$ & ball milling & $0.00-0.65$ & $\begin{array}{l}150 \\
2560\end{array}$ & $\begin{array}{l}810 / 150 \text { cycles } \\
400\end{array}$ & $71.2 \%$ & $\begin{array}{l}1 \mathrm{M} \mathrm{NaClO}_{4} \text { in } \\
\mathrm{DMC} / \mathrm{FEC}\end{array}$ \\
\hline
\end{tabular}

A flexible hybrid amorphous P-embedded, N-doped graphene paper (P@GN) was designed for SIBs by Zhang et al. ${ }^{113}$ This amorphous P@GN exhibited high capacity retention, with $85 \%$ of the initial capacity retained over 350 cycles and good rate capability, with the capacity of $809 \mathrm{~mA} \mathrm{~h} / \mathrm{g}$ at $1500 \mathrm{~mA} / \mathrm{g}$. The good electrochemical performance can be ascribed to: 1 ) the $\mathrm{N}$-doped flexible $\mathrm{GN}$ effectively buffers the volume changes and improves the conductivity of the whole electrode; and 2) the possibly formed robust P-C bonds between $\mathrm{P}$ and GN further enhance the stability of the electrode.

Unlike the conventional methods where the $\mathrm{P}$ and $\mathrm{C}$ components are assembled via mechanical mixing (milling or grinding), Yao et al. ${ }^{63}$ applied the vaporization-condensation ( $\mathrm{V}-\mathrm{C}$ ) technique to synthesize hollow porous carbon nanosphere/red phosphorus (HPCNS/P) composites. Compared to high energy mechanical milling, the $\mathrm{V}$-C strategy is an effective and mild process, in which the original morphologies, such as carbon frameworks, can be well preserved. By combining molecular dynamics (MD) simulations and density functional theory (DFT) calculations, the authors demonstrated that carbon frameworks with open pores in the range of 1-2 $\mathrm{nm}$ can endow the $\mathrm{P} / \mathrm{C}$ composite with high $\mathrm{P}$ loading, and sufficient oxygenated functional groups on the carbon surface are beneficial for forming chemical bonds with P. The capacity retention of the fully integrated HPCNS/P composite electrode consisting of 31.8 wt\% red $\mathrm{P}$ maintained reached over $80 \%$, with capacity of $1590 \mathrm{~mA} \mathrm{~h} / \mathrm{g}$ after 300 cycles. Furthermore, the electrode delivered a capacity of $548 \mathrm{~mA} \mathrm{~h} / \mathrm{g}$ with capacity retention of over $76 \%$ after 1000 cycles at $1 \mathrm{~A} / \mathrm{g}$, which is much better than that of commercial red $P$ with capacity of $209 \mathrm{~mA}$ $\mathrm{h} / \mathrm{g}$ after 100 cycles. The high rate cycling stability of $\mathrm{P} / \mathrm{C}$ composite can be ascribed to the well-preserved nanostructure of the electrode even after 1000 cycles. The loading level of red $\mathrm{P}$ in the composite needs be increased further, however, to enhance the capacity of the whole electrode, and the initial coulombic efficiency of $42.5 \%$ is not satisfactory.

Considering the low initial coulombic efficiency and low tap density caused by the incorporation of carbon in composite materials, Liu et al. ${ }^{111}$ combined electroless deposition with a chemical dealloying technique to synthesize red phosphorus (RP)@Ni-P core@shell nanostructures as a high-performance anode for SIBs. The authors pointed out that the shell thickness and composition of the composite could be easily tuned by the dealloying time, as shown in Fig. 7a. With the dealloying time of $8 \mathrm{~h}$, the RP@Ni-P composite as anode for SIBs presented a capacity of $1256.2 \mathrm{~mA} \mathrm{~h} / \mathrm{g}_{\text {composite }}$ after 200

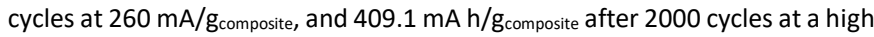
current density of $5 \mathrm{~A} / \mathrm{g}$ (Fig. 7b). Such long cycling life and good rate performance may be attributed to $: 1$ ) the in-situ generated $\mathrm{Ni}_{2} \mathrm{P}$ on the $\mathrm{RP}$ particle surfaces can facilitate intimate contact between RP and the Ni-P shell, which ensures strong electrode structural integrity; 2 ) the Ni-P shell has high conductivity, ensuring ultra-fast electrode transport.

Black phosphorus (BP) exists in three known crystalline modifications, orthorhombic, rhombohedral, and cubic, as well as in an amorphous form. ${ }^{126}$ Orthorhombic black phosphorus with its layered crystal structure is the most thermodynamically stable allotrope. ${ }^{114}$ In terms of appearance, properties, and structure, black phosphorus closely resembles graphite: it is black and flaky, and a good conductor of electricity $(\sim 300 \mathrm{~S} / \mathrm{m})$. It is composed of puckered sheets of covalently bonded phosphorus atoms. Compared with graphite, black phosphorus has a larger interlayer channel size (3.08 versus
$1.86 \AA$ ), indicating that both lithium ( $1.52 \AA$ ) and sodium $(2.04 \AA$ ) ions can be stored between layers of black phosphorus. A nanostructured BP/Ketjenblack- MWCNTs (BPC) composite with a P loading of 70 wt \% obtained via high energy ball milling (HEBM) was prepared by Xu et al. ${ }^{116}$ In the composite, the Ketjenblack possesses a high surface area of $1400 \mathrm{~m}^{2} / \mathrm{g}$ enabling a uniform distribution of BP in the composite, and the high conductivity of Ketjenblack and MWCNTs yields a dual conductive network that facilitates electron transport within the BPC composite; therefore, the BPC exhibited a high initial coulombic efficiency (> 90\%) and good cycling performance, with the capacity of $1700 \mathrm{~mA} \mathrm{~h} / \mathrm{g}(\mathrm{P})$ after 100 cycles at 1.3 $\mathrm{A} / \mathrm{g}$. Based on a series of characterizations, including both in-situ and ex-situ characterizations, it was observed that BP nanocrystals were first transformed to crystalline $\mathrm{Na}_{3} \mathrm{P}$ through an amorphous $\mathrm{NaP}$ intermediate during the sodiation process, and then converted back to amorphous phosphorus with a small amount of amorphous $\mathrm{NaP}$ remaining during the desodiation process.

As is well known, BP is one of the classes of two-dimensional (2D) materials similar to graphene, which can be exfoliated down to a few layers or even a monolayer using physical or chemical methods, and then the optical, phonon, and electronic properties of the materials change dramatically as a result. Hence, a nanostructured phosphorene-graphene hybrid with phosphorene layers sandwiched in between graphene layers fabricated by the liquid-phase exfoliation method (Fig. 8a) was designed by Cui's group. ${ }^{114}$ In this sandwichlike structure, the graphene layer provided an elastic buffer, and the phosphorene layer offered a short diffusion distance for $\mathrm{Na}^{+}$. As the anode for SIBs, the phosphorene-graphene hybrid showed a high capacity of $2440 \mathrm{~mA}$ $\mathrm{h} / \mathrm{g}_{\text {phosphorus }}$ at $0.05 \mathrm{~A} / \mathrm{g}$ and $83 \%$ capacity
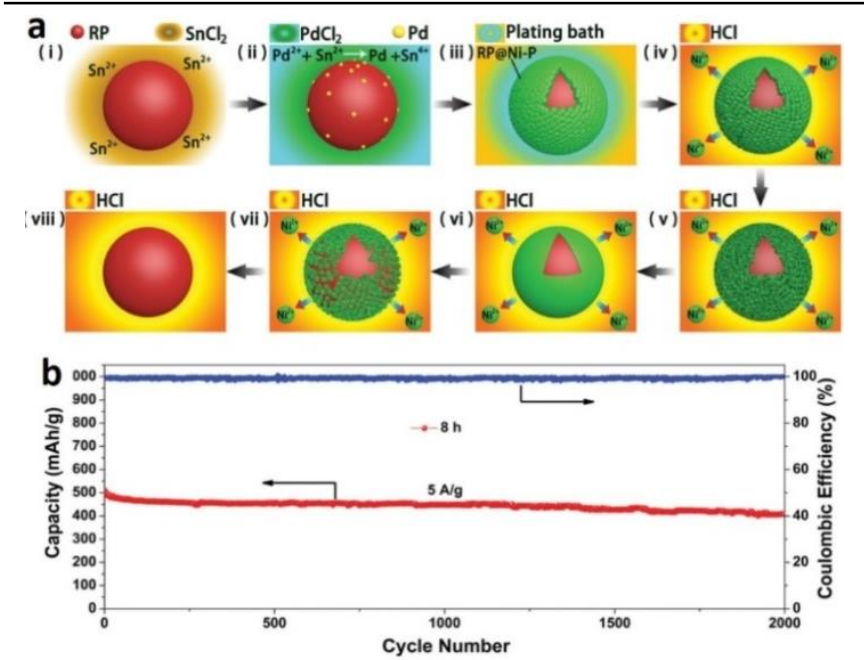

Fig. 7 Schematic illustration of electroless deposition of $\mathrm{Ni}$ on an $\mathrm{RP}$ nanoparticle $(a(i-i i i))$ and the evolution of the RP@Ni-P core@shell nanostructure through chemical dealloying (a(iv-viii)); (b) Long-term cycling performance of the $8 \mathrm{~h} \mathrm{RP@Ni-P} \mathrm{electrodes} \mathrm{at} 5 \mathrm{~A} / \mathrm{g}$ composite between 0.05 and 2.0 V. Reprinted from Ref. 111 with permission from the Royal Society of Chemistry. 
retention after 100 cycles, as well as reaching the capacities of 1218 and 496 $\mathrm{mA} \mathrm{h} / \mathrm{g}$ at the high rates of $3 \mathrm{C}$ and $10 \mathrm{C}$, respectively, after 100 cycles (Fig. 8b). According to the results of in-situ TEM and ex-situ X-ray diffraction (XRD) characterizations, it was demonstrated that the reaction mechanism of the phosphorene with $\mathrm{Na}^{+}$was based on two steps: intercalation and alloying, as shown in Fig. 8. Firstly, $\mathrm{Na}^{+}$ions are inserted into phosphorene layers along the $x$-axis-oriented channels to form $\mathrm{Na}_{0.17} \mathrm{P}$ phase; secondly, black $\mathrm{P}$ further alloys with $\mathrm{Na}^{+}$to form $\mathrm{Na} \times \mathrm{P}$ below $0.54 \mathrm{~V}$, which is primarily responsible for the specific capacity of black P (Fig. 8c-e).

In addition to a variety of $\mathrm{P}$-based composites that are being investigated as high performance anodes for SIBs, metal phosphide systems $\left(\mathrm{MP}_{x}, \mathrm{M}=\mathrm{Sn}\right.$, $\mathrm{Se}, \mathrm{Fe}, \mathrm{Co}, \mathrm{Cu}$, and $\mathrm{Ni}$ ) also present high reversible capacity, improved cycling stability, and good rate capability. ${ }^{117-125}{ }^{127-129}$ For instance, $\mathrm{Sn}_{4} \mathrm{P}_{3}$, which was examined as an anode material for SIBs for the first time by Kim et al., can alloy with $\mathrm{Na}^{+}$to form $\mathrm{Na}_{15} \mathrm{Sn}_{4}$ and $\mathrm{Na}_{3} \mathrm{P}$ during sodiation, corresponding to the theoretical gravimetric capacity of $1132 \mathrm{~mA} \mathrm{h/g}$ and the high theoretical volumetric capacity of $6650 \mathrm{~mA} \mathrm{~h} / \mathrm{cm}^{3}$ (vs. $5710 \mathrm{~mA} \mathrm{~h} / \mathrm{cm}^{3}$ for bare P), along with a high electrical conductivity of $30.7 \mathrm{~S} / \mathrm{cm}$ (vs. $3.5 \times 10^{-5} \mathrm{~s} / \mathrm{cm}$ for $\mathrm{P} /$ carbon). ${ }^{129}$ Moreover, the $\mathrm{Sn}_{4} \mathrm{P}_{3}$ electrode presented a lower redox potential of about $0.3 \mathrm{~V}$ compared to that for bare $\mathrm{P}(\sim 0.5 \mathrm{~V})$, suggesting that $\mathrm{Sn}_{4} \mathrm{P}_{3}$ as an anode material could contribute to higher energy density in the full cell.

A uniform yolk-shell $\mathrm{Sn}_{4} \mathrm{P}_{3} @ \mathrm{C}$ nanosphere electrode was designed by Yu's group, ${ }^{130}$ which exhibited a reversible capacity of $790 \mathrm{~mA} \mathrm{~h} / \mathrm{g}$, good rate capability (reversible capacity of $421 \mathrm{~mA} \mathrm{h/g}$ at $3 \mathrm{C}$ ), and stable cycling performance (capacity of $360 \mathrm{~mA} \mathrm{~h} / \mathrm{g}$ at $1.5 \mathrm{C}$ for 400 cycles). The enhanced performance can be ascribed to the high conductivity of the $\mathrm{Sn}_{4} \mathrm{P}_{3} @ \mathrm{C}$ and the rational design of the yolk-shell structure, which could accommodate volume expansion of the electrode during the charge-discharge processes. More recently, $\mathrm{Xu}$ et al. ${ }^{123}$ fabricated a nanocomposite of $\mathrm{Sn}_{4} \mathrm{P}_{3}$ and black phosphorus embedded in a graphene matrix via a mechanochemical transformation method from $\mathrm{SnP}_{3}$. This composite exhibited a stable cycling at a high rate, with a capacity of $550 \mathrm{~mA} \mathrm{h/g}$ remaining after 1000 cycles at 1 $\mathrm{A} / \mathrm{g}$, and good rate capability with capacities of 585 and 315 obtained at 2 and $10 \mathrm{~A} / \mathrm{g}$, respectively. Similar to this work, $\mathrm{Sn}_{4} \mathrm{P}_{3} /$ reduced graphene oxide (RGO) hybrids, which were synthesized via an in-situ low-temperature solution-based phosphorization from Sn/RGO, also presented long cycling stability with a capacity of $362 \mathrm{~mA} \mathrm{h/g}$ achieved after 1500 cycles at $1 \mathrm{~A} / \mathrm{g}$. These results demonstrated that the $\mathrm{Sn}_{4} \mathrm{P}_{3}$ anode may be a good candidate for high-performance SIBs with high energy density and long-term cycling life.

$\mathrm{SnP}_{3}$, due to its higher theoretical gravimetric capacity $(1616 \mathrm{~mA} \mathrm{~h} / \mathrm{g})$ and volumetric capacity $(6890 \mathrm{~mA} \mathrm{~h} / \mathrm{g})$ than for $\mathrm{Sn}_{4} \mathrm{P}_{3}$, has attracted attention as a potential anode for SIBs. Wang's group ${ }^{125}$ demonstrated that their asprepared $\mathrm{SnP}_{3} / \mathrm{C}$ composite could self-heal the pulverization and aggregation induced in the alloying reaction (Fig. 9). The crystalline $\mathrm{SnP}_{3}$ first breaks into nanometric Sn particles dispersed in a nanocrystalline/amorphous $\mathrm{Na}_{3} \mathrm{P}$ matrix through the conversion reaction, and then $\mathrm{Na}$ inserts itself into $\mathrm{Sn}$ to form $\mathrm{Na}_{15} \mathrm{Sn}_{4}$ through the alloying reaction, resulting in pulverization. During the desodiation, the $\mathrm{Na}$ first dealloys from $\mathrm{Na}_{15} \mathrm{Sn}_{4}$ to form $\mathrm{Sn}$ and then dealloys from $\mathrm{Na}_{3} \mathrm{P}$ to convert back to $\mathrm{SnP}_{3}$, thus healing the cracks in the $\mathrm{Sn}$ induced in the alloying process and preventing the $\mathrm{Sn}$ from aggregating. As a result, the $\mathrm{SnP}_{3} / \mathrm{C}$ electrode presented a high capacity of $810 \mathrm{~mA} \mathrm{~h} / \mathrm{g}$ at 150 $\mathrm{mA} / \mathrm{g}$ over 150 cycles and retained a capacity of $\sim 400 \mathrm{~mA} \mathrm{~h} / \mathrm{g}$ at the high current density of $2560 \mathrm{~mA} / \mathrm{g}$.
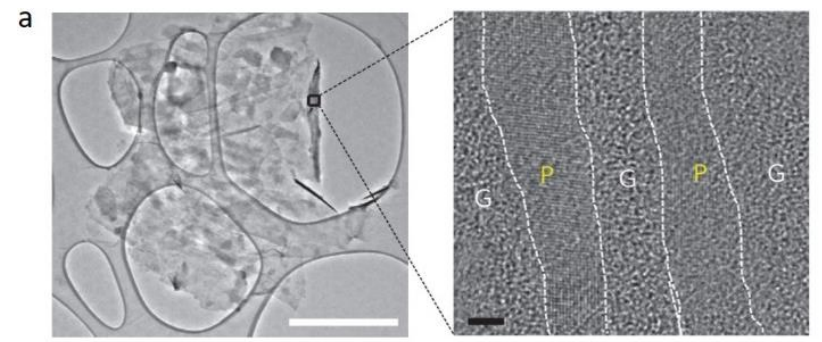

b
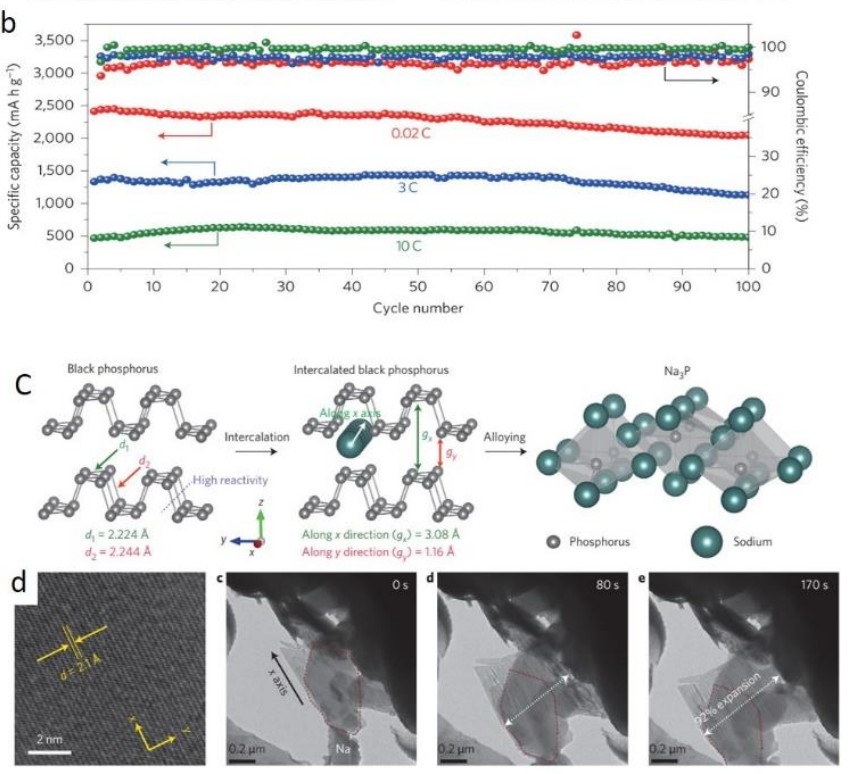

e

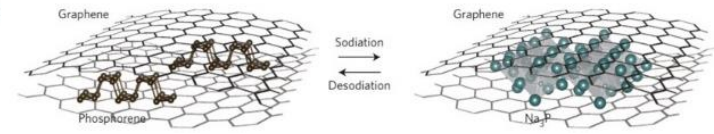

Fig. 8 (a) TEM image of the phosphorene-graphene hybrid; (b) Reversible desodiation capacity and Coulombic efficiency for the first 100 cycles; (c) Schematic illustration of black phosphorus before sodiation, at the first step of sodium-ion intercalation, and at the second step of alloying reaction to form $\mathrm{Na}_{3} \mathrm{P}$; (d) High-resolution bright-field TEM image of black phosphorus before sodiation, and time-lapse TEM images of sodiation in black phosphorus; (e) Structural evolution of the sandwich-like phosphorenegraphene structure during sodiation. Reprinted from Ref. 114 with permission from Nature Publishing Group.

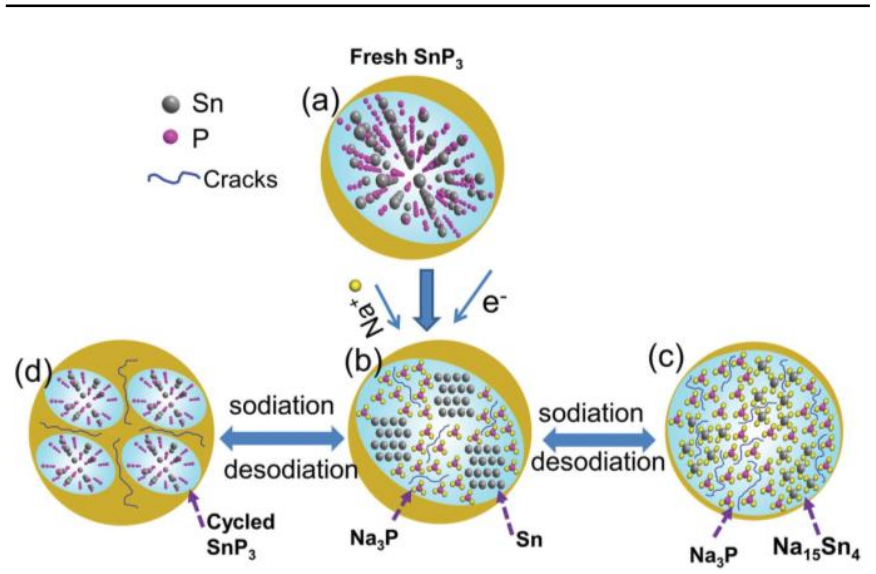

Fig. 9 Schematic illustration of the sodiation and desodiation of $\mathrm{SnP}_{3} / \mathrm{C}$ composite. The yellow outer layer denotes carbon. Reprinted from Ref. 125 with permission from John Wiley and Sons. 
Apart from $\mathrm{SnP}_{x}$, a new phosphide material $\left(\mathrm{Se}_{4} \mathrm{P}_{4}\right)$ with an amorphous structure was recently synthesized by the mechanical milling method. The $\mathrm{Se}_{4} \mathrm{P}_{4}$ undergoes a reversible Na-storage reaction of $\mathrm{Se}_{4} \mathrm{P}_{4}+2 \mathrm{Na}^{+}+20 e^{-} \leftrightarrow$ $4 \mathrm{Na}_{3} \mathrm{P}+4 \mathrm{Na}_{2} \mathrm{Se}$ during sodiation/desodiation, endowing it with a high theoretical capacity of $1219 \mathrm{~mA} \mathrm{~h} / \mathrm{g}$. As anode for $\mathrm{SIBs}_{1} \mathrm{Se}_{4} \mathrm{P}_{4}$ displayed reversible capacities of $1048 \mathrm{~mA} \mathrm{~h} / \mathrm{g}, 724 \mathrm{~mA} \mathrm{~h} / \mathrm{g}$, and $332 \mathrm{~mA} \mathrm{~h} / \mathrm{g}$ at 50, 500, and $3000 \mathrm{~mA} / \mathrm{g}$, respectively, and capacity of $804 \mathrm{~mA} \mathrm{~h} / \mathrm{g}$ was retained after 60 cycles. ${ }^{119}$

In addition, a few transition metal-based phosphides (TM-P) are also electrochemically active in sodiation via conversion reactions. ${ }^{118,121,131,132}$ Unlike $\mathrm{Sn}$ based phosphides, TM-P could react with $\mathrm{Na}^{+}$to form $\mathrm{Na}_{x} \mathrm{P}$ during sodiation, while the transition metal is not reactive with $\mathrm{Na}$. For instance, in the case of CoP, ${ }^{131}$ after the initial sodiation, the following sodium storage mechanism was $\mathrm{Na}_{3} \mathrm{P}+\mathrm{Co} \leftrightarrow \mathrm{Co}+\mathrm{P}+3 \mathrm{Na}^{+}+3 e^{-}$based on results of XPS and STEM, with the theoretical capacity calculated to $894 \mathrm{~mA} \mathrm{~h} / \mathrm{g}$.

Porous core/shell CoP@C nanostructures anchored on 3D RGO were synthesized via a low temperature phosphidation process from ZIF-67 with the CoP nanoparticles $10 \mathrm{~nm}$ in size grown on RGO (Fig. 10). ${ }^{117}$ As anode for SIBs, CoP@C-RGO-NF electrode exhibited a capacity of $473.1 \mathrm{~mA} \mathrm{h/g}$ at a current density of 100 mA/g after 100 cycles. In comparison, pure CoP@C anode exhibited poorer electrochemical performance, and the capacity was reduced to $151.4 \mathrm{~mA} \mathrm{~h} / \mathrm{g}$ after 100 cycles. The good electrochemical performance of CoP@C-RGO-NF hybrids may be attributed to the synergistic effects between the core/shell structured CoP@C polyhedra and the RGO network. Specifically, 1) the porous core/shell structure of the ZIF-67-derived CoP@C polyhedra retain enough space to alleviate the volume changes; 2) the carbon shell as a plastic layer can effectively enhance the electron transfer rate; and 3) the flexible RGO nanosheets enhance the charge transfer kinetics.

Similar to CoP, a CuP $/$ C hybrid exhibited a reversible capacity of $450 \mathrm{~mA}$ $\mathrm{h} / \mathrm{g}$ and good capacity retention of $95 \%$ over 100 cycles. ${ }^{121}$ The formation of $\mathrm{P}-\mathrm{O}-\mathrm{C}$ chemical bonds during the ball milling and the addition of the conductive carbon matrix guaranteed the stable cycling life of $\mathrm{CuP}_{2} / \mathrm{C}$. In addition, it was demonstrated that the metallic $\mathrm{Cu}$ is nearly inert during sodiation/desodiation processes, which is in good agreement with the report on CoP. ${ }^{117,131}$

In summary, the main limitations for the practical application of phosphorus electrode can be ascribed to: 1) the formation of toxic phosphine $\left(\mathrm{PH}_{3}\right)$ upon hydrolysis during the fabrication process; 2 ) the huge volume expansion of $\mathrm{P}$ electrode that occurs in charge/discharge processes; and 3) the low electrical conductivity of red $\mathrm{P}$ and the poor reactivity of black $\mathrm{P}$. The current research on $P$ electrode is essential to improve the conductivity of the electrode, minimize the particle size of active materials, and use novel synthesis methods to fabricate dedicate nanostructures. These issues, if unaddressed, would substantially sacrifice the reversible capacity and cycling life of batteries based on $\mathrm{P}$ anode. Further optimization of the composition and increasing the loading amount of $\mathrm{P}$ in the composite may be able to improve the low initial coulombic efficiency. Above all, carefully operating $\mathrm{P}$ based experiments is crucial for safety.
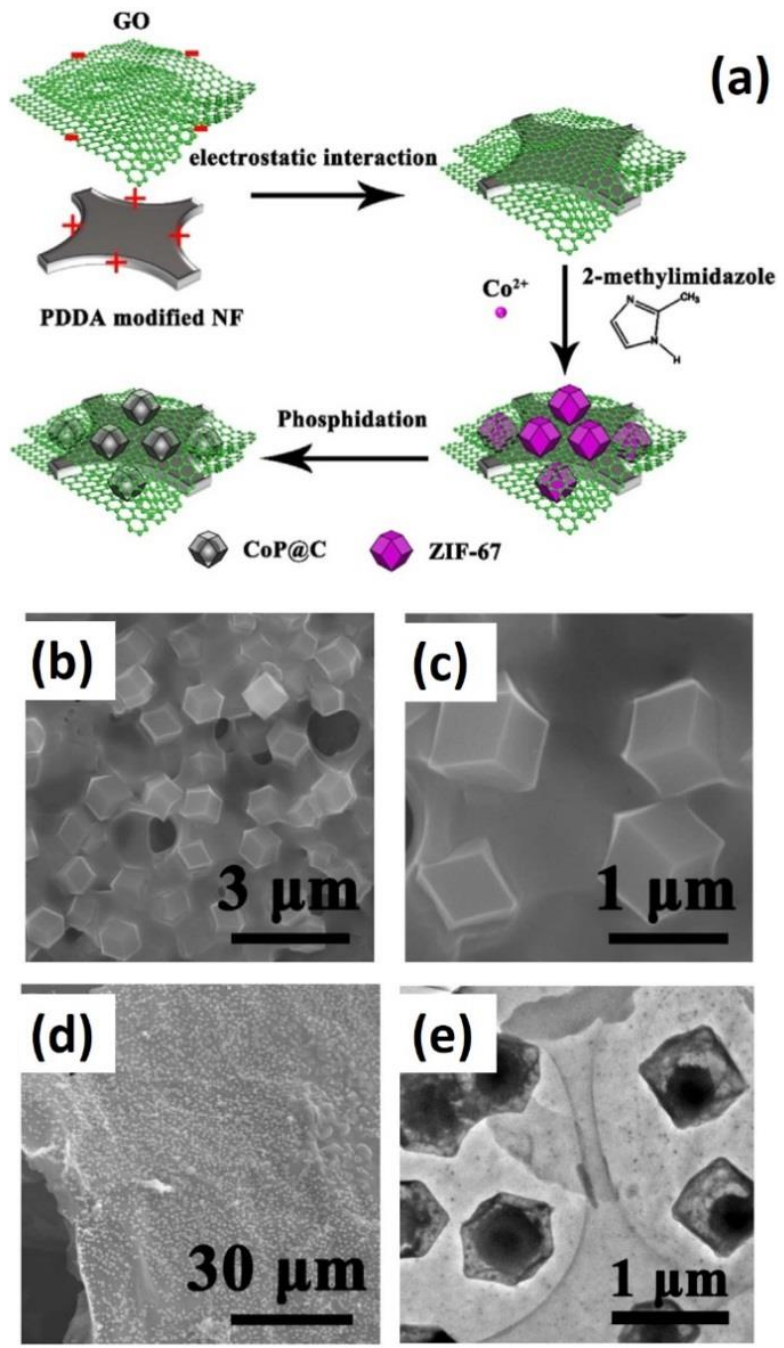

Fig. 10 (a) Schematic illustration of the synthesis process for CoP@C-RGO-NF; SEM images of (b, c) ZIF-67-GO-NF and (d) CoP@C-RGO-NF, (e) TEM image of CoP@C-RGO. Reprinted from Ref. 117 with permission from Elsevier.

\section{Metal oxides}

Metal oxides have been one of the most studied types of anode material in LIBs for decades, since they could generate higher capacities compared with intercalation compounds and generally more satisfactory cycling performance compared with metal alloys. As anodes for SIBs, metal oxides also have been intensively studied for years, and the recent progress on a variety of metal oxides is summarized in Table 4.

According to the sodiation/desodation reaction mechanism, metal oxides can be classified into two types:

(1) Conversion reaction based transition metal oxides

Generally, transition metals such as $\mathrm{Fe}, \mathrm{Co}, \mathrm{Nb}$, and $\mathrm{Cu}$ are electrochemically inactive in the oxide, so metal oxides react with $\mathrm{Na}^{+}$ through a one-step conversion reaction. 
Table 4 Electrochemical performance of metal oxide based anodes for SIBs.

\begin{tabular}{|c|c|c|c|c|c|c|c|}
\hline Type & Nanostructure & $\begin{array}{l}\text { Redox } \\
\text { potential } \\
\text { (V) vs. } \\
\mathrm{Na} / \mathrm{Na}^{+}\end{array}$ & $\begin{array}{l}\text { Current } \\
\text { density } \\
\text { (mA/g) }\end{array}$ & $\begin{array}{l}\text { Reversible capacity } \\
\quad(\mathrm{mA} \mathrm{h} / \mathrm{g})\end{array}$ & $1^{\text {st }} \mathrm{CE}$ & Electrolyte & Ref. \\
\hline \multirow{6}{*}{$\mathrm{Fe}_{x} \mathrm{O}_{y}$} & $\mathrm{Fe}_{2} \mathrm{O}_{3} / \mathrm{rGO}$ & $0.4-1.1$ & 50 & $500 / 100$ cycles & $71 \%$ & $\begin{array}{l}1 \mathrm{M} \mathrm{NaPF}_{6} \text { in } \\
\mathrm{EC} / \mathrm{DMC}+5 \% \\
\mathrm{FEC}\end{array}$ & 133 \\
\hline & $\begin{array}{l}\text { Amorphous } \\
\mathrm{Fe}_{2} \mathrm{O}_{3} / \mathrm{Gr}\end{array}$ & $0.73-1.70$ & $\begin{array}{l}100 \\
2000\end{array}$ & $\begin{array}{l}\sim 300 / 50 \text { cycles } \\
110 / 500 \text { cycles }\end{array}$ & $81.2 \%$ & $\begin{array}{l}1 \mathrm{M} \mathrm{NaSO}_{3} \mathrm{CF}_{3} \\
\text { in diglyme }\end{array}$ & 134 \\
\hline & $\begin{array}{l}\text { 3D Porous Y- } \\
\mathrm{Fe}_{2} \mathrm{O}_{3} @ \mathrm{C}\end{array}$ & $0.65-1.40$ & $\begin{array}{l}200 \\
2000\end{array}$ & $\begin{array}{l}740 / 200 \text { cycles } \\
358 / 1400 \text { cycles }\end{array}$ & $51.5 \%$ & $\begin{array}{l}1 \mathrm{M} \mathrm{NaClO}_{4} \text { in } \\
\mathrm{EC} / \mathrm{DEC}\end{array}$ & 34 \\
\hline & $\begin{array}{l}\text { core-shell } \\
\mathrm{Fe}_{2} \mathrm{O}_{3} @ \mathrm{TiO}_{2}\end{array}$ & $0.70-1.75$ & 100 & $267 / 300$ cycles & $50.5 \%$ & $\begin{array}{l}1 \mathrm{M} \mathrm{NaClO}_{4} \text { in } \\
\mathrm{PC}\end{array}$ & 135 \\
\hline & $\mathrm{Fe}_{3} \mathrm{O}_{4} / \mathrm{CNT}$ & $0.25-1.50$ & 100 & $377 / 300$ cycles & $56 \%$ & $\begin{array}{l}1 \mathrm{M} \mathrm{NaClO}_{4} \text { in } \\
\mathrm{EC} / \mathrm{PC}\end{array}$ & 136 \\
\hline & $\mathrm{Fe}_{3} \mathrm{O}_{4} \mathrm{QD} @ \mathrm{C}-\mathrm{GN}$ & $0.40-1.47$ & $\begin{array}{l}2000 \\
5000 \\
10000\end{array}$ & $\begin{array}{l}343 / 1000 \text { cycles } \\
234 / 1000 \text { cycles } \\
149 / 1000 \text { cycles }\end{array}$ & $62.4 \%$ & $\begin{array}{l}1 \mathrm{M} \mathrm{NaPF}_{6} \\
\text { in } \mathrm{EC} / \mathrm{DMC}\end{array}$ & 137 \\
\hline \multirow{5}{*}{$\mathrm{CO}_{3} \mathrm{O}_{4}$} & $\mathrm{CO}_{3} \mathrm{O}_{4}$ Nanosheet & $0.55-1.60$ & 800 & $300 / 100$ cycles & $55 \%$ & $\begin{array}{l}1 \mathrm{M} \mathrm{NaClO}{ }_{4} \text { in } \\
\mathrm{PC} \\
+2 \% \mathrm{FEC}\end{array}$ & 138 \\
\hline & $\begin{array}{l}\text { yolk-shell } \\
\mathrm{Co}_{3} \mathrm{O}_{4} @ \mathrm{C}\end{array}$ & $0.50-1.75$ & 1000 & $240 / 200$ cycles & $75 \%$ & $\begin{array}{l}1 \mathrm{M} \mathrm{NaClO}_{4} \text { in } \\
\mathrm{EC} / \mathrm{DMC}^{-}\end{array}$ & 139 \\
\hline & $\begin{array}{l}\text { Ni-doped } \\
\mathrm{Co} / \mathrm{CoO} / \mathrm{NC}\end{array}$ & $0.0-1.0$ & 500 & $218 / 100$ cycles & $54 \%$ & $\begin{array}{l}1 \mathrm{M} \mathrm{NaClO}_{4} \text { in } \\
\mathrm{EC} / \mathrm{DEC}\end{array}$ & 140 \\
\hline & Hollow $\mathrm{CO}_{3} \mathrm{O}_{4} / \mathrm{N}-\mathrm{C}$ & $0.46-1.64$ & 1000 & $229 / 150$ cycles & $65.7 \%$ & $\begin{array}{l}1 \mathrm{M} \mathrm{NaClO}{ }_{4} \text { in } \\
\mathrm{PC} \\
+5 \% \mathrm{FEC}\end{array}$ & 141 \\
\hline & $\mathrm{Co}_{3} \mathrm{O}_{4} @ \mathrm{NC}$ & $0.6-1.4$ & 1000 & $175 / 1100$ cycles & $63 \%$ & $\begin{array}{l}1 \mathrm{M} \mathrm{NaClO}_{4} \text { in } \\
\mathrm{PC} \\
+2 \% \mathrm{FEC}\end{array}$ & 142 \\
\hline \multirow{4}{*}{$\mathrm{CuO}_{x}$} & $\mathrm{CuO} / \mathrm{Cu}_{2} \mathrm{O}-\mathrm{GPC}$ & $0.52-2.18$ & 50 & $303 / 200$ cycles & $44.8 \%$ & $\begin{array}{l}1 \mathrm{M} \mathrm{NaClO} \text { in } \\
\mathrm{EC} / \mathrm{DEC} / \mathrm{PC}+5 \\
\% \mathrm{FEC}\end{array}$ & 143 \\
\hline & $\begin{array}{l}\text { CuO quantum } \\
\text { dots }\end{array}$ & $0.12-2.27$ & $\begin{array}{l}100 \\
500\end{array}$ & $\begin{array}{l}440 / 100 \text { cycles } \\
401 / 500 \text { cycles }\end{array}$ & $67 \%$ & $\begin{array}{l}1 \mathrm{M} \mathrm{NaPF}_{6} \\
\text { in } \mathrm{EC} / \mathrm{DMC}\end{array}$ & 144 \\
\hline & CuO@CMK & $0.01-2.31$ & 100 & $477 / 200$ cycles & - & $\begin{array}{l}1 \mathrm{M} \mathrm{NaClO}_{4} \text { in } \\
\mathrm{PC} \\
+5 \% \mathrm{FEC}\end{array}$ & 145 \\
\hline & 10-CuO/C & $0.12-2.19$ & $\begin{array}{l}50 \\
200\end{array}$ & $\begin{array}{l}426 / 100 \text { cycles } \\
402 / 600 \text { cycles }\end{array}$ & $82 \%$ & $\begin{array}{l}1 \mathrm{M} \mathrm{NaPF}_{6} \\
\text { in } \mathrm{EC} / \mathrm{DMC} \\
+5 \% \mathrm{FEC}\end{array}$ & 146 \\
\hline \multirow{3}{*}{$\mathrm{Nb}_{2} \mathrm{O}_{5}$} & $\begin{array}{l}\mathrm{T}-\mathrm{Nb}_{2} \mathrm{O}_{5} / \mathrm{C} \\
\text { Nanofibers }\end{array}$ & $0.40-1.08$ & $\begin{array}{l}1000 \\
8000\end{array}$ & $\begin{array}{c}150 / 5000 \text { cycles } \\
97\end{array}$ & - & $\begin{array}{l}1 \mathrm{M} \mathrm{NaClO}_{4} \text { in } \\
\mathrm{EC} / \mathrm{PC} \\
+5 \% \mathrm{FEC}\end{array}$ & 147 \\
\hline & $\begin{array}{l}\text { Mesoporous } \\
\mathrm{Nb}_{2} \mathrm{O}_{5} \text { Nanosheets }\end{array}$ & $\sim 0.75-1.50$ & $\begin{array}{l}1 C \\
20 C\end{array}$ & $\begin{array}{l}\text { 190/200 cycles } \\
\sim 100 / 1000 \text { cycles }\end{array}$ & - & $\begin{array}{l}1 \mathrm{M} \mathrm{NaClO}_{4} \text { in } \\
\mathrm{EC} / \mathrm{PC} \\
+5 \% \mathrm{FEC}\end{array}$ & 148 \\
\hline & $\begin{array}{l}\text { Ordered- } \\
\text { mesoporous } \\
\mathrm{Nb}_{2} \mathrm{O}_{5} / \mathrm{C}\end{array}$ & $\sim 0.5-1.0$ & 100 & $100 / 300$ cycles & - & $\begin{array}{l}1 \mathrm{M} \mathrm{NaPF}_{6} \\
\text { in EC/DEC }\end{array}$ & 149 \\
\hline
\end{tabular}




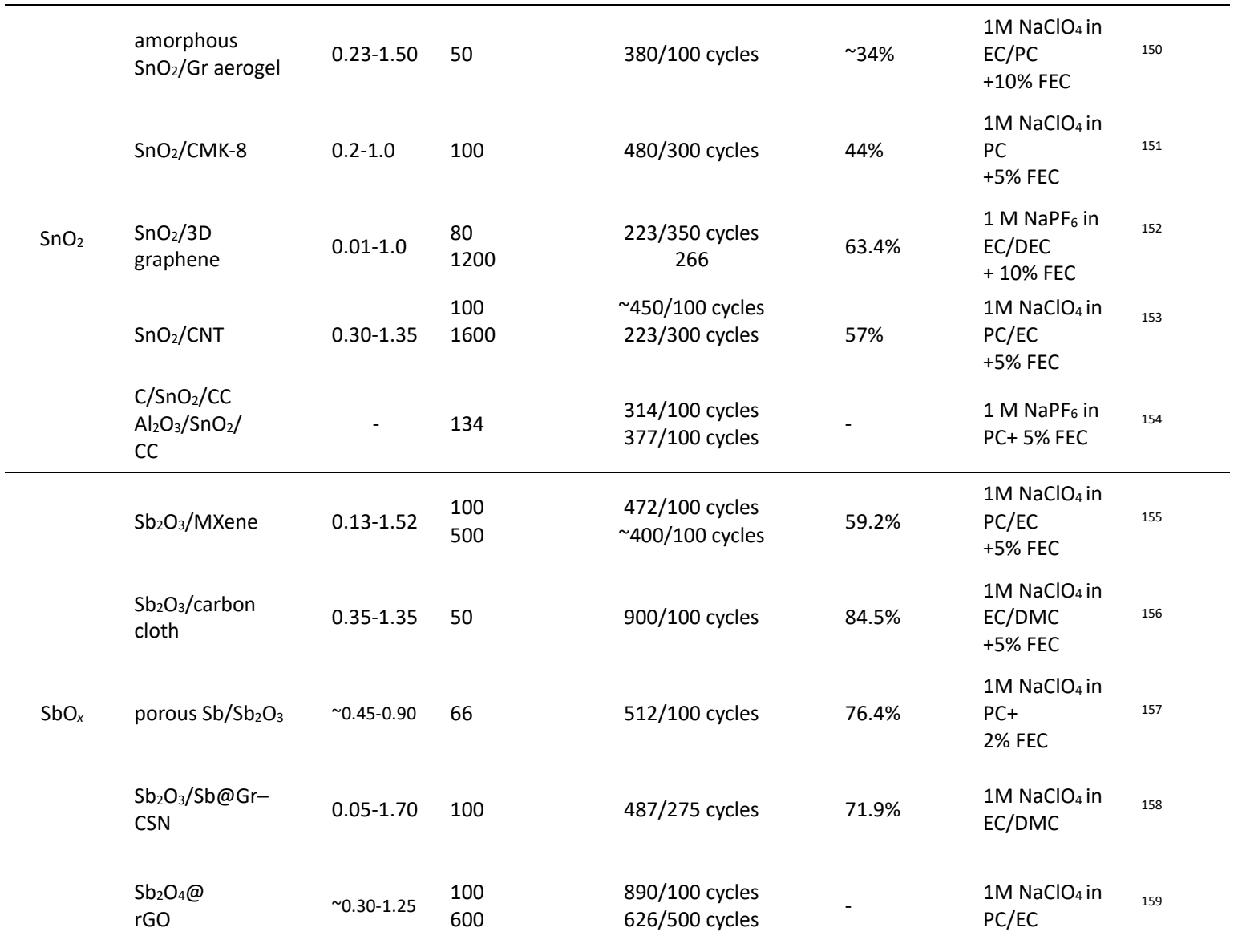

In order to understand whether the conversion reaction based on sodium is feasible or not, Klein et al. ${ }^{160}$ systematically investigated the basic thermodynamic properties of conversion-reaction based electrodes in respect to cell voltages, capacities, and energy densities. They calculated that the cell potential for sodium based metal oxides is usually $0.96 \mathrm{~V}$, which is lower than for their lithium based counterparts in LIBs. This characteristic could ensure higher energy density of batteries based on transition metal oxide anodes in SIBs compared with LIBs.

Iron oxides have been intensively studied as potential anode materials for SIBs due to their earth-abundance and environmental friendliness. The electrochemical activity towards sodium of $\mathrm{Fe}_{3} \mathrm{O}_{4}$ and $a-\mathrm{Fe}_{2} \mathrm{O}_{3}$ was first evaluated by Komaba's group, ${ }^{161,162}$ and they found that nanosized $\mathrm{Fe}_{3} \mathrm{O}_{4}$ and $a-\mathrm{Fe}_{2} \mathrm{O}_{3}$ (particles about $10 \mathrm{~nm}$ in size) could deliver a reversible capacity of $170 \mathrm{~mA} \mathrm{~h} / \mathrm{g}$ in the voltage ranges from $1.5 \mathrm{~V}$ to $4 \mathrm{~V}(\mathrm{vs}$. Li/Li+) and from $1.2 \mathrm{~V}$ to $4 \mathrm{~V}$, respectively. Nevertheless, both materials demonstrated poor cycling stability. In order to further probe the sodiation possibilities of $\mathrm{Fe}_{2} \mathrm{O}_{3}$, Valvo et al. ${ }^{163}$ demonstrated that $\mathrm{Fe}_{2} \mathrm{O}_{3}$ could reversibly undergo sodiation/desodiation over an extended voltage range from $0.05 \mathrm{~V}$ to $2.8 \mathrm{~V}$, which is much lower compared to the report by Komaba's group, further indicating the potential of $\mathrm{Fe}_{2} \mathrm{O}_{3}$ as a candidate anode for SIBs.

Efforts towards improving the capacity and cycling stability of iron-oxide based electrodes have been made by many groups. . $^{34,133-137,164}$ 3D porous $\gamma$ $\mathrm{Fe}_{2} \mathrm{O}_{3}$ nanoparticles with particles $5 \mathrm{~nm}$ in size uniformly embedded in a porous carbon matrix were fabricated as shown in Fig. $11 .^{34}$ The composite delivered a high discharge capacity of $740 \mathrm{~mA} \mathrm{~h} / \mathrm{g}$ at $200 \mathrm{~mA} / \mathrm{g}$ after 200 cycles; when the current density increased to $2 \mathrm{~A} / \mathrm{g}$, a capacity of $358 \mathrm{~mA} \mathrm{~h} / \mathrm{g}$ was retained in the $1400^{\text {th }}$ cycle. Such good cycling stability could be ascribed to: 1) the 3D porous nanostructures with carbon coating, which could buffer the volume expansion and enhance the charge transfer; and
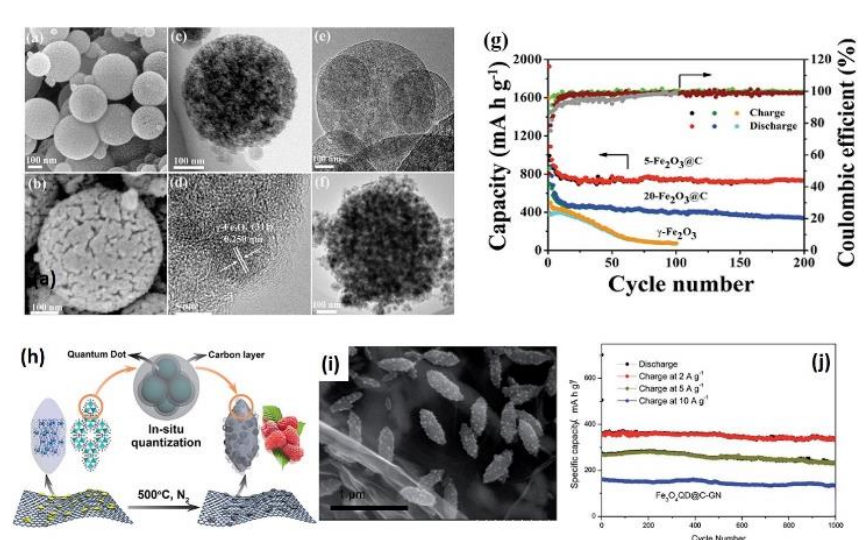

Fig. 11 (a-d) SEM and TEM images of 5- $\mathrm{Fe}_{2} \mathrm{O}_{3} @ \mathrm{C}$, (e) TEM image of 5- $\mathrm{Fe}_{2} \mathrm{O}_{3} @ \mathrm{C}$ after hydrochloric acid treatment for $12 \mathrm{~h}$, (f) TEM image of 5- $\mathrm{Fe}_{2} \mathrm{O}_{3} @ \mathrm{C}$ after thermal treatment at $450{ }^{\circ} \mathrm{C}$ for $2 \mathrm{~h}$, (g) cycling performances of 5- $\mathrm{Fe}_{2} \mathrm{O}_{3} @ \mathrm{C}$, $20-\mathrm{Fe}_{2} \mathrm{O}_{3} @ \mathrm{C}$, and $\gamma-\mathrm{Fe}_{2} \mathrm{O}_{3}$ at $200 \mathrm{~mA} / \mathrm{g} \cdot{ }^{34}$ Copyright 2014, John Wiley and Sons. (h) Schematic illustration of the in-situ quantization process in which metal oxide particles are uniformly dispersed in a 3D microstructured carbon matrix, (i) SEM image of the final raspberry-like $\mathrm{Fe}_{3} \mathrm{O}_{4} \mathrm{QD} @ \mathrm{C}-\mathrm{GN}$, and (j) cycling performance of $\mathrm{Fe}_{3} \mathrm{O}_{4} \mathrm{QD} @ \mathrm{C}-\mathrm{GN}$ at different current densities of 2, 5, and $10 \mathrm{~A} / \mathrm{g}$. Reprinted from Ref. 137 with permission from Royal Society of Chemistry. 
2) the ultrafine particle size, which could shorten the $\mathrm{Na}^{+}$diffusion distance and increase the number of active sites. Similar to this work, by downsizing the dimensions of the electrochemically active material to quantum dot size, raspberry-like carbon-coated $\mathrm{Fe}_{3} \mathrm{O}_{4}$ quantum dots embedded in $\mathrm{N}$-doped graphene $\left(\mathrm{Fe}_{3} \mathrm{O}_{4} \mathrm{QD} @ \mathrm{C}-\mathrm{GN}\right)$, derived from metal-organic frameworks (MOFs), not only possessed high electrical conductivity, but also avoided aggregation of $\mathrm{Fe}_{3} \mathrm{O}_{4}$ after long-term cycling. Furthermore, the nitrogendoped graphene sheets acted as a macroscopic conductive network supporting the MOF-derived microstructures. So the $\mathrm{Fe}_{3} \mathrm{O}_{4} \mathrm{QD} @ \mathrm{C}-\mathrm{GN}$ presented a high reversible capacity of 343,234 , and $149 \mathrm{~mA} \mathrm{~h} / \mathrm{g}$, even after 1000 cycles between $0.05 \mathrm{~V}$ and $3 \mathrm{~V}$ at current densities of 2,5 , and $10 \mathrm{~A} / \mathrm{g}$, respectively (Fig. 11h). ${ }^{137}$ These results demonstrate that tailoring the size of structures and introducing a conductive matrix are crucial for enhancing the electrochemical performance of the whole electrode. Furthermore, in order to gain insight into the properties of the electrode/electrolyte interface of $\mathrm{Fe}_{2} \mathrm{O}_{3}$ composites in LIBs and $\mathrm{SIBs}$, Philippe' group ${ }^{165}$ demonstrated that 1) a pre-deposited layer with the thickness of less than $5 \mathrm{~nm}$ was formed by simple contact of the electrode with the electrolyte in Na-half cells, while no predeposited layer was observed in any case for the Li-half cells; and 2) overall SEl coverage at the end of the discharge is more prominent in the Na halfcells $(\sim 7-8 \mathrm{~nm})$ than in Li half-cells $(\sim 4-5 \mathrm{~nm})$, indicating more sluggish kinetics for SIBs.

Analogously, a few researchers have exploited the electrochemical properties of $\mathrm{CO}_{3} \mathrm{O}_{4}$ as anode in $\mathrm{SIBs} .{ }^{138-142,166,167}$ The first discharge profile of nanostructured $\mathrm{CO}_{3} \mathrm{O}_{4}$, as reported by Chen's group, ${ }^{166}$ exhibited a broad peak centered at $0.5 \mathrm{~V}$ with a small peak at $0.75 \mathrm{~V}$. In the subsequent cycles, one cathodic peak was observed at around $0.54 \mathrm{~V}$, which is much lower than the corresponding one in LIBs $(\sim 1.2 \mathrm{~V})$. In the voltage window of $0.01 \mathrm{~V}-3 \mathrm{~V}$, the $\mathrm{CO}_{3} \mathrm{O}_{4}$ anode presented a reversible capacity of $447 \mathrm{~mA} \mathrm{~h} / \mathrm{g}$ after 50 cycles. In addition, monodispersed hierarchical $\mathrm{CO}_{3} \mathrm{O}_{4}$ spheres intertwined with carbon nanotubes showed capacities of 425, 230, and $184 \mathrm{~mA} \mathrm{~h} / \mathrm{g}$ at current densities of 160,1600 , and $3200 \mathrm{~mA} / \mathrm{g}$, respectively, but they displayed an unsatisfactory cycle life, with their capacity declining to $390 \mathrm{~mA} \mathrm{~h} / \mathrm{g}$ after only 25 cycles. ${ }^{167}$ In contrast, a holey assembly of $\mathrm{CO}_{3} \mathrm{O}_{4}$ nanoparticles (ACN) with $10 \mathrm{~nm}$ holes exhibited good cycling capability with capacity of $300 \mathrm{~mA} \mathrm{~h} / \mathrm{g}$ remaining after 100 cycles at $0.8 \mathrm{~A} / \mathrm{g}$. The in-situ TEM results demonstrated that small volume expansion (6\%) occurred for $2 \mathrm{D}$ holey $\mathrm{ACN}$ before and after sodiation, which can maintain the structural integrity and ensure long-term cycling life. ${ }^{138}$

$\mathrm{CuO}$ is also a promising anode candidate due to its abundance, chemical stability, and nontoxic nature, and recent studies on cupric oxides have made great progress. ${ }^{35,143-146,168}$ It was reported that $\mathrm{CuO}$ reacting with $\mathrm{Na}^{+}$ displayed two discharge plateaus at 1.15 and $0.35 \mathrm{~V}$ in the first discharge curve, corresponding to the formation of a SEI film and the decomposition of $\mathrm{CuO}$; in the following cycle, three discharge plateaus were located at 1.76, 0.74 , and $0.20 \mathrm{~V}$, indicating the consecutive formation of $\mathrm{Cu}_{1-x} \mathrm{Cu}_{x} \mathrm{O}_{1-x / 2}, \mathrm{Cu}_{2} \mathrm{O}$, and $\mathrm{Cu}$ in the $\mathrm{Na}_{2} \mathrm{O}$ matrix. Chen's group ${ }^{146}$ fabricated micro-/nano-structured $\mathrm{CuO} / \mathrm{C}$ spheres by aerosol spray pyrolysis. In comparison, 10-CuO/C (10 nm CuO particle size) delivered a capacity of $402 \mathrm{~mA} \mathrm{~h} / \mathrm{g}$ after 600 cycles at a current density of $200 \mathrm{~mA} / \mathrm{g}$, and a capacity of $304 \mathrm{~mA} \mathrm{~h} / \mathrm{g}$ was obtained at $2000 \mathrm{~mA} / \mathrm{g}$, while 40-CuO/C (40 nm CuO particle size) displayed a discharge capacity of only $217 \mathrm{~mA} \mathrm{~h} / \mathrm{g}$ after 50 cycles, which was because 40-CuO/C suffered from severe deformation in its structure and morphology after cycling. Furthermore, $\mathrm{CuO}$ quantum dots $2 \mathrm{~nm}$ in size that were embedded in carbon nanofibers were prepared by Jiao's group. As the anode for SIBs, 2CuO quantum dots presented enhanced cycling stability and rate performance, which maintained a capacity of $401 \mathrm{~mA} \mathrm{~h} / \mathrm{g}$ after 500 cycles at $500 \mathrm{~mA} / \mathrm{g}$, and a capacity of $250 \mathrm{~mA} \mathrm{~h} / \mathrm{g}$ was obtained at $5000 \mathrm{~mA} / \mathrm{g} \cdot{ }^{144}$
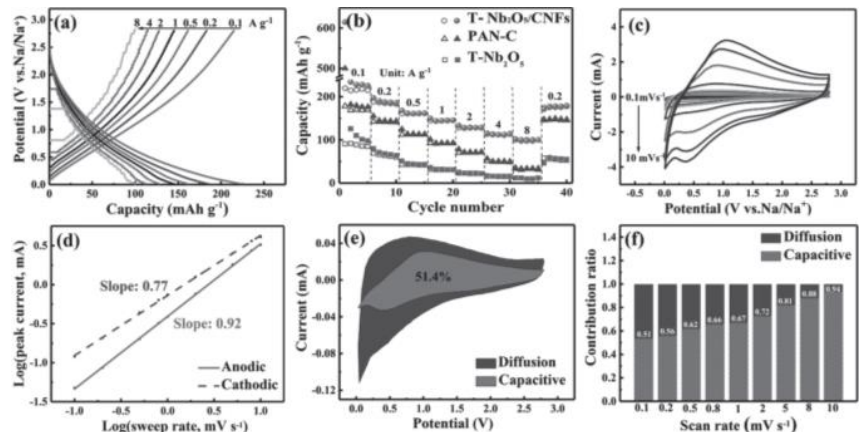

Fig. 12 (a) Charge-discharge profiles for $\mathrm{T}-\mathrm{Nb}_{2} \mathrm{O}_{5} / \mathrm{CNFs}$. (b) Comparison of rate performance at different current densities ranging from 0.1 to $8 \mathrm{~A} / \mathrm{g}$. (c) Cyclic voltammetry (CV) curves from 0.1 to $10 \mathrm{mV} / \mathrm{s}$. (d) Calculation of b-value during charge-discharge processes from the relationship between the sweep rate and the peak current. (e) Separation of contributions to the CV curve of capacitive and diffusion currents at the sweep rate of $0.1 \mathrm{mV} / \mathrm{s}$. f) Contributions of capacitive and diffusion controlled processes at different scan rates. Reprinted from Ref. 147 with permission from John Wiley and Sons.

Recently, orthorhombic $\mathrm{Nb}_{2} \mathrm{O}_{5}$ demonstrated outstanding high-rate capability and good cycling performance for lithium storage. ${ }^{169,170}$ It possesses a large interplanar lattice spacing of 3.9 Å between (001) planes, ${ }^{171}$ which is much larger than the diameter of $\mathrm{Na}^{+}$, so it is supposed that $\mathrm{Nb}_{2} \mathrm{O}_{5}$ may be a good host for facilitating fast $\mathrm{Na}^{+}$diffusion and storage. ${ }^{147-149}$ As expected, $\mathrm{T}$ $\mathrm{Nb}_{2} \mathrm{O}_{5} / \mathrm{CNFs}$ with the advantage of inherent pseudocapacitance delivered a stable capacity of $150 \mathrm{~mA} \mathrm{h/g}$ at $1 \mathrm{~A} / \mathrm{g}$ over 5000 cycles, and a reversible capacity of $97 \mathrm{~mA} \mathrm{~h} / \mathrm{g}$ at a high current density of $8 \mathrm{~A} / \mathrm{g}$. By means of kinetic analysis (Fig. 12), it was demonstrated that surface Faradaic reactions dominated the reaction of $\mathrm{Nb}_{2} \mathrm{O}_{5}$ at high rates, resulting in good rate performance. ${ }^{147}$ This indicates that $\mathrm{Nb}_{2} \mathrm{O}_{5}$ may potentially be a good candidate for high performance SIBs with prolonged cycling stability. In addition, some other metal oxides, such as $\mathrm{NiO}, 37,172$ and ternary metal oxides, such as $\mathrm{MnFe}_{2} \mathrm{O}_{4},{ }^{173} \mathrm{FeWO}_{4},{ }^{174} \mathrm{ZnSnO}_{3},{ }^{175}$ and $\mathrm{FeTiO}_{3}{ }^{176}$ have also been investigated.

\section{(2) Alloy reaction based metal oxides}

When the metal is electrochemically active, metal oxides can react with $\mathrm{Na}^{+}$ via a conversion reaction and a subsequent alloying reaction.

Among all of the metal oxide anodes, $\mathrm{SnO}_{2}$ has been one of the most intensively investigated materials in LIBs due to its capability for facile nanostructured design, high theoretical capacity, and low potential, so analogously, researchers are ready to develop $\mathrm{SnO}_{2}$ anode for SIBs based on the previous experience in LIBs. ${ }^{177}$ Its performance is based on this reaction:

$4 \mathrm{SnO}_{2}+31 \mathrm{Na}^{+}+31 e^{-} \leftrightarrow \mathrm{Na}_{15} \mathrm{Sn}_{4}+8 \mathrm{Na}_{2} \mathrm{O}$

$\mathrm{SnO}_{2}$ can deliver a theoretical sodium storage capacity of $1378 \mathrm{~mA} \mathrm{~h} / \mathrm{g}$, although, as a result of the irreversibility of the $\mathrm{Na}_{2} \mathrm{O}$ conversion, the theoretical reversible capacity falls to $667 \mathrm{~mA} \mathrm{~h} / \mathrm{g}$ if the contribution of $\mathrm{Na}_{2} \mathrm{O}$ is factored out. ${ }^{32}$ In this case, alloy-based metal oxides compare unfavorably with their corresponding bare metal anodes in terms of capacity. The enormous volume expansion occurring in the $\mathrm{Na}^{+}$storage process could be alleviated to some extent, however, in the presence of the $\mathrm{Na}_{2} \mathrm{O}$ matrix that is formed after the initial discharge process, which endows metal oxides with relatively longer cycling life compared with bare metals.

As demonstrated by Wang's group, ${ }^{178}$ in-situ TEM results revealed that a structure consisting of $\mathrm{Na}_{x} \mathrm{Sn}$ particles dispersed in a $\mathrm{Na}_{2} \mathrm{O}$ matrix could tolerate a huge amount of volume expansion ( $100 \%$ increase in diameter) during sodiation of $\mathrm{SnO}_{2}$ nanowires, while desodiation of $\mathrm{Na}_{x} \mathrm{Sn}$ would lead to the formation of $\mathrm{Sn}$ particles surrounded by pores due to condensation of 
vacancies from dealloying, resulting in eventual capacity fading of the bare $\mathrm{SnO}_{2}$ nanowires after several cycles. Therefore, similar to LIBs, several feasible strategies need to be applied to make the electrode material tolerate the huge volume expansion of $\mathrm{SnO}_{2}$, including tailoring the size of particles, constructing unique nanostructures, combining the active electrode with a flexible matrix, etc. ${ }^{150-154,179}$

$\mathrm{SnO}_{2}$ particles $(\sim 2 \mathrm{~nm})$ were embedded in ordered mesoporous CMK-8 carbon with 3D interconnected pore channels, and the composite exhibited capacity of $\sim 480 \mathrm{~mA} \mathrm{h/g}$ after 300 cycles as anode for SIBs, while the bare $\mathrm{SnO}_{2}$ electrode could retain capacity of less than $200 \mathrm{~mA} \mathrm{~h} / \mathrm{g}$ after 300 cycles. ${ }^{151}$ The specific capacity and cycling life were effectively improved by wrapping the $\mathrm{SnO}_{2}$ in 3D mesoporous carbon. Nevertheless, $\mathrm{SnO}_{2} @ \mathrm{CMK}-8$ presented insufficient capacity retention at high rates, partly due to the slow electron transfer between $\mathrm{CMK}-8$ and $\mathrm{SnO}_{2}$. When a nanostructured composite consisting of a $\mathrm{SnO}_{2}$ nanocrystal layer grown on hierarchical microfibers of carbon cloth with an extra carbon surface coating $\left(\mathrm{C} / \mathrm{SnO}_{2} / \mathrm{CC}\right)$ was fabricated, the rate capability of the $\mathrm{SnO}_{2}$ anode was significantly improved, with capacities of $501 \mathrm{~mA} \mathrm{~h} / \mathrm{g}$ and $144 \mathrm{~mA} \mathrm{~h} / \mathrm{g}$ at $0.1 \mathrm{C}$ and $30 \mathrm{C}$ respectively, ${ }^{154}$ and the reason for the enhanced rate performance can be ascribed to the dual channels in the conductive carbon fiber core and the carbon coating shell to facilitate fast electron transfer.

Besides $\mathrm{Sn}$ based oxides, various $\mathrm{Sb}$ based oxides have been investigated as anodes for $\mathrm{SIBs}$ as well, such as $\mathrm{Sb}_{2} \mathrm{O}_{4},{ }^{30,159} \mathrm{Sb}_{2} \mathrm{O}_{3},{ }^{31,155,156,180}$ and $\mathrm{SbO}_{x}{ }^{157,158}$ Compared with tin oxides, antimony oxides presented a more stable cycling life and a safer voltage plateau. $\mathrm{Hu}^{31}$ systematically investigated the reaction mechanism of $\mathrm{Sb}_{2} \mathrm{O}_{3}$ by XRD, HRTEM, and XPS. It was observed that $\mathrm{Na}^{+}$ initially intercalated into $\mathrm{Sb}_{2} \mathrm{O}_{3}$ above $0.8 \mathrm{~V}$ and then further reacted with $\mathrm{Na}^{+}$ to form $\mathrm{Sb}$ metal and $\mathrm{Na}_{2} \mathrm{O}$ between 0.8-0.4 V. Eventually, $\mathrm{NaSb}$ phase was formed after full discharging to $0.01 \mathrm{~V}$. The electrochemical reaction mechanism of $\mathrm{Sb}_{2} \mathrm{O}_{3}$ with sodium is in accordance with the combined conversion-alloying reactions

$$
\begin{aligned}
& \left.\mathrm{Sb}_{2} \mathrm{O}_{3}+x \mathrm{Na}^{+}+x e^{-} \rightarrow \mathrm{Na}_{x} \mathrm{Sb}_{2} \mathrm{O}_{3} \text { (1 } 1^{\text {st }} \text { discharge }\right) \\
& \mathrm{Na}_{x} \mathrm{Sb}_{2} \mathrm{O}_{3}+(6-x) \mathrm{Na}^{+}+(6-x) e^{-} \rightarrow 2 \mathrm{Sb}+3 \mathrm{Na}_{2} \mathrm{O} \\
& \left(1^{\text {st }} \text { discharge }\right) \\
& \mathrm{Sb}_{2} \mathrm{O}_{3}+6 \mathrm{Na}^{+}+6 e^{-} \leftrightarrow 2 \mathrm{Sb}+3 \mathrm{Na}_{2} \mathrm{O} \text { (after } 1^{\text {st }} \text { cycle) } \\
& \mathrm{Sb}+\mathrm{Na}^{+}+e^{-} \leftrightarrow \mathrm{NaSb}
\end{aligned}
$$

Based on the reaction mechanism, a complete conversion-alloying reaction will involve a total of $8 \mathrm{Na}$ atoms per formula unit, resulting in a theoretical capacity of $735 \mathrm{~mA} \mathrm{~h} / \mathrm{g}$. In the experiment, the $\mathrm{Sb}_{2} \mathrm{O}_{3}$ exhibited a capacity of $550 \mathrm{~mA} \mathrm{~h} / \mathrm{g}$ at $0.05 \mathrm{~A} / \mathrm{g}$ and a reversible capacity of $414 \mathrm{~mA} \mathrm{~h} / \mathrm{g}$ at $0.5 \mathrm{~A} / \mathrm{g}$ after 200 cycles. In order to further improve the electrochemical performance of $\mathrm{Sb}_{2} \mathrm{O}_{3}$, Wang et al. ${ }^{158}$ prepared a $\mathrm{Sb}_{2} \mathrm{O}_{3} / \mathrm{Sb} @$ graphene composite anchored on a network of carbon sheets, which demonstrated that $92.7 \%$ of the desodiation capacity ( $487 \mathrm{~mA} \mathrm{~h} / \mathrm{g}$ ) was retained after 275 cycles at the current density of $0.1 \mathrm{~A} / \mathrm{g}$.

Compared to $\mathrm{Sb}_{2} \mathrm{O}_{3}, \mathrm{Sb}_{2} \mathrm{O}_{4}$ possesses higher theoretical capacity (1227 mA $\mathrm{h} / \mathrm{g}$ ) based on the following reactions:

$$
\begin{aligned}
& \mathrm{Sb}_{2} \mathrm{O}_{4}+8 \mathrm{Na}^{+}+8 e^{-} \leftrightarrow 2 \mathrm{Sb}+4 \mathrm{Na}_{2} \mathrm{O}, \\
& 2 \mathrm{Sb}+6 \mathrm{Na}^{+}+6 e^{-} \leftrightarrow N a_{3} \mathrm{Sb} .
\end{aligned}
$$

Very few studies have been reported for $\mathrm{Sb}_{2} \mathrm{O}_{4}$ as anode material, however, for SIBs due to its large voltage hysteresis, low reversibility, and high redox potential. Sun et al. obtained reversible discharge capacities of 896 at $\mathrm{C} / 70$ with $\mathrm{Sb}_{2} \mathrm{O}_{4} / \mathrm{Na}^{30}$ Recently, a $\mathrm{Sb}_{2} \mathrm{O}_{4} @$ rGO composite as anode for SIBs was found to provide long cycling stability and high rate capability. At $0.6 \mathrm{~A} / \mathrm{g}$, a capacity of $626 \mathrm{~mA} \mathrm{h/g}$ was maintained over 500 cycles. This result represented significant progress on $\mathrm{Sb}_{2} \mathrm{O}_{4} / \mathrm{Na} .{ }^{159}$

Above all, most transition metal oxides with an electrochemically inactive metal element presented reversible capacities of less than $500 \mathrm{~mA} \mathrm{~h} / \mathrm{g}$ and poor long-term cycling life, which compared unfavorably with those for LIBs. For alloy reaction-based metal oxides, although these metal oxides showed higher reversible capacity due to the activity of the metal elements towards sodium, pulverization of the electrode and loss of contact with the current collector induced by huge volume expansion would hinder their further development. Tailoring the size down to below $10 \mathrm{~nm}$ or embedding the active electrode material in a 2D or 3D matrix may be effective for enhancing the reversible capacity and the cycling stability. Further in-depth understanding the interface behavior between the electrode and electrolyte during the charge/discharge processes may offer new insights for the optimization of current SIB systems and the design of new electrode materials for SIBs.

\section{Metal sulfides/selenide}

Recently, metal sulfides/selenides have attracted increasing attention from researchers due to their impressive electrochemical reactivity with sodium, as shown by such characteristics as long cycling life, high power density, and high energy density. Table 5 summarizes the recent progress on a variety of metal sulfides/selenides in terms of their electrochemical performance in SIBs.

According to the reaction mechanism of these metal sulfides/selenides with sodium, metal sulfides/selenides can be classified into two types:

(1) Conversion mechanism

$\mathrm{MoS}_{2}$ is a typical intercalation host for rechargeable batteries, which is composed of layers of molybdenum atoms coordinated to six sulfur atoms and has an interlayer spacing of approximately $6.2 \AA$, nearly double that of graphite (3.35 ̊) (Fig. 13a). Due to its laminar nature, $\mathrm{MoS}_{2}$ layers are bonded by weak van der Waals forces, so $\mathrm{MoS}_{2}$ is inherently able to accommodate other larger metal cations such as $\mathrm{Na}^{+}$and $\mathrm{Mg}^{2+}$ in addition to $\mathrm{Li}^{+}$. As an anode for LIBs, MoS 2 has a high reversible capacity and good cycling stability. At present, a few studies have been conducted on bulk $\mathrm{MoS}_{2}$ as a sodium intercalation host. Based on previous knowledge from LIBs, bulk $\mathrm{MoS}_{2}$ offers few satisfactory electrochemical properties for lithium storage, ${ }^{181}$ but its nanostructured counterparts are the focus of much attention for SIBs due to its dichalcogenide structure and large interlayer spacing. Park et al. reported the electrochemical properties of $\mathrm{MoS}_{2}$ as an intercalation host for SIBs and suggested a two-step reaction mechanism, where distortion of the $\mathrm{MoS}_{2}$ structure occurs in the low plateau region from insertion of $1.1 \mathrm{Na}$ ions due to induced microstrains. ${ }^{182}$ Such discharge behavior is different from that in $\mathrm{Li} / \mathrm{MoS}_{2}$ cells, which presented one smooth plateau when Li was inserted into layered $\mathrm{MoS}_{2}{ }^{183}$ The distorted bulk $\mathrm{MoS}_{2}$ structure after a deep discharge process will not fully recover to the pristine $\mathrm{MoS}_{2}$ structure during charging, so the bulk $\mathrm{MoS}_{2}$ maintained a capacity of only $89 \mathrm{~mA} \mathrm{h/g}$ after 100 cycles in the voltage window of $0.4-2.6 \mathrm{~V}$ in SIBs. Hence, in order to improve the electrochemical performance of $\mathrm{MoS}_{2}$ anode, researchers have been seeking effective approaches to fabricate few-layered or even single-layered $\mathrm{MoS}_{2}$, which can relieve the strain and decrease the barrier for $\mathrm{Na}^{+}$intercalation, ${ }^{184}$, 185 or to construct carbon-MoS 2 composites to further enhance the transport of electrons and ions, ${ }^{61,64,186-193}$ or regulate the working voltage window to control the reaction at a given step. ${ }^{194}$

For instance, Zhu et al. ${ }^{193}$ prepared single-layered $\mathrm{MoS}_{2}$ nanoplates with thickness and lateral dimensions of approximately $0.4 \mathrm{~nm}$ and $4 \mathrm{~nm}$, respectively, which exhibited initial lithiation/de-lithiation capacities of $1712 / 1267 \mathrm{~mA} \mathrm{~h} / \mathrm{g}$ at $0.1 \mathrm{~A} / \mathrm{g}$. In contrast, due to the sluggish kinetics of sodium insertion and extraction, the capacity for sodium storage was only 854 $\mathrm{mA} \mathrm{h} / \mathrm{g}$ at $0.1 \mathrm{~A} / \mathrm{g}$, which is lower than that in LIBs, but much higher than that of bulk MoS${ }_{2}$. This indicates that the single layer nature of the $\mathrm{MoS}_{2}$ would be of benefit for $\mathrm{Na}^{+}$storage since it could shorten the $\mathrm{Na}^{+}$migration in the sulfide in all directions and make the interfacial storage, insertion, and conversion reaction more efficient. Zhu's group ${ }^{185}$ prepared 


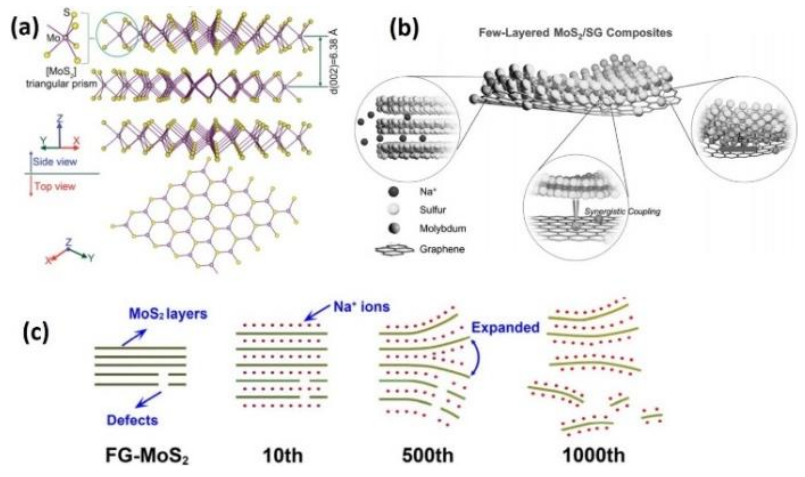

Fig. 13 (a) Refined structural model of the exfoliated $\mathrm{MoS}_{2}$ viewed along the [110] and [001] directions. The Mo and S atoms are colored in purple and yellow, respectively. Reprinted from Ref. 192 with permission from John Wiley and Sons. (b)Schematic illustration of few-layered $\mathrm{MoS}_{2} / \mathrm{S}$-doped graphene composites with unique microstructure originating from the synergistic coupling effect. Reprinted from Ref. 64 with permission from John Wiley and Sons. (c) Schematic illustration of the changes in FG-MoS layers over 1000 cycles. The Na intercalation sites would increase after the MoS layers expand. Reprinted from Ref. 194 with permission from John Wiley and Sons.

ultrathin $\mathrm{MoS}_{2}$ nanosheets $(\sim 2 \mathrm{~nm})$ with an expanded spacing of approximately $0.99 \mathrm{~nm}$ on the surfaces of carbon nanotubes (CNTs). The composite delivered a reversible specific capacity of $504.6 \mathrm{~mA} \mathrm{~h} / \mathrm{g}$ after 100 cycles at $50 \mathrm{~mA} / \mathrm{g}$. The improved cycling life may result from thin nanosheets and the 3D hierarchical nanostructure, which could provide short Na-ion diffusion channels and high conductivity for $\mathrm{Na}$-ion storage. Similar works have been conducted by many groups. ${ }^{40}, 191,192,217,218$ These works have deepened our understanding of graphene-like $\mathrm{MoS}_{2}$ nanosheets and offered multiple concepts for the fabrication of single layer $\mathrm{MoS}_{2}$ as a highperformance anode material for SIBs. By rationally designed a freestanding architecture, the $\mathrm{MoS}_{2} @$ carbon paper exhibited a high reversible capacity, high ICE, good cycling performance, and excellent rate capability for SIBs. Furthermore, the sodiation/desodiation mechanism was investigated by the in situ Raman spectroscopy measurements and a $\mathrm{MoS}_{2}$ phase transition from $2 \mathrm{H}-\mathrm{MoS}_{2}$ to $1 \mathrm{~T}-\mathrm{MoS}_{2}$ starts at $0.9 \mathrm{~V}$ during discharge was revealed. ${ }^{189}$ The reversibility of the phase transition from $2 \mathrm{H}-\mathrm{MoS}_{2}$ to $1 \mathrm{~T}-\mathrm{MoS}_{2}$ was observed during the sodium-ion intercalation/deintercalation process.

Very recently, few-layered $\mathrm{MoS}_{2}$ coupled with S-doped graphene was prepared by Li et al. (Fig. 13b). Under a strong synergistic coupling effect via $\mathrm{S}$ dopants from the S-graphene component, the composite exhibited longterm highly reversible $\mathrm{Na}^{+}$storage, in which the capacities of $619.2 \mathrm{~mA} \mathrm{~h} / \mathrm{g}$ and $265 \mathrm{~mA} \mathrm{~h} / \mathrm{g}$ were retained after 100 and 1000 cycles at 200 and 1000 $\mathrm{mA} / \mathrm{g}$, respectively. ${ }^{64}$ Heterogeneous atom (S) doping may enable electronrich graphene sheets centered at the doping atom, and the synergistic coupling effect via $\mathrm{S}$ dopant atoms between $\mathrm{MoS}_{2}$ and S-doped graphene could be effective to enhance the cycling stability. Moreover, owing to the volume expansion and structural changes during the conversion reaction of $\mathrm{MoS}_{2}$ in the sodiation process, Chen's group ${ }^{194}$ restricted the cut-off voltages within the range of $0.4-3 \mathrm{~V}$, so that an intercalation mechanism rather than a conversion reaction took place. Consequently, the $\mathrm{MoS}_{2}$ electrode presented a reversible capacity that was not as high as that in the voltage window of 0.1$3 \mathrm{~V}$, but the cycling performance was significantly improved, so that the capacities of $300 \mathrm{~mA} \mathrm{~h} / \mathrm{g}$ and $195 \mathrm{~mA} \mathrm{~h} / \mathrm{g}$ was obtained at $1 \mathrm{~A} / \mathrm{g}$ and $10 \mathrm{~A} / \mathrm{g}$ after 1500 cycles, respectively. The stable cycling performance could be ascribed to the more expanded and flexible nature of the $\mathrm{MoS}_{2}$ layers after the discharging process compared to the original $\mathrm{MoS}_{2}$ (Fig. 13c). This phenomenon was barely observed for $\mathrm{Li}_{-} \mathrm{MoS}_{2}$ or Na-MoS 2 batteries with cutoff voltages up to $0.1 \mathrm{~V}$, where the conversion mechanism may destroy the layered structure and generate Mo metal embedded in a $\mathrm{Na}_{2} \mathrm{~S}$ matrix.

In addition, heterostructures in which the 2D MoS is combined with different active metal sulfides or oxides, such as $\mathrm{MoS}_{2} / \mathrm{SnS}, \mathrm{MoS}_{2} / \mathrm{Ni}_{3} \mathrm{~S}_{2}$, $\mathrm{MoS}_{2} / \mathrm{Fe}_{3} \mathrm{O}_{4}$, etc. $\left(\mathrm{MoS}_{2}-\mathrm{MX}\right)$, ${ }^{190,219,220}$ were also demonstrated to play an important role in fast ion/electron transportation and offer more active sites for SIBs. For instance, it was reported that the reversible capacity of yolk-shell SnS-MoS $\mathrm{S}_{2}$ was enhanced compared to the bare yolk-shell SnS and yolk-shell $\mathrm{MoS}_{2}$, in which the capacity after 100 cycles for SnS-MoS, $\mathrm{SnS}$, and MoS 2 was 396,240 , and $260 \mathrm{~mA} \mathrm{~h} / \mathrm{g}$, respectively. ${ }^{219}$ The enhanced sodium-ion storage properties of the yolk-shell SnS-MoS 2 composite microspheres can be ascribed to the synergetic effect of the yolk-shell structure and the uniform mixing of the SnS and $\mathrm{MoS}_{2}$ nanocrystals.

Unlike $\mathrm{MoS}_{2}$, few studies on $\mathrm{MoS}_{3}$ had been reported until an amorphous chain-like $\mathrm{MoS}_{3}$ was recently presented as anode for SIBs by Ye et al. ${ }^{195}$ Different from the 2D layered structure of $\mathrm{MoS}_{2}, \mathrm{MoS}_{3}$ is a one-dimensional (1D) chain-like structure (Fig. 14a), which has more open sites conducive toward active $\mathrm{Na}^{+}$storage, facilitating the fast diffusion of $\mathrm{Na}^{+}$. In addition, $\mathrm{MoS}_{3}$ has an amorphous structure, inherently possessing lower activation energy barriers toward structural rearrangement during the possible conversion reaction. In this report, the authors demonstrated that the $\mathrm{MoS}_{3} / \mathrm{CNT}$ as anode for SIBs exhibited good cycling stability, with a capacity of $565 \mathrm{~mA} \mathrm{~h} / \mathrm{g}$ retained after 500 cycles at $50 \mathrm{~mA} / \mathrm{g}$, and $235 \mathrm{~mA} \mathrm{~h} / \mathrm{g}$ at 10 $\mathrm{A} / \mathrm{g}$. In contrast, the $\mathrm{MoS}_{2}$ presented unsatisfactory electrochemical performance. The reason may be attributed to the higher adsorption energy between $\mathrm{Na}^{+}$and $\mathrm{S}$ atoms, and the smaller $\mathrm{Na}^{+}$diffusion energy barrier for $\mathrm{MoS}_{3}$ compared to $\mathrm{MoS}_{2}$ based on the DFT simulation. This may provide a new perspective that, besides $\mathrm{MoS}_{2}, \mathrm{MoS}_{3}$ may be also a good candidate for highperformance SIBs.

In addition, some other metal sulfides such as $\mathrm{WS}_{2}, \mathrm{VS}_{2}$, and $\mathrm{V}_{5} \mathrm{~S}_{8}$, with reaction mechanisms involving intercalation of sodium at the beginning and a subsequent conversion reaction, were also applied as anodes for SIBs since they possessed similar layered structure to $\operatorname{MoS}_{2} .^{214,215,221}$ Yang et al. ${ }^{215}$
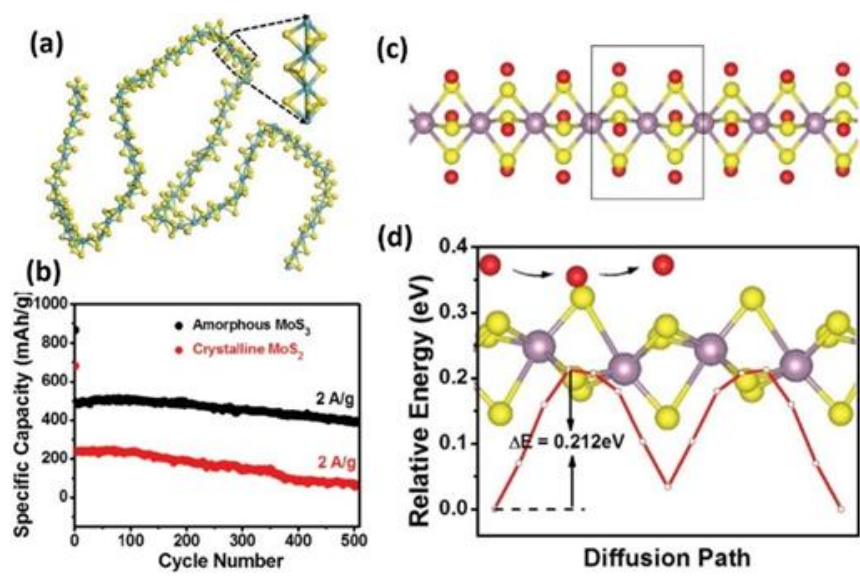

(d)

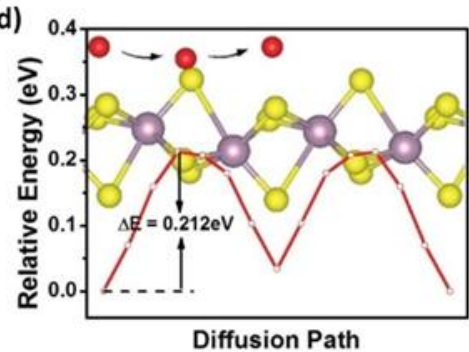

Fig. 14 (a) 1D chain-like $\mathrm{MoS}_{3}$; the blue and yellow spheres represent Mo and $\mathrm{S}$ atoms, respectively. (b) Cycling stability at $2 \mathrm{~A} / \mathrm{g}$. DFT calculations of the $\mathrm{Na}^{+}$ storage and diffusion properties of amorphous $\mathrm{MoS}_{3}$ chains: (c) Optimal adsorption sites of $\mathrm{Na}^{+}$on the $\mathrm{MoS}_{3}$ chain, with its unit cell indicated by the black square, (d) optimized diffusion path and energy barrier $(\Delta E)$ of $\mathrm{Na}^{+}$along the $\mathrm{MoS}_{3}$ chain. Reprinted from Ref. 195 with permission from John Wiley and Sons. 
Table 5 Electrochemical performance of a variety of metal sulfide/selenide based anodes for SIBs.

\begin{tabular}{|c|c|c|c|c|c|c|c|}
\hline Material & Nanostructure & $\begin{array}{c}\text { Redox } \\
\text { potential } \\
(\mathrm{V}) \\
\text { vs. } \mathrm{Na} / \mathrm{Na}^{+}\end{array}$ & $\begin{array}{l}\text { Current } \\
\text { density } \\
(\mathrm{mA} / \mathrm{g})\end{array}$ & $\begin{array}{l}\text { Reversible capacity } \\
\quad(\mathrm{mA} \mathrm{h} / \mathrm{g})\end{array}$ & $1^{\text {st }} \mathrm{CE}$ & Electrolyte & Ref. \\
\hline \multirow{10}{*}{$\begin{array}{c}\mathrm{MoS}_{x} / \mathrm{MoSe}_{2} \\
\end{array}$} & $\begin{array}{l}\mathrm{MoS}_{2} @ \mathrm{~N}-\mathrm{C} @ \text { carbon } \\
\text { cloth }\end{array}$ & $\sim 0.3-1.8$ & $\begin{array}{l}200 \\
1000\end{array}$ & $\begin{array}{l}\text { 619/100 cycles } \\
265 / 1000 \text { cycles }\end{array}$ & $52 \%$ & $\begin{array}{l}1 \mathrm{M} \mathrm{NaClO}{ }_{4} \text { in } \\
\mathrm{EC} / \mathrm{DMC}+5 \% \mathrm{FEC}\end{array}$ & 61 \\
\hline & $\begin{array}{l}\mathrm{MoS}_{2} / \mathrm{S} \text {-doped } \\
\text { graphene }\end{array}$ & $0.4-2.3$ & $\begin{array}{l}100 \\
1000 \\
5000\end{array}$ & $\begin{array}{l}439 / 100 \text { cycles } \\
309 / 1000 \text { cycles } \\
264\end{array}$ & $91.2 \%$ & $1 \mathrm{M} \mathrm{NaPF}_{6}$ in $\mathrm{EC} / \mathrm{DEC}$ & 64 \\
\hline & $\mathrm{MoS}_{2} /$ E-graphene & $\sim 1.25-2.50$ & $\begin{array}{l}1000 \\
2000\end{array}$ & $\begin{array}{l}509 / 200 \text { cycles } \\
423\end{array}$ & $96 \%$ & $\begin{array}{l}1 \mathrm{M} \mathrm{NaPF}_{6} \\
\text { in DME }\end{array}$ & 186 \\
\hline & $\mathrm{MoS}_{2} / \mathrm{SWNT}$ & $0.65-2.30$ & $\begin{array}{l}500 \\
10000 \\
20000\end{array}$ & $\begin{array}{l}315 / 1000 \text { cycles } \\
296 \\
192\end{array}$ & $57 \%$ & $1 \mathrm{M} \mathrm{NaPF}_{6}$ in $\mathrm{EC} / \mathrm{DEC}$ & 187 \\
\hline & Mesoporous $\mathrm{MoS}_{2} / \mathrm{C}$ & $0.39-1.70$ & $\begin{array}{l}1000 \\
10000 \\
20000\end{array}$ & $\begin{array}{l}390 / 2500 \text { cycles } \\
312 \\
244\end{array}$ & $68.7 \%$ & $\begin{array}{l}1 \mathrm{M} \mathrm{NaClO}{ }_{4} \text { in } \\
\mathrm{EC} / \mathrm{DMC}+5 \% \mathrm{FEC}\end{array}$ & 188 \\
\hline & $\begin{array}{l}\text { Free-standing } \\
\mathrm{MoS}_{2} / \text { carbon paper }\end{array}$ & $0.2-1.2$ & $\begin{array}{l}80 \\
160 \\
1000\end{array}$ & $\begin{array}{l}286 / 100 \text { cycles } \\
230 / 100 \text { cycles } \\
205\end{array}$ & $79.5 \%$ & $\begin{array}{l}1 \mathrm{M} \mathrm{NaClO}_{4} \text { in } \\
\mathrm{EC} / \mathrm{PC}+5 \% \mathrm{FEC}\end{array}$ & 189 \\
\hline & $\mathrm{Ni}_{3} \mathrm{~S}_{2} @ \mathrm{MoS}_{2}$ & $0.56-1.67$ & $\begin{array}{l}200 \\
5000\end{array}$ & $\begin{array}{l}483 / 100 \text { cycles } \\
207 / 400 \text { cycles }\end{array}$ & $83.8 \%$ & $\begin{array}{l}1 \mathrm{M} \mathrm{NaPF}_{6} \text { in } \mathrm{EC} / \mathrm{DEC}+ \\
3 \% \mathrm{FEC}\end{array}$ & 190 \\
\hline & 3D-MoS 2 /graphene & $0.5-3.0$ & $\begin{array}{l}1500 \\
5000 \\
10000\end{array}$ & $\begin{array}{l}322 / 600 \text { cycles } \\
306 \\
234\end{array}$ & $71.9 \%$ & $\begin{array}{l}1 \mathrm{M} \mathrm{NaClO}_{4} \text { in } \\
\mathrm{EC} / \mathrm{DMC}+5 \% \mathrm{FEC}\end{array}$ & 191 \\
\hline & $\mathrm{MoS}_{2}$ nanoflowers & $0.368-1.850$ & $\begin{array}{l}40 \\
80 \\
160 \\
320 \\
50 \\
1000 \\
10000\end{array}$ & $\begin{array}{l}386 / 100 \text { cycles } \\
330 / 100 \text { cycles } \\
305 / 100 \text { cycles } \\
251 / 100 \text { cycles } \\
350 / 200 \text { cycles } \\
300 / 500 \text { cycles } \\
195 / 500 \text { cycles }\end{array}$ & $53 \%$ & $\begin{array}{l}1 \mathrm{M} \mathrm{NaCF}_{3} \mathrm{SO}_{3} \text { in } \\
\text { DEGDME }\end{array}$ & 192 \\
\hline & $\begin{array}{l}\mathrm{MoSe}_{2} @ \mathrm{~N}, \mathrm{P} \text { - carbon } \\
\text { nanosheet }\end{array}$ & $0.62-1.90$ & $\begin{array}{l}50 \\
5000 \\
10000 \\
20000 \\
50000 \\
500 \\
1000 \\
5000 \\
8000 \\
15000 \\
\end{array}$ & $\begin{array}{l}565 / 100 \text { cycles } \\
420 \\
334 \\
235 \\
90 \\
387 / 1000 \text { cycles } \\
315 / 1000 \text { cycles } \\
232 / 1000 \text { cycles } \\
168 / 1000 \text { cycles } \\
216\end{array}$ & $70.4 \%$ & $\begin{array}{l}1 \mathrm{M} \mathrm{NaPF}_{6} \text { in EC/DEC+ } \\
5 \% \mathrm{FEC}\end{array}$ & 195 \\
\hline \multirow{5}{*}{$\operatorname{CoS}_{x} / \operatorname{CoSe}_{x}$} & M-CoS@C & $0.45-1.83$ & $\begin{array}{l}200 \\
20000\end{array}$ & $\begin{array}{l}532 / 100 \text { cycles } \\
190\end{array}$ & - & $\begin{array}{l}1 \mathrm{M} \mathrm{NaClO}_{4} \text { in } \mathrm{PC}+5 \% \\
\mathrm{FEC}\end{array}$ & 196 \\
\hline & $\begin{array}{l}\mathrm{N} \text {-doped } \\
\text { carbon@CoS coaxial } \\
\text { nanotubes }\end{array}$ & $0.5-\sim 1.8$ & 3000 & $220 / 1400$ cycles & - & $1 \mathrm{M} \mathrm{NaClO}_{4}$ in $\mathrm{EC} / \mathrm{DEC}$ & 197 \\
\hline & CoScC-NWs & $0.65-1.78$ & $\begin{array}{l}100 \\
2000 \\
5000\end{array}$ & $\begin{array}{l}294 / 100 \text { cycles } \\
265 \\
235\end{array}$ & $\begin{array}{l}54 \% \\
59 \%\end{array}$ & $\begin{array}{l}1 \mathrm{M} \mathrm{NaClO}_{4} \text { in } \mathrm{PC}+5 \% \\
\mathrm{FEC}\end{array}$ & 198 \\
\hline & CoSecC-NWs, & $0.77-1.82$ & $\begin{array}{l}100 \\
2000 \\
5000\end{array}$ & $\begin{array}{l}200 / 100 \text { cycles } \\
268 \\
241\end{array}$ & & & \\
\hline & $\begin{array}{l}\mathrm{Cog}_{8} \\
\mathrm{QD} @ \mathrm{HCP} @ \mathrm{rGO}\end{array}$ & $0.98-1.70$ & $\begin{array}{l}300 \\
1600 \\
3200 \\
6400\end{array}$ & $\begin{array}{l}628 / 500 \text { cycles } \\
529 \\
448 \\
330\end{array}$ & $89 \%$ & $\begin{array}{l}0.5 \mathrm{M} \mathrm{NaCF}_{3} \mathrm{SO}_{3} \text { in } \\
\text { DEGDME }\end{array}$ & 199 \\
\hline
\end{tabular}




\begin{tabular}{|c|c|c|c|c|c|c|c|}
\hline & $\begin{array}{l}\mathrm{CoS} \text { and } \mathrm{Co}_{9} \mathrm{~S}_{8} @ \mathrm{~N}, \\
\text { S-carbon }\end{array}$ & $0.5-1.7$ & $\begin{array}{l}1000 \\
5000 \\
10000\end{array}$ & $\begin{array}{l}\sim 600 / 200 \text { cycles } \\
534 \\
526\end{array}$ & $94.5 \%$ & $1 \mathrm{M} \mathrm{NaCF}_{3} \mathrm{SO}_{3}$ in DG & 200 \\
\hline & $\begin{array}{l}\text { Free-standing } \\
\mathrm{CoS}_{2} / \text { carbon } \\
\text { nanofiber }\end{array}$ & $0.25-1.30$ & $\begin{array}{l}1000 \\
10000\end{array}$ & $\begin{array}{l}315.7 / 1000 \text { cycles } \\
219\end{array}$ & $85 \%$ & $\begin{array}{l}1 \mathrm{M} \mathrm{NaCF}_{3} \mathrm{SO}_{3} \text { in } \\
\text { DEGDME }\end{array}$ & 201 \\
\hline & $\begin{array}{l}\mathrm{H}-\mathrm{CoS}_{2} \\
\text { micro/nanostructure } \\
\mathrm{s}\end{array}$ & $0.47-2.40$ & $\begin{array}{l}1000 \\
1000\end{array}$ & $\begin{array}{l}690 / 100 \text { cycles } \\
240 / 800 \text { cycles }\end{array}$ & $92 \%$ & $\begin{array}{l}1 \mathrm{M} \mathrm{NaCF}_{3} \mathrm{SO}_{3} \text { in } \\
\text { DEGDME }\end{array}$ & 67 \\
\hline & Urchin-like $\mathrm{CoSe}_{2}$ & $0.72-1.82$ & $\begin{array}{l}1000 \\
5000 \\
10000 \\
50000\end{array}$ & $\begin{array}{l}410 / 1800 \text { cycles } \\
378 \\
354 \\
97\end{array}$ & - & $\begin{array}{l}1 \mathrm{M} \mathrm{NaCF}_{3} \mathrm{SO}_{3} \text { in } \\
\text { DEGDME }\end{array}$ & 202 \\
\hline \multirow{7}{*}{$\begin{array}{l}\mathrm{SnS}_{x} / \\
\mathrm{SnSe}_{x}\end{array}$} & SnS@3D N-graphene & $0.07-1.37$ & 2000 & $510 / 1000$ cycles & $80.1 \%$ & $\begin{array}{l}1 \mathrm{M} \mathrm{NaClO}{ }_{4} \text { in } \mathrm{PC}+5 \% \\
\mathrm{FEC}\end{array}$ & 203 \\
\hline & SnS@C nanotubes & $0.36-1.35$ & 200 & $440 / 100$ cycles & $76 \%$ & $\begin{array}{l}1 \mathrm{M} \mathrm{NaClO} \text { in } \\
\mathrm{EC} / \mathrm{DMC}+5 \% \mathrm{FEC}\end{array}$ & 204 \\
\hline & SnS $2 @ N C-R G O$ & $\sim 0.5-2.0$ & $\begin{array}{l}1000 \\
5570 \\
11200\end{array}$ & $\begin{array}{l}480 / 1000 \text { cycles } 370 \\
250\end{array}$ & $73 \%$ & $\begin{array}{l}1 \mathrm{M} \mathrm{NaClO}{ }_{4} \text { in } \\
\mathrm{EC} / \mathrm{DEC}+5 \% \mathrm{FEC}\end{array}$ & 205 \\
\hline & $\mathrm{SnS}_{2} @ \mathrm{rGO}$ & $\sim 0.5-1.5$ & $\begin{array}{l}200 \\
400 \\
800 \\
6400 \\
12800\end{array}$ & $\begin{array}{l}509 / 300 \text { cycles } \\
360 / 500 \text { cycles } \\
286 / 1000 \text { cycles } \\
452 \\
337\end{array}$ & $64.2 \%$ & $\begin{array}{l}1 \mathrm{M} \mathrm{NaPF}_{6} \text { in } \\
\mathrm{EC} / \mathrm{DEC}+5 \% \mathrm{FEC}\end{array}$ & 206 \\
\hline & $\begin{array}{l}\mathrm{SnS}_{2} \text { nanosheets- } \\
160 \mathrm{SS}\end{array}$ & $0.59-1.66$ & 100 & $647 / 50$ cycles & $59 \%$ & $\begin{array}{l}1 \mathrm{M} \mathrm{NaPF}_{6} \text { in } \mathrm{PC}+5 \% \\
\mathrm{FEC}\end{array}$ & 207 \\
\hline & $\begin{array}{l}\text { SnSe nanosheet } \\
\text { clusters }\end{array}$ & $0.13-1.67$ & $\begin{array}{l}200 \\
2000 \\
5000 \\
10000\end{array}$ & $\begin{array}{l}271 / 100 \text { cycles } \\
183 / 100 \text { cycles } \\
70 / 100 \text { cycles } \\
200\end{array}$ & - & $\begin{array}{l}1 \mathrm{M} \mathrm{NaPF} 6 \text { in } \\
\mathrm{EC} / \mathrm{DEC}+5 \% \mathrm{FEC}\end{array}$ & 208 \\
\hline & SnSSe & $0.60-1.99$ & $\begin{array}{l}500 \\
5000\end{array}$ & $\begin{array}{l}400 / 600 \text { cycles } \\
330 / 1000 \text { cycles }\end{array}$ & - & $\begin{array}{l}1 \mathrm{M} \mathrm{NaCF}_{3} \mathrm{SO}_{3} \text { in } \\
\mathrm{DEGDME}\end{array}$ & 66 \\
\hline \multirow{6}{*}{$\begin{array}{l}\mathrm{SbS}_{x} / \\
\mathrm{Sb}_{2} \mathrm{Se}_{3}\end{array}$} & $\mathrm{Sb}_{2} \mathrm{~S}_{3} / \mathrm{rGO}$ & $0.25-1.30$ & $\begin{array}{l}50 \\
1500 \\
3000\end{array}$ & $\begin{array}{l}636.5 / 50 \text { cycles } \\
611 \\
520\end{array}$ & - & $\begin{array}{l}1 \mathrm{M} \mathrm{NaClO} \text { in } \mathrm{PC}+5 \% \\
\mathrm{FEC}\end{array}$ & 41 \\
\hline & $\begin{array}{l}\text { carbon-coated } \mathrm{Sb}_{2} \mathrm{~S}_{3} \\
\text { nanorod }\end{array}$ & $0.40-1.64$ & $\begin{array}{l}100 \\
1000 \\
2000\end{array}$ & $\begin{array}{l}570 / 100 \text { cycles } \\
415 \\
337\end{array}$ & - & $\begin{array}{l}1 \mathrm{M} \mathrm{NaClO}_{4} \text { in } \mathrm{PC}+5 \% \\
\mathrm{FEC}\end{array}$ & 209 \\
\hline & $\mathrm{Sb}_{2} \mathrm{~S}_{3} / \mathrm{S}-\mathrm{GS}$ & $0.27-1.33$ & 2000 & $524.4 / 900$ cycles & $\sim 75 \%$ & $\begin{array}{l}1 \mathrm{M} \mathrm{NaClO}_{4} \text { in } \mathrm{PC}+5 \% \\
\mathrm{FEC}\end{array}$ & 210 \\
\hline & $\begin{array}{l}\text { Amorphous } \mathrm{Sb}_{2} \mathrm{~S}_{3} \\
\text { nanoparticle }\end{array}$ & $\sim 0.2-\sim 1.2$ & $\begin{array}{l}50 \\
3000\end{array}$ & $\begin{array}{l}512 / 100 \text { cycles } \\
534\end{array}$ & $65 \%$ & $\begin{array}{l}1 \mathrm{M} \mathrm{NaClO}_{4} \text { in } \\
\mathrm{EC} / \mathrm{DEC}+5 \% \mathrm{FEC}\end{array}$ & 211 \\
\hline & $\mathrm{Sb}_{2} \mathrm{~S}_{5} / 3 \mathrm{D}-\mathrm{GS}-8$ & $0.39-1.97$ & $\begin{array}{l}200 \\
10000\end{array}$ & $\begin{array}{l}748 / 300 \text { cycles } \\
525\end{array}$ & $73.6 \%$ & $\begin{array}{l}1 \mathrm{M} \mathrm{NaClO} \text { in } \\
\mathrm{EC} / \mathrm{PC}+5 \% \mathrm{FEC}\end{array}$ & 212 \\
\hline & $\mathrm{Sb}_{2} \mathrm{Se}_{3} / \mathrm{rGO}$ & $0.3-2.2$ & $\begin{array}{l}1000 \\
100 \\
1000 \\
2000 \\
\end{array}$ & $\begin{array}{l}417 / 500 \text { cycles } \\
682 \\
448 \\
386 \\
\end{array}$ & $71.3 \%$ & $\begin{array}{l}1 \mathrm{M} \mathrm{NaCF}_{3} \mathrm{SO}_{3} \text { in } \\
\mathrm{DEGDME}\end{array}$ & 213 \\
\hline $\mathrm{VS}_{x}$ & $\mathrm{VS}_{2}$ nanosheet & $0.5-2.2$ & $\begin{array}{l}100 \\
1000 \\
1000 \\
2000\end{array}$ & $\begin{array}{l}700 / 100 \text { cycles } \\
500 / 200 \text { cycles } \\
550 \\
400\end{array}$ & - & $\begin{array}{l}1 \mathrm{M} \mathrm{NaClO} \text { in } \\
\mathrm{EC} / \mathrm{DEC}+6 \% \mathrm{FEC}\end{array}$ & 214 \\
\hline
\end{tabular}




\begin{tabular}{|c|c|c|c|c|c|c|c|}
\hline & $\begin{array}{l}\text { exfoliated } \\
\mathrm{V}_{5} \mathrm{~S}_{8} / \text { graphite }\end{array}$ & $0.11-2.10$ & $\begin{array}{l}1000 \\
2000 \\
5000 \\
10000\end{array}$ & $\begin{array}{l}496 / 500 \text { cycles } \\
485 \\
389 \\
344\end{array}$ & & $1 \mathrm{M} \mathrm{NaClO}{ }_{4}$ in $\mathrm{PC}$ & 215 \\
\hline & $\begin{array}{l}\mathrm{ZnS}-\mathrm{Sb}_{2} \mathrm{~S}_{3} @ \mathrm{C} \text { core- } \\
\text { double shell }\end{array}$ & $0.17-1.28$ & 100 & $630 / 120$ cycles & $61.4 \%$ & $\begin{array}{l}1 \mathrm{M} \mathrm{NaClO} 4 \text { in } \mathrm{PC}+5 \% \\
\mathrm{FEC}\end{array}$ & 56 \\
\hline composite & C@SnS/SnO & $0.00-1.15$ & $\begin{array}{l}810 \\
2430\end{array}$ & $\begin{array}{l}409 / 500 \text { cycles } \\
360 / 500 \text { cycles }\end{array}$ & $74.6 \%$ & $\begin{array}{l}1 \mathrm{M} \mathrm{NaClO}{ }_{4} \text { in } \\
E C / D E C+5 \% \text { FEC }\end{array}$ & 216 \\
\hline
\end{tabular}

systematically investigated the sodiation/desodiation reaction of $\mathrm{V}_{5} \mathrm{~S}_{8}$. Based on in-situ XRD characterization, $\mathrm{V}_{5} \mathrm{~S}_{8}$ could react with $\mathrm{Na}^{+}$as follows (Fig. 15):

$\mathrm{Na}^{+}$intercalation: $V_{5} S_{8}+x \mathrm{Na}^{+}+x e^{-} \rightarrow N a_{x} V_{5} S_{8}(>0.4 \mathrm{~V})$

$\mathrm{Na}^{+}$intercalation: $V_{5} S_{8}+x N a^{+}+x e^{-} \rightarrow N_{x} V_{5} S_{8}$

and partial $\mathrm{Na}^{+}$conversion: $N a_{x} V_{5} S_{8}+(16-x) N a^{+}+(16-x) e^{-} \rightarrow$ $8 \mathrm{Na}_{2} \mathrm{~S}+5 \mathrm{~V}(0.4-0.25 \mathrm{~V})$

Full $\mathrm{Na}^{+}$conversion: $\mathrm{Na}_{x} \mathrm{~V}_{5} \mathrm{~S}_{8}+(16-x) \mathrm{Na}^{+}+(16-x) e^{-} \rightarrow 8 \mathrm{Na}_{2} \mathrm{~S}+$ $5 \mathrm{~V}(<0.25 \mathrm{~V})$

The reverse reactions (13) and (14) take place at $<1.35 \mathrm{~V}$ and $>1.35 \mathrm{~V}$, respectively, during the charging process

$8 N a_{2} S+5 V \rightarrow N a_{x} V_{5} S_{8}+(16-x) N a^{+}+(16-x) e^{-}(<1.35 V)$

(13)

$N a_{x} V_{5} S_{8} \rightarrow V_{5} S_{8}+x N a^{+}+x e^{-}(>1.35 V)$

Electrochemical evaluations indicated that $\mathrm{V}_{5} \mathrm{~S}_{8} / \mathrm{C}$ demonstrated a reversible discharge capacity $(682 \mathrm{~mA} \mathrm{h/g}$ at $0.1 \mathrm{~A} / \mathrm{g})$, a reasonable cycle life (496 mA h/g at $1 \mathrm{~A} / \mathrm{g}$ after 500 cycles), and high-rate capacities of 389 and $344 \mathrm{~mA} \mathrm{~h} / \mathrm{g}$ at 5 and $10 \mathrm{~A} / \mathrm{g}$, respectively, which demonstrated that $\mathrm{V}_{5} \mathrm{~S}_{8}$ as a new layered transition metal sulfide may be a promising anode for high performance SIBs.

$\mathrm{MoSe}_{2}$ as anode for rechargeable batteries has not been investigated as extensively as $\mathrm{MoS}_{2}$, due to its low specific capacity and high cost of Se. The volumetric capacity of $\mathrm{MoSe}_{2}$ is close to that of $\mathrm{MoS}_{2}$, however, and Se has a higher electrical conductivity $\left(1 \times 10^{-3} \mathrm{~S} / \mathrm{m}\right)$ than $\mathrm{S}\left(5 \times 10^{-28} \mathrm{~S} / \mathrm{m}\right) .^{222}$ The layered transition metal sulfide $\mathrm{MoSe}_{2}$ as anode for SIBs displayed three main cathodic peaks at around $1.4,0.65$, and $0.44 \mathrm{~V}$, corresponding to the intercalation of $\mathrm{Na}$-ions into the $\mathrm{MoSe}_{2}$ lattice and the conversion reaction from $\mathrm{Na}_{x} \mathrm{MoSe}_{2}$ to Mo metal nanograins, as well as the formation of a gel-like polymeric layer in the initial discharge process. ${ }^{223} \mathrm{MoSe}_{2}$ grown on N, P-codoped were prepared by Niu et al, ${ }^{65}$ which displayed good long-term cycling capability with a reversible capacity of $378 \mathrm{~mA} \mathrm{~h} / \mathrm{g}$ maintained after 1000 cycles at $0.5 \mathrm{~A} / \mathrm{g}$. This electrochemical performance is comparable to that of MoS2. ${ }^{189}$ When tested in a full cell with $\mathrm{Na}_{3} \mathrm{~V}_{2}\left(\mathrm{PO}_{4}\right)_{3} / \mathrm{C}$ as the cathode in the voltage window of 1-3.4 V, the capacity calculated by the mass of anode materials could be stabilized at $276 \mathrm{~mA} \mathrm{h/g}$ after 200 cycles at $0.5 \mathrm{~A} / \mathrm{g}$. At 0.1 $\mathrm{kW} / \mathrm{kg}$, the full cell could deliver an energy density of $113.6 \mathrm{Wh} / \mathrm{kg}$ total.

Other transition metal sulfides/selenides, such as $\operatorname{CoS}, \operatorname{CoS}_{2}, \operatorname{Co}_{9} S_{8}, \operatorname{CoSe}$, $\mathrm{CoSe}_{2},{ }^{67,196-202} \mathrm{FeS}, \mathrm{FeS}_{2}, \mathrm{FeSe}_{2},{ }^{224-227}$ and $\mathrm{CuS}^{2}{ }^{228}$ have also been investigated as potential anodes for electrochemical sodium storage owing to their low cost, abundant resources, high theoretical capacities, and electrical conductivity. Transition metal sulfides/selenides displayed a lower redox voltage range for sodium storage than lithium storage owing to a lower thermodynamic cell voltage, making these materials more suitable as anodes. ${ }^{160}$ Their sodium-storage capacity is typically lower than their lithiumstorage capacity, and much less than the theoretical value. Moreover, the cycling stability and voltage hysteresis were even worse for sodium storage. ${ }^{224}$ Hence, various methods, such as rational electrode design, working voltage window control, or optimization of electrolytes, were applied to enhance the electrochemical performance of transition metal sulfides/selenides for SIBs. ${ }^{67}$, 196-202

As reported by Pan et al., ${ }^{201}$ in the voltage window of $0.1-2.9 \mathrm{~V}$, the capacity of $\mathrm{CoS}_{2} @ M C N F$ anode in SIBs decreased from 560 mA h/g to 130 mA h/g within 150 cycles, while by adjusting the cut-off voltage to $0.4-2.9 \mathrm{~V}$, the capacity of $507 \mathrm{~mA} \mathrm{~h} / \mathrm{g}$ was retained in the $100^{\text {th }}$ cycles at $100 \mathrm{~mA} / \mathrm{g}$, and a capacity of $315 \mathrm{~mA} \mathrm{~h} / \mathrm{g}$ was even obtained after 1000 cycles at $1 \mathrm{~A} / \mathrm{g}$. A similar phenomenon has also been observed by Liu et al. ${ }^{67}$ These results illustrate that, although upgrading the discharge terminal voltage may have
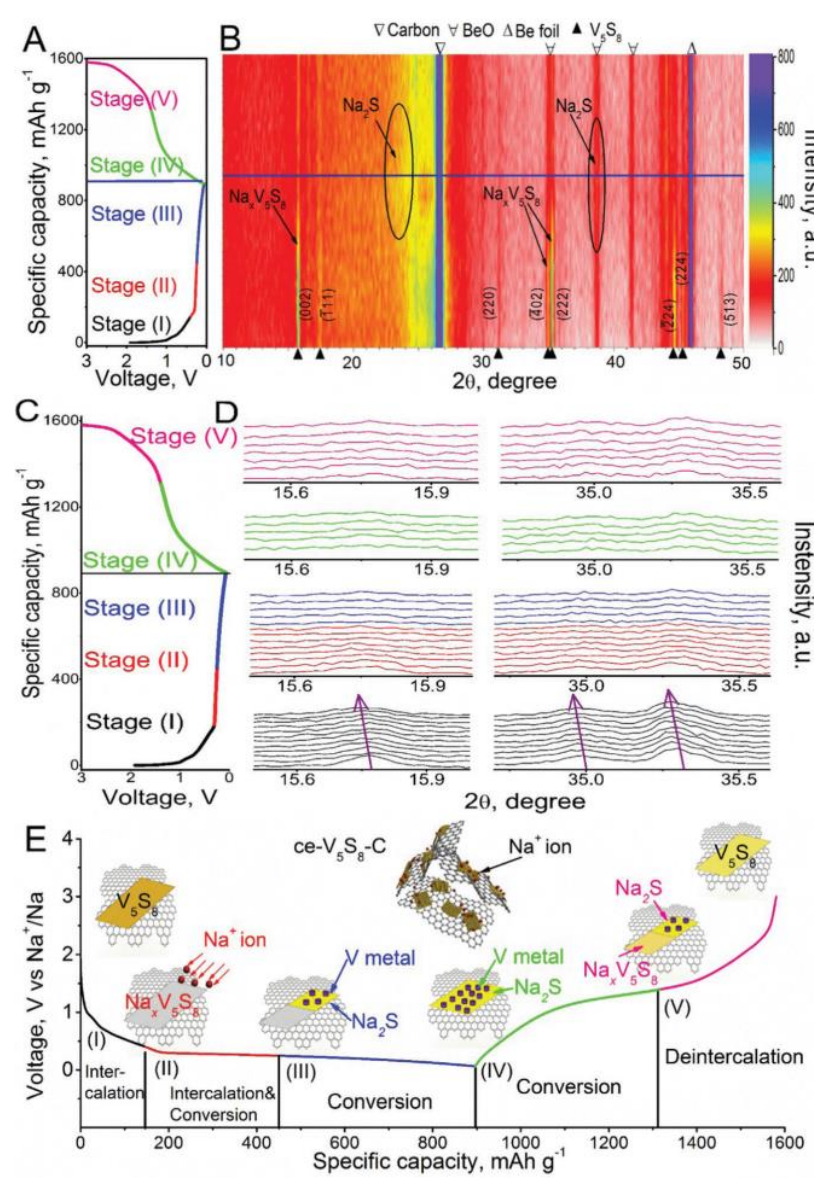

Fig. 15 Charge-discharge profiles ( $A$ and $C$ ), the corresponding contour plots (B), and selected $2 \theta$ region plot (D) from the in situ XRD results at different discharge/charge states of the ce- $\mathrm{V}_{5} \mathrm{~S}_{8}-\mathrm{C}$ hybrid anodes, and a schematic illustration of the energy storage mechanism of the ce- $\mathrm{V}_{5} \mathrm{~S}_{8}-\mathrm{C}$ hybrid anode at different stages (E). Reprinted from Ref. 215 with permission from The Royal Society of Chemistry. 
sacrificed some capacity, their cycling performance was significantly improved. Systematic investigation of the reaction mechanism in different working voltage ranges is needed, however, to fully understand sodiation/desodiation processes in transition metal sulfides/selenides.

In addition to modifying the voltage window, optimizing the electrolyte used in the battery could be another effective strategy to achieve high-rate capability and long-term cyclability. Zhang et al. ${ }^{202}$ compared the electrochemical performance of $\mathrm{CoS}_{2}$ in $\mathrm{SIBs}$ in different electrolytes. When using $1 \mathrm{M} \mathrm{NaClO}_{4}$ in propylene carbonate $(\mathrm{PC})$ and $1 \mathrm{M} \mathrm{NaPF}_{6}$ in ethylene carbonate/diethyl carbonate (EC/DEC, $v / v=1: 1$ ) as the electrolyte, respectively, $\mathrm{CoSe}_{2}$ electrode nearly failed after 100 cycles. In contrast, in $1 \mathrm{M}$ $\mathrm{NaCF}_{3} \mathrm{SO}_{3}$ with diethyleneglycol dimethylether (DEGDME), the capacity of $\mathrm{CoSe}_{2}$ electrode reached $410 \mathrm{~mA}$ h/g even after 1800 cycles. The good cycling performance can be attributed to the fact that the carbonate-based electrolytes can react with the intermediate products of transition-metal disulfides and diselenides, resulting in prompt depletion of the active materials. A similar approach also has been used in CUS anode. ${ }^{228}$

\section{(2) Conversion-alloying mechanism}

Another class of metal sulfides/selenides, including $\mathrm{SnS}_{2}$, SnS, SnSe, SnSSe, and $\mathrm{Sb}_{2} \mathrm{~S}_{3}, 209,210,216,229-232$ undergo a reaction mechanism involving conversion and alloying reactions. $\mathrm{SnS}_{2}$ has a $\mathrm{Cdl}_{2}$-type layered structure $(a=0.3648 \mathrm{~nm}$ $c=0.5899 \mathrm{~nm}$, space group P3m1), consisting of a layer of tin atoms sandwiched between two layers of hexagonally close packed sulfur atoms. This layered structure with a large interlayer spacing $(c=0.5899 \mathrm{~nm})$ would be of benefit for easy insertion and extraction of guest species, and adapt more easily to the volume changes in the host during cycling. This was confirmed by the performance of $\mathrm{SnS}_{2}$ as a reversible lithium storage host in several studies. ${ }^{229-232}$

For a $\mathrm{SnS}_{2} / \mathrm{Na}$ cell, the reaction proceeds in three steps: ${ }^{233}$

$\mathrm{SnS}_{2}+\mathrm{Na}^{+}+e^{-} \leftrightarrow \mathrm{NaSnS}_{2}$

$\mathrm{NaSnS}_{2}+3 \mathrm{Na}^{+}+3 e^{-} \leftrightarrow \mathrm{Sn}+2 \mathrm{Na}_{2} \mathrm{~S}$

$\mathrm{Sn}+x \mathrm{Na}^{+}+x e^{-} \leftrightarrow \mathrm{Na}_{15} \mathrm{Sn}_{4} \quad(x=3.75)$

In the initial discharging process, $\mathrm{Na}^{+}$can intercalate into the $\mathrm{SnS}_{2}$ layers at $1.5-1.7 \mathrm{~V}(15)$, then continue to react with $\mathrm{NaSnS}_{2}$ to form Sn metal (16), and finally alloy with $\mathrm{Sn}$ to form $\mathrm{Na}_{15} \mathrm{Sn}_{4}$ (17), so $\mathrm{SnS}_{2}$ can deliver a high theoretical capacity of $1136 \mathrm{~mA} \mathrm{h/g.} 420 \%$ volume expansion upon the formation of $\mathrm{Na}_{15} \mathrm{Sn}_{4}$ would occur, however, resulting in electrode disintegration and gradual loss of electrical contact with the current collector.

Hence, the authors designed a $\mathrm{SnS}_{2}$ - reduced graphene oxide $\left(\mathrm{SnS}_{2}-\mathrm{RGO}\right)$ hybrid to buffer the volume changes and inhibit the aggregation of Sn during cycling. The $\mathrm{SnS}_{2}-\mathrm{RGO}$ hybrid showed good cycling stability, delivering a discharge capacity of $628 \mathrm{~mA} \mathrm{h/g}$ after 100 cycles. In comparison, the capacity of the bare $\mathrm{SnS}_{2}$ electrode decreased to only $113 \mathrm{~mA}$ h/g after 100 cycles.

A different mechanism for $\mathrm{SnS}_{2}$ anode during the sodiation process was proposed by Meng's group. ${ }^{234}$ They observed that $\mathrm{Na}_{2} \mathrm{~S}_{2}$ formed instead of $\mathrm{Na}_{2} \mathrm{~S}$ in the fully discharged state, and they proposed the following reaction mechanism:

$\mathrm{SnS}_{2}+\mathrm{Na}^{+}+e^{-} \leftrightarrow \mathrm{Sn}+\mathrm{Na}_{2} \mathrm{~S}_{2}$ (theoretical capacity: $293 \mathrm{~mA} \mathrm{~h} / \mathrm{g}$ ) (18) $\mathrm{Sn}+3.75 \mathrm{Na}^{+}+3.75 e^{-} \leftrightarrow N a_{3.75} S n$ (theoretical capacity: $549 \mathrm{~mA}$ h/g) (19)

The overall theoretical capacity for $\mathrm{SnS}_{2}$ is $842 \mathrm{~mA} \mathrm{~h} / \mathrm{g}$, and the as-formed $\mathrm{Na}_{2} \mathrm{~S}_{2}$ works as a matrix to relieve the strain from the huge volume expansion of the $\mathrm{Na}-\mathrm{Sn}$ alloy reaction.

Although the defined reaction mechanism for $\mathrm{SnS}_{2}$ is still needs further confirmation, progress on the electrochemical performance has been made by many groups recently by using decorated carbonaceous materials as a conductive matrix, or fabricating few-layered active material to shorten the $\mathrm{Na}^{+}$migration paths, etc. ${ }^{205-207}$ For instance, one-step formation of $\mathrm{SnS}_{2} / \mathrm{rGO}$ from $\mathrm{SnO}_{2}$ nanocrystals $2-4 \mathrm{~nm}$ in size deposited on an amino-functionalized graphene interface was reported by Jiang et al. Due to the fine particle size, the uniform distribution of $\mathrm{SnS}_{2}$ on the surface of ethylenediamine (EDA)functionalized graphene, and the structural integrity after long-term cycling, the composite exhibited good cycling and rate performance, with a capacity of $680 \mathrm{~mA} \mathrm{~h} / \mathrm{g}$ after 100 cycles at $200 \mathrm{~mA} / \mathrm{g}$, and $480 \mathrm{~mA} \mathrm{~h} / \mathrm{g}$ after 1000 cycles at $1 \mathrm{~A} / \mathrm{g}$, as well as $250 \mathrm{~mA} \mathrm{~h} / \mathrm{g}$ at a high current density of $11.2 \mathrm{~A} / \mathrm{g} .{ }^{205}$

As demonstrated by Guo's group, ${ }^{43} \mathrm{SnS}$ also has a unique layered structure with a large interlayer spacing $(c=0.433 \mathrm{~nm}$, space group Pnma) and presented more promising electrochemical performance than $\mathrm{SnS}_{2}$ electrode. The reaction mechanism of $\mathrm{SnS}$ with $\mathrm{Na}^{+}$was investigated by ex-situ XRD (Fig. $16 a, b)$, revealing that the reversible sodiation/desodiation of SnS proceeded in a two-phase reaction as follows:

$$
\mathrm{SnS}+2 \mathrm{Na}^{+}+2 e^{-} \leftrightarrow \mathrm{Na}_{2} \mathrm{~S}+\mathrm{Sn} \quad \text { (20) }
$$$$
4 \mathrm{Sn}+15 \mathrm{Na}^{+}+15 e^{-} \leftrightarrow \mathrm{Na}_{15} \mathrm{Sn}_{4} \quad \text { (21) }
$$

The whole discharging process involves a lattice volume change of $242 \%$ relative to SnS, which is smaller than those of $\mathrm{Sn}(420 \%)$ and $\mathrm{SnS}_{2}(324 \%)$. As a result, the SnS@graphene composite delivered a reversible capacity of 940 $\mathrm{mA} \mathrm{h} / \mathrm{g}$ after 50 cycles at $30 \mathrm{~mA} / \mathrm{g}$, and 492 and $308 \mathrm{~mA} \mathrm{~h} / \mathrm{g}$ after 250 cycles at high current densities of 810 and $7290 \mathrm{~mA} / \mathrm{g}$, respectively, which is better than that of SnS $@$ @graphene electrode (Fig. 16c). The improved electrochemical performance can be attributed to: 1) The volume change (242\%) for SnS during the discharging process was smaller. 2) The SnS experienced a two-structural-phase transformation mechanism (orthorhombic-SnS to cubic-Sn to orthorhombic- $\mathrm{Na}_{3.75} \mathrm{Sn}$ ), while the $\mathrm{SnS}_{2}$ experienced a three-structural-phase transformation mechanism (hexagonal$\mathrm{SnS}_{2}$ to tetragonal-Sn to orthorhombic- $\mathrm{Na}_{3.75} \mathrm{Sn}$ ) during the sodiation process (Fig. 16b). The small structural changes of SnS during the conversion are expected to be conducive to good structural stability.

Compared to $\mathrm{SnS}_{\mathrm{x}}$, the binary IV-VI SnSe, known as a laminar semiconductor with orthorhombic crystal structure, is a new anode material for the alkali-ion batteries. The band gap of SnSe is as narrow as $0.9 \mathrm{eV}$, which guarantees higher electrical conductivity than other metal chalcogenides such as $\mathrm{SnO}_{2}$ and $\mathrm{SnS}_{x}{ }^{235}$ Nevertheless, slow $\mathrm{Na}$ ions diffusion
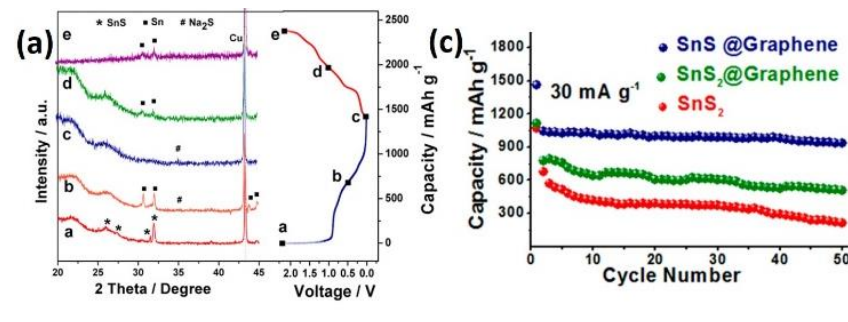

(b)

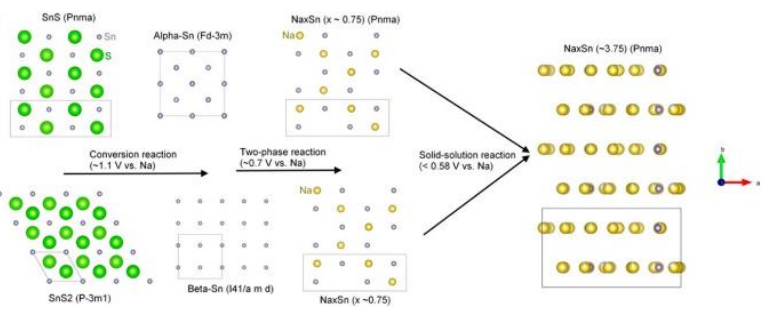

Fig. 16 (a) Ex-situ XRD patterns of the SnS@graphene electrode collected at various points as indicated in the corresponding voltage profile; (b) Schematic illustration of the structural evolution of orthorhombic-SnS and hexagonal$\mathrm{SnS}_{2}$ during the sodiation; (c) Cycling performances of SnS@graphene, $\mathrm{SnS}_{2} @$ graphene, and $\mathrm{SnS}_{2}$ electrodes. Reprinted from Ref. 43 with permission from American Chemical Society.

and instability of the solid electrolyte interphase caused by repeated volume expansion and contraction resulted in kinetic problems, as well as low energy density compared to SnS, which make it difficult to fully utilize the conversion reactions, thus leading to limited capacity and rate capability in practice. 
Therefore, construction of thin-layered SnSe nanosheet/nanoplates to shorten the diffusion length and improve electrode/electrolyte contact, or fabrication of ternary tin selenium sulfide to enhance the energy density may be an effective approach to mitigate these issues.66, 208235 For instance, layered SnSSe synthesized by a simple solid-state reaction as anode for SIBs delivered a stable capacity of $330 \mathrm{~mA} \mathrm{~h} / \mathrm{g}$ after 1000 cycles at the current density of $5 \mathrm{~A} / \mathrm{g}$ in the voltage range of 0.1-3 $\mathrm{V}$ with no capacity fading, and it exhibited the capacities of 226 and $161 \mathrm{~mA} \mathrm{~h} / \mathrm{g}$ at the high current densities of 7.5 and $10 \mathrm{~A} / \mathrm{g}$. The large interlayer spacing, preferred growth along the (001) crystal plane, and easily exfoliated lamellae, along with its partial pseudocapacitive capacity contribution, may be of benefit for good electrochemical performance. ${ }^{66}$

On the basis of a similar reaction mechanism to that of $\mathrm{SnS}_{x}, \mathrm{Sb}_{2} \mathrm{~S}_{3}$ also has drawn significant attention because of its attractive reversible theoretical capacity of $946 \mathrm{~mA} \mathrm{~h} / \mathrm{g}$ by accommodating 12 moles of $\mathrm{Na}^{+}$per $\mathrm{Sb}_{2} \mathrm{~S}_{3}$ mole The sodiation kinetics and the evolution of phase transformation in $\mathrm{Sb}_{2} \mathrm{~S}_{3}$ electrode were systematically investigated based on in-situ TEM examination and in situ electron diffraction along with DFT calculations and molecular dynamics (MD) simulations by Yao et al. ${ }^{209}$ They proposed that during the first sodiation process, $\mathrm{Na}^{+}$was inserted into the voids between the $\left(\mathrm{Sb}_{4} \mathrm{~S}_{6}\right)_{n}$ moieties at an ultrafast speed during the first sodiation, leading to amorphization of the crystalline $\mathrm{Sb}_{2} \mathrm{~S}_{3}$ and an expansion of $\sim 54 \%$. Then, the generated $\mathrm{Na}_{x} \mathrm{Sb}_{2} \mathrm{~S}_{3}$ intermediate phases were transformed into $\mathrm{Na}_{2} \mathrm{~S}$ and $\mathrm{Na}_{3} \mathrm{Sb}$ with a trace of $\mathrm{Sb}$ crystals during the consecutive conversion/alloying reactions. Upon subsequent desodiation, the $\mathrm{Na}^{+}$extracted from the crystalline sodiated composites resulted in amorphous $\mathrm{Sb}_{2} \mathrm{~S}_{3}$ (Fig. 17). The reactions between $\mathrm{Sb}_{2} \mathrm{~S}_{3}$ and sodium are summarized as follows:

$\mathrm{Na}^{+}$intercalation reaction:

$\mathrm{Sb}_{2} \mathrm{~S}_{3}+x N a^{+}+x e^{-} \leftrightarrow N a_{x} \mathrm{Sb}_{2} \mathrm{~S}_{3}(x<12)$

Conversion/Alloying reactions:

$N a_{x} S b_{2} S_{3}+(12-x) N a^{+}+(12-x) e^{-} \leftrightarrow 2 N a_{3} S b+3 N a_{2} S$
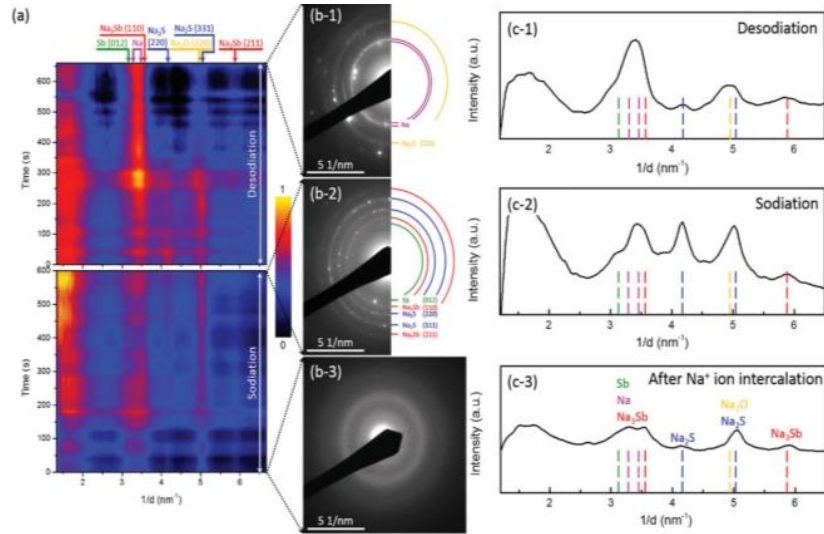

Fig. 17 Phase evolution during the first sodiation and desodiation processes of $\mathrm{Sb}_{2} \mathrm{~S}_{3}$ electrode probed by in-situ electron diffraction. (a) Colored intensity profiles as a function of reaction time for the first sodiation and desodiation processes. (b) SAED patterns for b-3) $\mathrm{Na}^{+}$ion intercalated, b-2) sodiated, and b-1) desodiated states. (c) Corresponding radially integrated intensity profiles of electron diffraction for $\mathrm{c}-3$ ) $\mathrm{Na}^{+}$ion intercalated, c-2) sodiated, and c-1) desodiated states. Reprinted from Ref. 209 with permission from Wiley and Johnson.

Hence, based on the above analysis, the authors constructed carbon coated $\mathrm{Sb}_{2} \mathrm{~S}_{3}$ since the mechanically robust and highly conductive carbon layer can constrain the radial expansion of $\mathrm{Sb}_{2} \mathrm{~S}_{3}$ and accelerate the sodiation process, giving rise to enhanced sodium storage performance. In comparison, the $\mathrm{Sb}_{2} \mathrm{~S}_{3} / \mathrm{C}$ presented a reversible specific capacity of $570 \mathrm{~mA} / \mathrm{g}$ after 100 cycles, while the pristine $\mathrm{Sb}_{2} \mathrm{~S}_{3}$ presented a poor reversible capacity of $114 \mathrm{~mA}$ $\mathrm{h} / \mathrm{g}$ under the same conditions. In addition, a few other $\mathrm{Sb}_{2} \mathrm{~S}_{3}$-based, $\mathrm{Sb}_{2} \mathrm{~S}_{5}$ based and $\mathrm{Sb}_{2} \mathrm{Se}_{3}$-based anodes also demonstrated good $\mathrm{Na}^{+}$storage capacities. ${ }^{41,210-213}$

The majority of metal-sulfide/selenide electrodes offer higher capacity, higher energy density, and more stable cycling performance than their metal oxide counterparts in SIBs, in virtue of the greater stability of the $\mathrm{Na}_{2} \mathrm{~S}$ formed in the $\mathrm{SIB}$ compared with $\mathrm{Na}_{2} \mathrm{O}$ in the LIB, and there are lower reaction voltage plateaus for metal sulfides/selenides compared with metal oxides. Nevertheless, the large volume expansion of metal sulfides occurring during sodiation/desodiation processes and their inherent low conductivity still degrade their electrochemical performance. Therefore, a variety of methods such as design of nanostructures and optimization of the working voltage window and electrolytes are required to develop high-performance metal sulfide/selenide electrodes for SIBs.

\section{Summary and outlook}

Due to the high cost and scarcity of lithium resources, sodium ion batteries have attracted increasing attention from researchers worldwide, and nowadays are experiencing a boom in development. As sodium shows similar reaction mechanisms to those in lithium ion batteries, so massive research experience could be directly applied to the sodium ion batteries. Nevertheless, owing to the lower energy density of SIBs such as carbon-based anodes compared with LIBs, the development of high performance anodes is urgently required to make SIBs comparable to LIBs. Therefore, in this review, we have summarized the recent research progress on high performance anodes for SIBs, including the metals/alloys, phosphorus/phosphides, and metal oxides/sulphides/selenides. Since these anode materials can store sodium ions via the conversion, alloying, or combined reactions, they typically have much higher theoretical capacity compared with the insertion-based materials and thus showing great potential for the commercialization of SIBs for applications in large-scale energy storage. More than $100 \%$ volume change and less than $80 \%$ initial coulombic efficiency were observed, however, during charging/discharging process in most anode materials with high reversible capacities, which has actually hindered their practical application at present because for commercial batteries, the volume change should be less than 30\%; therefore, the concerns associated with those potential anodes, such as low capacity utilization, inferior rate capability, poor cycling stability resulting from the huge volume changes, and sluggish sodium diffusion dynamics also have been discussed, while the effective approaches, ranging from electrode material structural design, and electrolyte optimization to voltage window control, to further enhance the electrochemical performance have been reviewed. Specifically: 1) electrode material structural design, such as nanocrystallization, surface modification and forming hybrids with other materials can effectively accommodate the large volume changes during the sodiation/desodiation processes, reduce the initial irreversible capacity loss, and shorten the ion/electron diffusion distance, thus improving the energy density, power density and cycling lifespan; 2) Choosing proper electrolytes, for example, the ether-based electrolytes, which normally will provide a much higher initial coulombic efficiency and ultralong cycling life for metal sulphides anodes; 3 ) Controlling the voltage range can limit the sodiation/desodiation reactions to within the conversion step and inhibit the alloy step, which will reduce the volume change and contribute capacity, thus extensively improving the high-rate and long-term cycling performance. Based on the current progress on anodes for SIBs, metal sulfides such as layered $\mathrm{MoS}_{2}$, SnS, red phosphorus, phosphides such as $\mathrm{Sn}_{4} \mathrm{P}_{3}$ may be able to meet requirements such as high energy density and long cycling life for commercialization after optimization, although the 
cost of these anode materials is still quite high, so it may be still a long way before such high-energy-density anode materials can be commercialized

Although great progress has been achieved on improving the electrochemical performance of anode materials for SIBs, there are still many tough challenges hindering their practical application. Currently, most of the reported high reversible capacities were achieved based on constructing nanostructured anode materials with a quite low mass loading. The low tap density of nanomaterials, however, will dramatically reduce the volumetric capacity of the SIBs containing them. To improve the gravimetric capacity and effectively retain the volumetric capacity of potential high performance anodes, further studies are needed on the rational design anode materials with favorable architecture, such as the micro-/nano-structures or hierarchical structures self-assembled from nanoscale building blocks, thus fully utilizing the potential advantages of nano- and micro-sized structures. Constructing 3D binder-free flexible electrodes might be another effective approach to improve the energy density and reduce the cost of SIBs. In addition, most of the applied synthesis strategies (for instance, CVD, liquidphase exfoliation, or electrospinning) for the fabrication of nanostructured electrodes normally have low yield and redundant procedures, making them difficult to scale up to a practical level. For large-scale commercial applications, an advanced synthetic methodology characterized by low cost and good scalability needs to be developed in the future. Thirdly, single phase anode materials usually cannot simultaneously meet the expected performance requirements in terms of high energy density, high power density, and long cycling lifespan for practical use of SIBs. More attention needs to be paid to investigate heterostructured materials constructed from two or more components, such as high-capacity anode and high-rate anode, or highly stable anode. By taking advantage of both components, electrode materials with battery-like high capacity and capacitor-like rate performance can be confidently expected. Additionally, some electrochemical reaction mechanisms are not clear as yet, and the interaction between the electrode surface and electrolyte, and the reaction kinetics needs to be further understood. The most widely used electrolytes in current SIBS are the carbonate-based electrolytes, which will result in large initial capacity loss due to the unstable SEI film, whereas the ether-based electrolytes will sacrifice the capacity contributed in the alloying reaction. Some advanced characterization techniques, particularly in-situ techniques, such as X-ray diffraction, neutron diffraction, soft $\mathrm{X}$-ray absorption spectroscopy, and Raman spectroscopy can be employed for in-depth studies of the structure and kinetics of electrode materials and the electrode/electrolyte interfaces, thus optimizing current SIB systems and developing novel attractive electrode materials. Moreover, although there have been very few reports, other issues, such as cost, safety, and environmental effects, also need to be taken into account when selecting electrode materials. Considering grid-level application of SIBs, only those materials that feature high availability of raw materials, environmental friendliness, and high safety can be further considered as potential anode materials. From the perspective of practical applications, in order to fully utilize the potential of SIBs, further work needs to be conducted on electrode design, electrolyte composition, in-depth studies on the interfaces between electrodes and electrolytes, etc.

\section{Conflicts of interest}

There are no conflicts to declare.

\section{Acknowledgements}

This work was financially supported by Youth Project in Nature Science Foundation of Jiangsu Province (Grant No: BK20161006), the Australian Research Council (ARC) (FT150100109), National Natural Science Foundation of China (No.51702046), Shanghai Pujiang Program (No. 17PJ1400100),
Shanghai Committee of Science and Technology (No. 17ZR1401000), and State Key Laboratory for Modification of Chemical Fibers and Polymer Materials, Donghua University. The authors would like to thank Dr. Tania Silver at the University of Wollongong for critical reading of the manuscript.

\section{References}

1. Y. Zheng, T. Zhou, X. Zhao, W. K. Pang, H. Gao, S. Li, Z. Zhou, H. Liu, Z. Guo, Adv. Mater., 2017, 29, 1700396.

2. N. Ortiz-Vitoriano, N. E. Drewett, E. Gonzalo and T. Rojo, Energy Environ. Sci., 2017, 10, 1051-1074.

3. Y. Liu, D. He, R. Han, G. Wei and Y. Qiao, Chem. Commun., 2017, 53, 55695572

4. Y. Liu, Y. Qiao, G. Wei, S. Li, Z. Lu, X. Wang and X. Lou, Energy Storage Materials, 2017, 11, 274-281.

5. Y. Qiao, M. Ma, Y. Liu, S. Li, Z. Lu, H. Yue, H. Dong, Z. Cao, Y. Yin and S. Yang, J. Mater. Chem. A, 2016, 4, 15565-15574.

6. S. Zhang, F. Yao, L. Yang, F. Zhang and S. Xu, Carbon, 2015, 93, 143-150.

7. D. Stevens and J. Dahn, J. Electrochem. Soc., 2000, 147, 1271-1273.

8. S. Fu, J. Ni, Y. Xu, Q. Zhang and L. Li, Nano Lett., 2016, 16, 4544-4551.

9. C. Chen, H. Xu, T. Zhou, Z. Guo, L. Chen, M. Yan, L. Mai, P. Hu, S. Cheng and Y. Huang, Adv. Energy Mater., 2016, 6, 1600322

10. F. Wang, X. Wu, C. Li, Y. Zhu, L. Fu, Y. Wu and X. Liu, Energy Environ. Sci., 2016 9, 3570-3611.

11. K. Dai, H. Zhao, Z. Wang, X. Song, V. Battaglia and G. Liu, J. Power Sources, 2014, 263, 276-279.

12. Y. Xu, Y. Zhu, Y. Liu and C. Wang, Adv. Energy Mater., 2013, 3, 128-133.

13. H. Zhu, Z. Jia, Y. Chen, N. Weadock, J. Wan, O. Vaaland, X. Han, T. Li and L. Hu, Nano Lett., 2013, 13, 3093-3100.

14. A. Darwiche, C. Marino, M. T. Sougrati, B. Fraisse, L. Stievano and L. Monconduit, J. Am. Chem. Soc., 2012, 134, 20805-20811.

15. M. K. Datta, R. Epur, P. Saha, K. Kadakia, S. K. Park and P. N. Kumta, J. Power Sources, 2013, 225, 316-322.

16. H. Hou, M. Jing, Y. Yang, Y. Zhu, L. Fang, W. Song, C. Pan, X. Yang and X. Ji, ACS Appl. Mater. Interfaces, 2014, 6, 16189-16196.

17. Y. Liu, N. Zhang, L. Jiao, Z. Tao and J. Chen, Adv. Funct. Mater., 2015, 25, 214220

18. Y. Zhu, X. Han, Y. Xu, Y. Liu, S. Zheng, K. Xu, L. Hu and C. Wang, ACS Nano, 2013, 7, 6378-6386

19. Y. N. Ko and Y. C. Kang, Chem. Commun., 2014, 50, 12322-12324.

20. L. Wu, X. Hu, J. Qian, F. Pei, F. Wu, R. Mao, X. Ai, H. Yang and Y. Cao, Energy Environ. Sci., 2014, 7, 323-328.

21. A. Darwiche, R. Dugas, B. Fraisse and L. Monconduit, J. Power Sources, 2016 304, 1-8.

22. P. R. Abel, Y.-M. Lin, T. de Souza, C.-Y. Chou, A. Gupta, J. B. Goodenough, G. S Hwang, A. Heller and C. B. Mullins, J. Phys. Chem. C, 2013, 117, 18885-18890.

23. D. Su, S. Dou and G. Wang, Nano Energy, 2015, 12, 88-95.

24. B. Farbod, K. Cui, W. P. Kalisvaart, M. Kupsta, B. Zahiri, A. Kohandehghan, E. M. Lotfabad, Z. Li, E. J. Luber and D. Mitlin, ACS Nano, 2014, 8, 4415-4429.

25. P. R. Abel, M. G. Fields, A. Heller and C. B. Mullins, ACS Appl. Mater. Interfaces, 2014, 6, 15860-15867.

26. L. Li, K. H. Seng, D. Li, Y. Xia, H. K. Liu and Z. Guo, Nano Research, 2014, 7 1466-1476.

27. L. Ji, W. Zhou, V. Chabot, A. Yu and X. Xiao, ACS Appl. Mater. Interfaces, 2015 7, 24895-24901.

28. J. Liu, Z. Yang, J. Wang, L. Gu, J. Maier and Y. Yu, Nano Energy, 2015, 16, 389398.

29. W. Li, C. Hu, M. Zhou, H. Tao, K. Wang, S. Cheng and K. Jiang, J. Power Sources, 2016, 307, 173-180

30. Q. Sun, Q.-Q. Ren, H. Li and Z.-W. Fu, Electrochem. Commun., 2011, 13, 1462 1464.

31. M. Hu, Y. Jiang, W. Sun, H. Wang, C. Jin and M. Yan, ACS Appl. Mater Interfaces, 2014, 6, 19449-19455.

32. D. Su, H.-J. Ahn and G. Wang, Chem. Commun., 2013, 49, 3131-3133.

33. Longkai, Zhiqiang, Qing, Zhao, Jing, Liang and Chen, Nano Research, 2015, 8 184-192.

34. N. Zhang, X. Han, Y. Liu, X. Hu, Q. Zhao and J. Chen, Adv. Energy Mater., 2015, 5, 1401123.

35. S. Yuan, X. I. Huang, D. I. Ma, H. g. Wang, F. z. Meng and X. b. Zhang, Adv. Mater., 2014, 26, 2273-2279.

36. Z. G. Wu, Y. J. Zhong, J. Liu, J. H. Wu, X. D. Guo, B. Zhong and Z. Zhang, J. Mater. Chem. A, 2015, 3, 10092-10099.

37. F. Zou, Y.-M. Chen, K. Liu, Z. Yu, W. Liang, S. M. Bhaway, M. Gao and Y. Zhu, ACS Nano, 2015, 10, 377-386.

38. S. Peng, X. Han, L. Li, Z. Zhu, F. Cheng, M. Srinivansan, S. Adams and S Ramakrishna, Small, 2016, 12, 1350-1368.

39. Y. X. Wang, J. Yang, S. L. Chou, H. K. Liu, W. X. Zhang, D. Zhao and S. X. Dou, Nat. Commun., 2015, 6, 8689 . 
40. X. Xie, Z. Ao, D. Su, J. Zhang and G. Wang Adv. Funct. Mater, 2015, 25, 1393 1403

41. Y. Denis, P. V. Prikhodchenko, C. W. Mason, S. K. Batabyal, J. Gun, S. Sladkevich, A. G. Medvedev and O. Lev, Nat. Commun., 2013, 4, 2922

42. Y. Zhao and A. Manthiram, Chem. Commun., 2015, 51, 13205-13208.

43. T. Zhou, W. K. Pang, C. Zhang, J. Yang, Z. Chen, H. K. Liu and Z. Guo, ACS Nano, 2014, 8, 8323-8333.

44. E. Clynen, D. Stubbe, A. De Loof and L. Schoofs, Cheminform, 2014, 49, 3131 3133.

45. W. Li, Z. Yang, M. Li, Y. Jiang, X. Wei, X. Zhong, L. Gu and Y. Yu, Nano Lett. 2016, 16, 1546-1553

46. J. Qian, X. Wu, Y. Cao, X. Ai and H. Yang, Angew. Chem., 2013, 125, 47314734.

47. Y. Kim, Y. Kim, A. Choi, S. Woo, D. Mok, N. S. Choi, Y. S. Jung, J. H. Ryu, S. M. Oh and K. T. Lee, Chem. Commun., 2014, 26, 4139-4144.

48. L. Zhao, J. Zhao, Y. S. Hu, H. Li, Z. Zhou, M. Armand and L. Chen, Adv. Energy Mater, 2012, 2, 962-965.

49. H. Pan, X. Lu, X. Yu, Y. S. Hu, H. Li, X. Q. Yang and L. Chen, Adv. Energy Mater. 2013, 3, 1186-1194.

50. X. Yu, H. Pan, W. Wan, C. Ma, J. Bai, Q. Meng, S. N. Ehrlich, Y. S. Hu and X. Q. Yang, Nano Lett., 2013, 13, 4721.

51. Y. Xu, E. M. Lotfabad, H. Wang, B. Farbod, Z. Xu, A. Kohandehghan and D. Mitlin, Chem. Commun., 2013, 49, 8973.

52. S. Komaba, W. Murata, T. Ishikawa, N. Yabuuchi, T. Ozeki, T. Nakayama, A Ogata, K. Gotoh and K. Fujiwara, Adv. Funct. Mater., 2011, 21, 3859-3867.

53. A. Ponrouch, A. R. Goñi and M. R. Palacín, Electrochem. Commun., 2013, 27 , 85-88.

54. Y. Li, S. Xu, X. Wu, J. Yu, Y. Wang, Y. S. Hu, H. Li, L. Chen and X. Huang, J. Mater Chem. A, 2015, 3, 71-77.

55. R. R. Gaddam, E. Jiang, N. Amiralian, P. K. Annamalai, D. J. Martin, N. A. Kumar and X. Zhao, Sustainable Energy \& Fuels, 2017, 1, 1090-1097.

56. S. Dong, C. Li, X. Ge, Z. Li, X. Miao and L. Yin, ACS Nano, 2017, 11, 6474-6482.

57. Y. Liu, A. Zhang, C. Shen, Q. Liu, X. Cao, Y. Ma, L. Chen, C. Lau, T.C. Chen and F. Wei, ACS Nano, 2017, 11, 5530-5537.

58. J. S. Cho, J.-S. Park and Y. C. Kang, Nano Research, 2017, 10, 897-907.

59. F. Xie, L. Zhang, D. Su, M. Jaroniec and S. Z. Qiao, Adv. Mater., 2017, 29,

60. Y. Liu, Y. Qiao, W. Zhang, P. Hu, C. Chen, Z. Li, L. Yuan, X. Hu and Y. Huang, J. Alloys Compd., 2014, 586, 208-215.

61. W. Ren, H. Zhang, C. Guan and C. Cheng, Adv. Funct. Mater., 2017, 27 1702116.

62. W. Li, S. Hu, X. Luo, Z. Li, X. Sun, M. Li, F. Liu and Y. Yu, Adv. Mater., 2017, 29 1605820

63. S. Yao, J. Cui, J. Huang, J. Q. Huang, W. G. Chong, L. Qin, Y. W. Mai and J. K. Kim, Adv. Energy Mater., 2017, 1702267.

64. G. Li, D. Luo, X. Wang, M. H. Seo, S. Hemmati, A. Yu and Z. Chen, Adv. Funct Mater., 2017, 27, 1702562.

65. F. Niu, J. Yang, N. Wang, D. Zhang, W. Fan, J. Yang and Y. Qian, Adv. Funct. Mater., 2017, 1700522.

66. X. Wang, D. Chen, Z. Yang, X. Zhang, C. Wang, J. Chen, X. Zhang and M. Xue, Adv. Mater., 2016, 28, 8645-8650.

67. X. Liu, K. Zhang, K. Lei, F. Li, Z. Tao and J. Chen, Nano Research, 2016, 9, 198206

68. V. L. Chevrier and G. Ceder, J. Electrochem. Soc., 2011, 158, A1011-A1014.

69. J. Yang, Y. Wang, W. Li, L. Wang, Y. Fan, W. Jiang, W. Luo, Y. Wang, B. Kong and C. Selomulya, Adv. Mater., 2017, 29, 1700523.

70. W. Luo, Y. Wang, L. Wang, W. Jiang, S.-L. Chou, S. X. Dou, H. K. Liu and J. Yang, ACS Nano, 2016, 10, 10524-10532.

71. L. Li, K. H. Seng, C. Feng, H. K. Liu and Z. Guo, J. Mater. Chem. A, 2013, 1 7666-7672.

72. K. H. Seng, M.-h. Park, Z. P. Guo, H. K. Liu and J. Cho, Nano Lett., 2013, 13, 1230-1236

73. K. H. Seng, M. H. Park, Z. P. Guo, H. K. Liu and J. Cho, Angew. Chem., 2012, 124, 5755-5759.

74. C.-Y. Chou, M. Lee and G. S. Hwang, J. Phys. Chem. C, 2015, 119, 14843-14850.

75. J. W. Wang, X. H. Liu, S. X. Mao and J. Y. Huang, Nano Lett., 2012, 12, 5897 5902.

76. M. Mao, F. Yan, C. Cui, J. Ma, M. Zhang, T. Wang and C. Wang, Nano Lett. 2017, 17, 3830-3836.

77. M. Fukunishi, N. Yabuuchi, M. Dahbi, J.-Y. Son, Y. Cui, H. Oji and S. Komaba, J. Phys. Chem. C, 2016, 120, 15017-15026.

78. M. Sha, H. Zhang, Y. Nie, K. Nie, X. Lv, N. Sun, X. Xie, Y. Ma and X. Sun, J. Mater. Chem. A, 2017, 5, 6277-6283.

79. Y. Liu, Y. Xu, Y. Zhu, J. N. Culver, C. A. Lundgren, K. Xu and C. Wang, ACS Nano, 2013, 7, 3627-3634.

80. J. Liu, L. Yu, C. Wu, Y. Wen, K. Yin, F.-K. Chiang, R. Hu, J. Liu, L. Sun, L. Gu, J. Maier, Y. Yu and M. Zhu, Nano Lett., 2017, 17, 2034-2042.

81. X. Zhang, P. Li, R. Zang, S. Wang, Y. Zhu, C. Li and G. Wang, Chem-Asian J., 2017, 12, 116-121

82. Z. Liu, X.-Y. Yu, X. W. Lou and U. Paik, Energy Environ. Sci., 2016, 9, 2314-2318,
83. N. Wang Z. Bai, Y. Qian and J. Yang Adv. Mater, 2016, 28, 4126-4133.

84. L. Liang, Y. Xu, C. Wang, L. Wen, Y. Fang, Y. Mi, M. Zhou, H. Zhao and Y. Lei, Energy Environ. Sci., 2015, 8, 2954-2962.

85. H. Hou, M. Jing, Y. Yang, Y. Zhang, Y. Zhu, W. Song, X. Yang and X. Ji, J. Mater Chem. A, 2015, 3, 2971-2977.

86. S. Liu, J. Feng, X. Bian, J. Liu and H. Xu, Energy Environ. Sci., 2016, 9, 1229 1236.

87. X. Wang, L. Fan, D. Gong, J. Zhu, Q. Zhang and B. Lu, Adv. Funct. Mater., 2016 26, 1104-1111.

88. C. Yue, Y. Yu, S. Sun, X. He, B. Chen, W. Lin, B. Xu, M. Zheng, S. Wu, J. Li, J. Kang and L. Lin, Adv. Funct. Mater., 2015, 25, 1386-1392.

89. C. Wang, L. Wang, F. Li, F. Cheng and J. Chen, Adv. Mater., 2017, 29, 1702212

90. F. Yang, F. Yu, Z. Zhang, K. Zhang, Y. Lai and J. Li, Chem-Eur J., 2016, 22, 2333 2338.

91. W. Chen and D. Deng, Carbon, 2015, 87, 70-77.

92. X. Xie, K. Kretschmer, J. Zhang, B. Sun, D. Su and G. Wang, Nano Energy, 2015 , 13, 208-217

93. P. K. Allan, J. M. Griffin, A. Darwiche, O. J. Borkiewicz, K. M. Wiaderek, K. W. Chapman, A. J. Morris, P. J. Chupas, L. Monconduit and C. P. Grey, J. Am. Chem. Soc., 2016, 138, 2352-2365.

94. H. Hou, M. Jing, Y. Zhang, J. Chen, Z. Huang and X. Ji, J. Mater. Chem. A, 2015 , 3, 17549-17552.

95. M. He, K. Kravchyk, M. Walter and M. V. Kovalenko, Nano Lett., 2014, 14, $1255-1262$

96. X. Liu, Y. Du, X. Xu, X. Zhou, Z. Dai and J. Bao, J. Phys. Chem. C, 2016, 120 3214-3220.

97. C. Nithya and S. Gopukumar, J. Mater Chem. A, 2014, 2, 10516-10525.

98. W. Luo, P. Zhang, X. Wang, Q. Li, Y. Dong, J. Hua, L. Zhou and L. Mai, J. Power Sources, 2016, 304, 340-345.

99. M. Stojić, D. Kostić and B. Stošić, Physica B+C, 1986, 138, 125-128

100. D. Li, K. H. Seng, D. Shi, Z. Chen, H. K. Liu and Z. Guo, J. Mater. Chem. A, 2013 1, 14115-14121.

101. X. Lu, E. R. Adkins, Y. He, L. Zhong, L. Luo, S. X. Mao, C.-M. Wang and B. A. Korgel, Chem. Mater., 2016, 28, 1236-1242.

102. C. Wang, L. Wang, F. Li, F. Cheng and J. Chen, Adv. Mater., 2017, 29, 1702212

103. L. Ji, M. Gu, Y. Shao, X. Li, M. H. Engelhard, B. W. Arey, W. Wang, Z. Nie, J. Xiao and C. Wang, Adv. Mater., 2014, 26, 2901-2908.

104. A. Nie, L.-y. Gan, Y. Cheng, X. Tao, Y. Yuan, S. Sharifi-Asl, K. He, H. AsayeshArdakani, V. Vasiraju, J. Lu, F. Mashayek, R. Klie, S. Vaddiraju, U. Schwingenschlögl and R. Shahbazian-Yassar, Adv. Funct. Mater., 2016, 26 543-552.

105. H. Xie, W. P. Kalisvaart, B. C. Olsen, E. J. Luber, D. Mitlin and J. M. Buriak, J. Mater. Chem. A, 2017, 5, 9661-9670.

106. Y. Kim, Y. Kim, Y. Park, Y. N. Jo, Y.-J. Kim, N.-S. Choi and K. T. Lee, Chem Commun., 2015, 51, 50-53

107. D.-H. Nam, K.-S. Hong, S.-J. Lim and H.-S. Kwon, J. Power Sources, 2014, 247 423-427.

108. L. Baggetto, E. Allcorn, R. R. Unocic, A. Manthiram and G. M. Veith, J. Mater. Chem. A, 2013, 1, 11163-11169.

109. A. Darwiche, M. Toiron, M. T. Sougrati, B. Fraisse, L. Stievano and L. Monconduit, J. Power Sources, 2015, 280, 588-592.

110. J. Sun, G. Zheng, H.-W. Lee, N. Liu, H. Wang, H. Yao, W. Yang and Y. Cui, Nano Lett., 2014, 14, 4573-4580.

111. S. Liu, J. Feng, X. Bian, J. Liu, H. Xu and Y. An, Energy Environ. Sci., 2017, 10, $1222-1233$

112. J. Zhou, X. Liu, W. Cai, Y. Zhu, J. Liang, K. Zhang, Y. Lan, Z. Jiang, G. Wang and Y. Qian, Adv. Mater., 2017, 1700214

113. C. Zhang, X. Wang, Q. Liang, X. Liu, Q. Weng, J. Liu, Y. Yang, Z. Dai, K. Ding, Y. Bando, J. Tang and D. Golberg, Nano Lett., 2016, 16, 2054-2060.

114. J. Sun, H.-W. Lee, M. Pasta, H. Yuan, G. Zheng, Y. Sun, Y. Li and Y. Cui, Nat Nano, 2015, 10, 980-985.

115. Y. Zhang, W. Sun, Z.-Z. Luo, Y. Zheng, Z. Yu, D. Zhang, J. Yang, H. T. Tan, J. Zhu and X. Wang, Nano Energy, 2017, 40, 576-586.

116. G.-L. Xu, Z. Chen, G.-M. Zhong, Y. Liu, Y. Yang, T. Ma, Y. Ren, X. Zuo, X.-H. Wu and X. Zhang, Nano Lett., 2016, 16, 3955-3965.

117. X. Ge, Z. Li and L. Yin, Nano Energy, 2017, 32, 117-124.

118. Z. Li, L. Zhang, X. Ge, C. Li, S. Dong, C. Wang and L. Yin, Nano Energy, 2017 32, 494-502.

119. Y. Lu, P. Zhou, K. Lei, Q. Zhao, Z. Tao and J. Chen, Adv. Energy Mater., 2017 7, 1601973-1601980.

120. S.-O. Kim and A. Manthiram, Chem. Mater, 2016, 28, 5935-5942.

121. S.-O. Kim and A. Manthiram, Chem. Commun., 2016, 52, 4337-4340.

122. M. Fan, Y. Chen, Y. Xie, T. Yang, X. Shen, N. Xu, H. Yu and C. Yan, Adv. Funct. Mater, 2016, 26, 5019-5027.

123. Y. Xu, B. Peng and F. M. Mulder, Adv. Energy Mater., 2017, 1701847.

124. Q. Li, Z. Li, Z. Zhang, C. Li, J. Ma, C. Wang, X. Ge, S. Dong and L. Yin, Adv. Energy Mater., 2016, 6, 1600376

125. X. Fan, J. Mao, Y. Zhu, C. Luo, L. Suo, T. Gao, F. Han, S.-C. Liou and C. Wang, Adv. Energy Mater., 2015, 5, 1500174-n/a.

126. X. Ling, H. Wang, S. Huang, F. Xia and M. S. Dresselhaus, Proceedings of the 
National Academy of Sciences, 2015, 112, 4523-4530.

127. W. Li, S.-L. Chou, J.-Z. Wang, J. H. Kim, H.-K. Liu and S.-X. Dou, Adv. Mater. 2014, 26, 4037-4042.

128. J. Qian, Y. Xiong, Y. Cao, X. Ai and H. Yang, Nano Lett., 2014, 14, 1865-1869.

129. Y. Kim, Y. Park, A. Choi, N.-S. Choi, J. Kim, J. Lee, J. H. Ryu, S. M. Oh and K. T. Lee, Adv. Mater., 2013, 25, 3045-3049.

130. J. Liu, P. Kopold, C. Wu, P. A. van Aken, J. Maier and Y. Yu, Energy Environ. Sci. 2015, 8, 3531-3538.

131.W.-J. Li, Q.-R. Yang, S.-L. Chou, J.-Z. Wang and H.-K. Liu, J. Power Sources, 2015, 294, 627-632.

132. J. Fullenwarth, A. Darwiche, A. Soares, B. Donnadieu and L. Monconduit, J. Mater. Chem. A, 2014, 2, 2050-2059.

133. T. Li, A. Qin, L. Yang, J. Chen, Q. Wang, D. Zhang and H. Yang, ACS Appl. Mater Interfaces, 2017, 9, 19900-19907.

134. D. Li, J. Zhou, X. Chen and H. Song, ACS Appl. Mater. Interfaces, 2016, 8 30899-30907.

135. Y. Fu, Q. Wei, X. Wang, H. Shu, X. Yang and S. Sun, J. Mater. Chem. A, 2015, 3, $13807-13818$

136. X. Wang, X. Liu, G. Wang, Y. Xia and H. Wang, J. Mater. Chem. A, 2016, 4 $18532-18542$

137. L.-Y. Qi, Y.-W. Zhang, Z.-C. Zuo, Y.-L. Xin, C.-K. Yang, B. Wu, X.-X. Zhang and H.H. Zhou, J. Mater. Chem. A, 2016, 4, 8822-8829.

138. D. Chen, L. Peng, Y. Yuan, Y. Zhu, Z. Fang, C. Yan, G. Chen, R. ShahbazianYassar, J. Lu and K. Amine, Nano Lett., 2017, 17, 3907-3913.

139. Y. Wu, J. Meng, Q. Li, C. Niu, X. Wang, W. Yang, W. Li and L. Mai, Nano Research, 2017, 10, 2364-2376.

140. Y. V. Kaneti, J. Zhang, Y.-B. He, Z. Wang, S. Tanaka, M. S. A. Hossain, Z.-Z. Pan, B. Xiang, Q.-H. Yang and Y. Yamauchi, J. Mater. Chem. A, 2017, 5, 1535615366.

141. W. Kang, Y. Zhang, L. Fan, L. Zhang, F. Dai, R. Wang and D. Sun, ACS Appl. Mater. Interfaces, 2017, 9, 10602-10609.

142. Y. Wang, C. Wang, Y. Wang, H. Liu and Z. Huang, J. Mater. Chem. A, 2016, 4 5428-5435.

143. A.-Y. Kim, M. K. Kim, K. Cho, J.-Y. Woo, Y. Lee, S.-H. Han, D. Byun, W. Choi and J. K. Lee, ACS Appl. Mater. Interfaces, 2016, 8, 19514-19523.

144. X. Wang, Y. Liu, Y. Wang and L. Jiao, Small, 2016, 12, 4865-4872.

145. P. C. Rath, J. Patra, D. Saikia, M. Mishra, J.-K. Chang and H.-M. Kao, J. Mater. Chem. A, 2016, 4, 14222-14233.

146. Y. Lu, N. Zhang, Q. Zhao, J. Liang and J. Chen, Nanoscale, 2015, 7, 2770-2776.

147. L. Yang, Y. E. Zhu, J. Sheng, F. Li, B. Tang, Y. Zhang and Z. Zhou, Small, 2017 13, 1702588.

148. L. Wang, X. Bi and S. Yang, Adv. Mater., 2016, 28, 7672-7679.

149. H. Kim, E. Lim, C. Jo, G. Yoon, J. Hwang, S. Jeong, J. Lee and K. Kang, Nano Energy, 2015, 16, 62-70.

150. L. Fan, X. Li, B. Yan, J. Feng, D. Xiong, D. Li, L. Gu, Y. Wen, S. Lawes and X. Sun Adv. Energy Mater., 2016, 6, 1502057.

151. J. Patra, P. C. Rath, C.-H. Yang, D. Saikia, H.-M. Kao and J.-K. Chang, Nanoscale 2017, 9, 8674-8683.

152. J.-I. Lee, J. Song, Y. Cha, S. Fu, C. Zhu, X. Li, Y. Lin and M.-K. Song, Nano Research, 2017, 10, 4398

153. J. Cui, Z.-L. Xu, S. Yao, J. Huang, J.-Q. Huang, S. Abouali, M. A. Garakani, X. Ning and J.-K. Kim, J. Mater. Chem. A, 2016, 4, 10964-10973.

154. Y. Liu, X. Fang, M. Ge, J. Rong, C. Shen, A. Zhang, H. A. Enaya and C. Zhou, Nano Energy, 2015, 16, 399-407.

155. X. Guo, X. Xie, S. Choi, Y. Zhao, H. Liu, C. Wang, S. Chang and G. Wang, J. Mater. Chem. A, 2017, 5, 12445-12452.

156. J. Fei, Y. Cui, J. Li, Z. Xu, J. Yang, R. Wang, Y. Cheng and J. Hang, Chem. Commun., 2017, 53, 13165-13167.

157. D.-H. Nam, K.-S. Hong, S.-J. Lim, M.-J. Kim and H.-S. Kwon, Small, 2015, 11 2885-2892

158. N. Li, S. Liao, Y. Sun, H. W. Song and C. X. Wang, J. Mater. Chem. A, 2015, 3 5820-5828

159. K. Ramakrishnan, C. Nithya, B. Kundoly Purushothaman, N. Kumar and S. Gopukumar, ACS Sustainable Chemistry \& Engineering, 2017, 5, 5090-5098.

160. F. Klein, B. Jache, A. Bhide and P. Adelhelm, Phys. Chem. Chem. Phys., 2013 15, 15876-15887.

161. S. Komaba, T. Mikumo, N. Yabuuchi, A. Ogata, H. Yoshida and Y. Yamada, J. Electrochem. Soc., 2010, 157, A60-A65.

162. S. Komaba, T. Mikumo and A. Ogata, Electrochem. Commun., 2008, 10, 1276 1279.

163. M. Valvo, F. Lindgren, U. Lafont, F. Björefors and K. Edström, J. Power Sources, 2014, 245, 967-978.

164. Z.-g. Wu, Y.-j. Zhong, J. Liu, J.-h. Wu, X.-d. Guo, B.-h. Zhong and Z.-y. Zhang, J. Mater. Chem. A, 2015, 3, 10092-10099.

165. B. Philippe, M. Valvo, F. Lindgren, H. k. Rensmo and K. Edström, Chem. Mater. 2014, 26, 5028-5041.

166. M. M. Rahman, A. M. Glushenkov, T. Ramireddy and Y. Chen, Chem. Commun., 2014, 50, 5057-5060.

167. Z. Jian, P. Liu, F. Li, M. Chen and H. Zhou, J. Mater. Chem. A, 2014, 2, 13805 13809.
168. L. Wang, K. Zhang, Z. Hu, W. Duan, F. Cheng and J. Chen, Nano Research, 2014, 7, 199-208.

169. V. Augustyn, J. Come, M. A. Lowe, J. W. Kim, P.-L. Taberna, S. H. Tolbert, H. D. Abruña, P. Simon and B. Dunn, Nat. Mater., 2013, 12, 518-522.

170. J. W. Kim, V. Augustyn and B. Dunn, Adv. Energy Mater., 2012, 2, 141-148.

171. X. Wang, G. Li, Z. Chen, V. Augustyn, X. Ma, G. Wang, B. Dunn and Y. Lu, Adv. Energy Mater., 2011, 1, 1089-1093.

172. W. Sun, X. Rui, J. Zhu, L. Yu, Y. Zhang, Z. Xu, S. Madhavi and Q. Yan, J. Power Sources, 2015, 274, 755-761.

173. Y. Liu, N. Zhang, C. Yu, L. Jiao and J. Chen, Nano Lett., 2016, 16, 3321-3328.

174. W. Wang, L. Hu, J. Ge, Z. Hu, H. Sun, H. Sun, H. Zhang, H. Zhu and S. Jiao, Chem. Mater., 2014, 26, 3721-3730.

175. L. P. Wang, Y. Zhao, C. Wei, C. Wong, M. Srinivasan and Z. J. Xu, J. Mater Chem. A, 2015, 3, 14033-14038.

176. L. Yu, J. Liu, X. Xu, L. Zhang, R. Hu, J. Liu, L. Ouyang, L. Yang and M. Zhu, ACS Nano, 2017, 11, 5120-5129.

177. J. S. Chen and X. W. Lou, Small, 2013, 9, 1877.

178. M. Gu, A. Kushima, Y. Shao, J.-G. Zhang, J. Liu, N. D. Browning, J. Li and C. Wang, Nano Lett., 2013, 13, 5203-5211.

179. Y.-X. Wang, Y.-G. Lim, M.-S. Park, S.-L. Chou, J. H. Kim, H.-K. Liu, S.-X. Dou and Y.-J. Kim, J. Mater. Chem. A, 2014, 2, 529-534.

180.J. Pan, N. Wang, Y. Zhou, X. Yang, W. Zhou, Y. Qian and J. Yang, Nano Research 2017, 10, 1794-1803.

181. J. Xiao, D. Choi, L. Cosimbescu, P. Koech, J. Liu and J. P. Lemmon, Chem. Mater., 2010, 22, 4522-4524

182. J. Park, J.-S. Kim, J.-W. Park, T.-H. Nam, K.-W. Kim, J.-H. Ahn, G. Wang and H.J. Ahn, Electrochim. Acta, 2013, 92, 427-432.

183. Y. Miki, D. Nakazato, H. Ikuta, T. Uchida and M. Wakihara, J. Power Sources, 1995, 54, 508-510.

184. G. S. Bang, K. W. Nam, J. Y. Kim, J. Shin, J. W. Choi and S.-Y. Choi, ACS Appl. Mater. Interfaces, 2014, 6, 7084-7089.

185. S. Zhang, X. Yu, H. Yu, Y. Chen, P. Gao, C. Li and C. Zhu, ACS Appl. Mater Interfaces, 2014, 6, 21880-21885.

186. G. Wang, J. Zhang, S. Yang, F. Wang, X. Zhuang, K. Müllen and X. Feng, Adv. Energy Mater., 2017, 1702254.

187. Y. Liu, X. He, D. Hanlon, A. Harvey, J. N. Coleman and Y. Li, ACS Nano, 2016 10, 8821-8828.

188. Y. Lu, Q. Zhao, N. Zhang, K. Lei, F. Li and J. Chen, Adv. Funct. Mater., 2016, 26, 911-918.

189. X. Xie, T. Makaryan, M. Zhao, K. L. Van Aken, Y. Gogotsi and G. Wang, Adv. Energy Mater., 2016, 6, 1502161.

190. J. Wang, J. Liu, H. Yang, D. Chao, J. Yan, S. V. Savilov, J. Lin and Z. X. Shen, Nano Energy, 2016, 20, 1-10.

191. S. H. Choi, Y. N. Ko, J. K. Lee and Y. C. Kang, Adv. Funct. Mater., 2015, 25 $1780-1788$

192. D. Su, S. Dou and G. Wang, Adv. Energy Mater., 2015, 5, 1401205.

193. C. Zhu, X. Mu, P. A. van Aken, Y. Yu and J. Maier, Angew. Chem. Int. Ed., 2014, 53, 2152-2156

194.Z. Hu, L. Wang, K. Zhang, J. Wang, F. Cheng, Z. Tao and J. Chen, Angew. Chem. 2014, 126, 13008-13012.

195. H. Ye, L. Wang, S. Deng, X. Zeng, K. Nie, P. N. Duchesne, B. Wang, S. Liu, J. Zhou and F. Zhao, Adv. Energy Mater., 2017, 7, 1601602.

196. Q. Li, L. Li, K. A. Owusu, W. Luo, Q. An, Q. Wei, Q. Zhang and L. Mai, Nano Energy, 2017, 41, 109-116.

197. Y. Chen, X. Li, K. Park, L. Zhou, H. Huang, Y. W. Mai and J. B. Goodenough, Angew. Chem. Int. Ed., 2016, 55, 15831-15834.

198. C. Wu, Y. Jiang, P. Kopold, P. A. van Aken, J. Maier and Y. Yu, Adv. Mater., 2016 28, 7276-7283.

199. Z. Chen, R. Wu, M. Liu, H. Wang, H. Xu, Y. Guo, Y. Song, F. Fang, X. Yu and D. Sun, Adv. Funct. Mater., 2017, 27, 1702046.

200. Q. Guo, Y. Ma, T. Chen, Q. Xia, M. Yang, H. Xia and Y. Yu, ACS Nano, 2017, 11, 12658-12667.

201. Y. Pan, X. Cheng, Y. Huang, L. Gong and H. Zhang, ACS Appl. Mater. Interfaces, 2017, 9, 35820-35828.

202. K. Zhang, M. Park, L. Zhou, G. H. Lee, W. Li, Y. M. Kang and J. Chen, Adv. Funct Mater., 2016, 26, 6728-6735.

203. X. Xiong, C. Yang, G. Wang, Y. Lin, X. Ou, J.-H. Wang, B. Zhao, M. Liu, Z. Lin and K. Huang, Energy Environ. Sci., 2017, 10, 1757-1763.

204. X.-W. D. Lou, Angew. Chem., 2017, 129, $12370-12373$.

205. Y. Jiang, M. Wei, J. Feng, Y. Ma and S. Xiong, Energy Environ. Sci., 2016, 9 , 1430-1438.

206. Y. Zhang, P. Zhu, L. Huang, J. Xie, S. Zhang, G. Cao and X. Zhao, Adv. Funct. Mater., 2015, 25, 481-489.

207. W. Sun, X. Rui, D. Yang, Z. Sun, B. Li, W. Zhang, Y. Zong, S. Madhavi, S. Dou and Q. Yan, ACS Nano, 2015, 9, 11371-11381.

208. S. Yuan, Y. H. Zhu, W. Li, S. Wang, D. Xu, L. Li, Y. Zhang and X. B. Zhang, Adv Mater., 2017, 29, 1602469.

209. S. Yao, J. Cui, Z. Lu, Z. L. Xu, L. Qin, J. Huang, Z. Sadighi, F. Ciucci and J. K. Kim Adv. Energy Mater., 2017, 7, 1602149

210. X. Xiong, G. Wang, Y. Lin, Y. Wang, X. Ou, F. Zheng, C. Yang, J.-H. Wang and 
M. Liu, ACS Nano, 2016, 10, 10953-10959.

211. S. M. Hwang, J. Kim, Y. Kim and Y. Kim, J. Mater. Chem. A, 2016, 4, 17946 17951.

212. Y. Lu, N. Zhang, S. Jiang, Y. Zhang, M. Zhou, Z. Tao, L. A. Archer and J. Chen, Nano Lett., 2017, 17, 3668-3674.

213. X. Ou, C. Yang, X. Xiong, F. Zheng, Q. Pan, C. Jin, M. Liu and K. Huang, AdV. Funct. Mater., 2017, 27, 1606242.

214. J. Zhou, L. Wang, M. Yang, J. Wu, F. Chen, W. Huang, N. Han, H. Ye, F. Zhao and Y. Li, Adv. Mater., 2017, 29, 1702061.

215. C. Yang, X. Ou, X. Xiong, F. Zheng, R. Hu, Y. Chen, M. Liu and K. Huang, Energy Environ. Sci., 2017, 10, 107-113.

216. Y. Zheng, T. Zhou, C. Zhang, J. Mao, H. Liu and Z. Guo, Angew. Chem. Int. Ed. 2016, 55, 3408-3413.

217. M. Xu, F. Yi, Y. Niu, J. Xie, J. Hou, S. Liu, W. Hu, Y. Li and C. M. Li, J. Mater. Chem. A, 2015, 3, 9932-9937.

218.J. Wang, C. Luo, T. Gao, A. Langrock, A. C. Mignerey and C. Wang, Small, 2015, 11, 473-481.

219. S. H. Choi and Y. C. Kang, ACS Appl. Mater. Interfaces, 2015, 7, 24694-24702. 220. Y. Chen, B. Song, X. Tang, L. Lu and J. Xue, Small, 2014, 10, 1536-1543.

221. Y. Wang, D. Kong, W. Shi, B. Liu, G. J. Sim, Q. Ge and H. Y. Yang, Adv. Energy Mater., 2016, 6, 1601057.

222. S. Xin, L. Yu, Y. You, H.-P. Cong, Y.-X. Yin, X.-L. Du, Y.-G. Guo, S.-H. Yu, Y. Cui and J. B. Goodenough, Nano Lett., 2016, 16, 4560-4568.

223. Y. Ko, S. Choi, S. Park and Y. Kang, Nanoscale, 2014, 6, 10511-10515.

224. X. Wei, W. Li, J.-a. Shi, L. Gu and Y. Yu, ACS Appl. Mater. Interfaces, 2015, 7, 27804-27809.

225. S. Y. Lee and Y. C. Kang, Chem.Eur. J, 2016, 22, 2769-2774.

226. Z. Liu, T. Lu, T. Song, X.-Y. Yu, X. W. Lou and U. Paik, Energy Environ. Sci., 2017, 10, $1576-1580$.

227. K. Zhang, Z. Hu, X. Liu, Z. Tao and J. Chen, Adv. Mater., 2015, 27, 3305-3309.

228. J. Li, D. Yan, T. Lu, W. Qin, Y. Yao and L. Pan, ACS Appl. Mater. Interfaces, 2017 9, 2309-2316.

229. J. w. Seo, J. t. Jang, S. w. Park, C. Kim, B. Park and J. Cheon, Adv. Mater., 2008 20, 4269-4273.

230. C. Zhai, N. Du and H. Z. D. Yang, Chem. Commun., 2011, 47, 1270-1272.

231. Y. Du, Z. Yin, X. Rui, Z. Zeng, X.-J. Wu, J. Liu, Y. Zhu, J. Zhu, X. Huang and Q. Yan, Nanoscale, 2013, 5, 1456-1459.

232. Q. Wu, L. Jiao, J. Du, J. Yang, L. Guo, Y. Liu, Y. Wang and H. Yuan, J. Power Sources, 2013, 239, 89-93.

233. B. Qu, C. Ma, G. Ji, C. Xu, J. Xu, Y. S. Meng, T. Wang and J. Y. Lee, Adv. Mater, 2014, 26, 3854-3859.

234. C. Ma, J. Xu, J. Alvarado, B. Qu, J. Somerville, J. Y. Lee and Y. S. Meng, Chem Mater., 2015, 27, 5633-5640.

235. W. Wang, P. Li, H. Zheng, Q. Liu, F. Lv, J. Wu, H. Wang and S. Guo, Small, 2017 1702228. 